\title{
Teachers' perceptions of changes to teaching practice and the influence of professional development: Experienced EFL teachers in South Korea
}

BY

JEONG HYUN CHO

\begin{abstract}
A thesis
submitted to the Victoria University of Wellington in fulfilment of the requirements for the degree of Master of Education
\end{abstract}

Victoria University of Wellington

2014 


\begin{abstract}
This multiple-case study investigated experienced English-as-a-foreign-language (EFL) teachers' perceptions of changes to teaching practice as a result of professional development (PD) in South Korea. The study used one-on-one semi-structured interviews as the primary data source to capture teachers' views on changes to their practice and the impact of their PD experiences.
\end{abstract}

The study drew upon cultural historical activity theory as a theoretical framework and the literature on PD and teacher change to understand the relationship between PD and teacher change, and the influences on this relationship.

This study found that various aspects of the teachers' context - the English education curriculum, teacher culture, the school environment, and education policy - and the complex interrelationship among these factors led these teachers to develop a passive attitude towards PD learning and implementation. So, despite engaging in diverse PD experiences over their career, they rarely considered implementing changes within their teaching practice.

This study revealed these experienced EFL teachers' overarching concern about their levels of English proficiency. It showed that they were inclined to value newly qualified teachers' capability over their own long teaching experience. They felt isolated within a stagnant teacher culture where they perceived that there was limited support for professional development from either school or education policy. Finally, they felt caught between the conflicting demands of the English education curriculum and classroom teaching.

These experienced EFL teachers might be encouraged to develop a more positive attitude if their expertise and capacity were acknowledged as valuable. This would require an investment of time and effort to allow them to prepare for and contribute to PD learning and implementation. Orchestrated efforts from policymakers, school administrators, and teachers could help bring about substantial changes in experienced teachers' teaching practice and enable them to share their expertise with other educators. 


\section{Acknowledgements}

This journey could not be successful without great people who have supported me. I wish to thank the teachers who participated in this project and shared their stories.

I wish to thank my supervisors; Anita Mortlock who gave me precious insights to start this journey smoothly, Sue Cherrington who provided the warmest support and helped me plan ahead, and Margaret Gleeson who encouraged me to have a positive spirit to go forward with thoughtful guidance despite the constraints of time and distance. I highly respect your experience and expertise and appreciate your emotional support.

To my beloved husband, Jeongbin Ok, thank you for being always with me, inspiring me to seek for what I can do best, and believing in me to complete this thesis. I also thank my family in South Korea for cheering me up and encouraging me to keep going.

I am thankful to Kaye Stannard for proofreading my thesis and providing useful suggestions.

Finally, I am grateful for the financial support through a research grant (No. 203949) from the Faculty of Grants and Leave Committee (FGLC) and a Victoria Master's (by thesis) Scholarship from the University Scholarships Committee (URC). 


\section{Table of Contents}

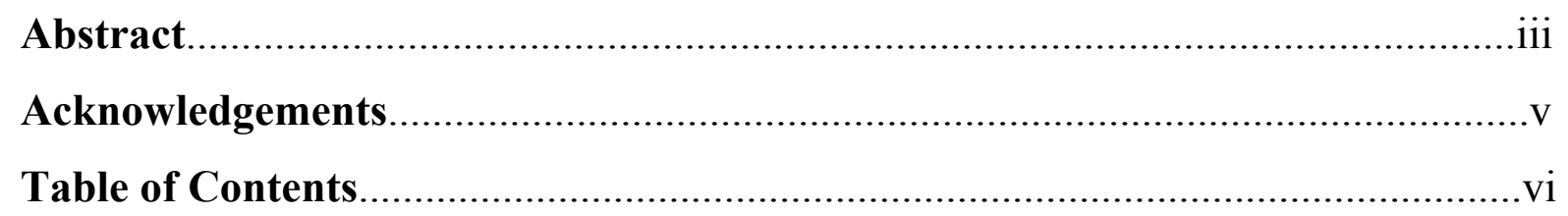

\section{Chapter 1: Introduction}

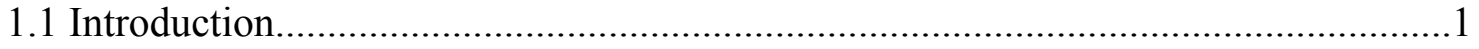

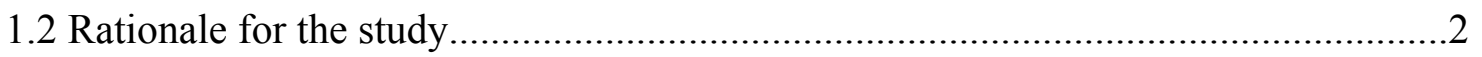

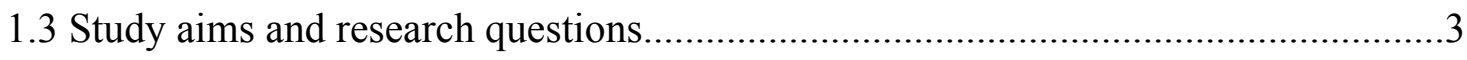

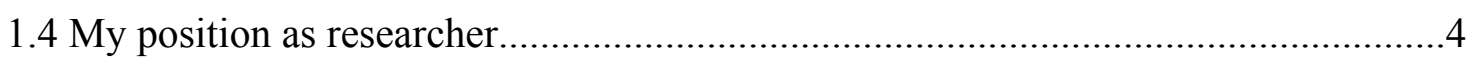

1.5 The context of teacher PD in South Korea...........................................................

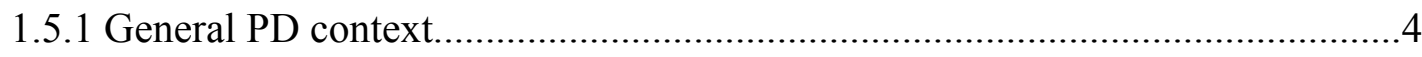

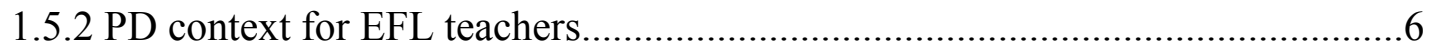

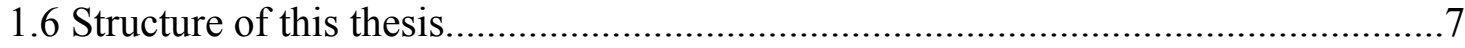

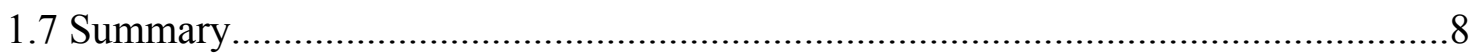

\section{Chapter 2: Literature review}

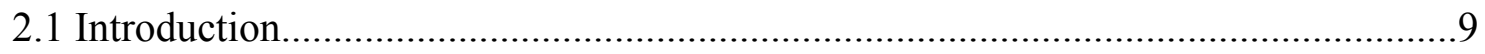

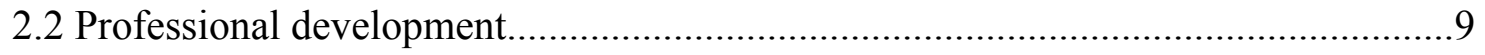

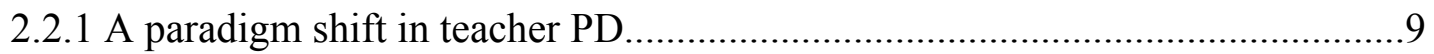

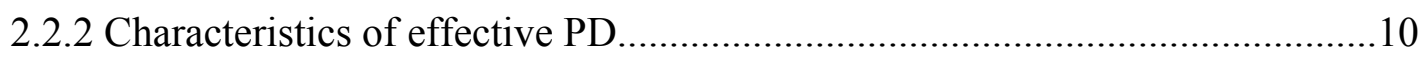

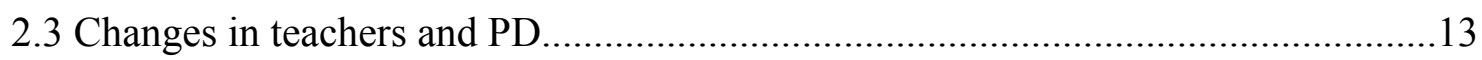

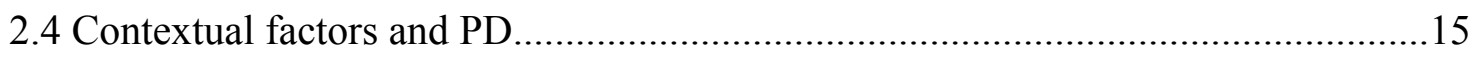

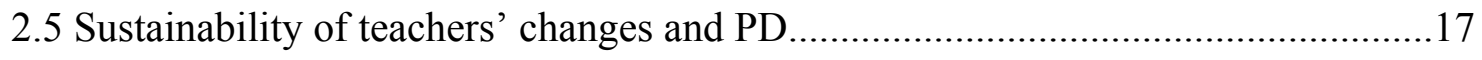

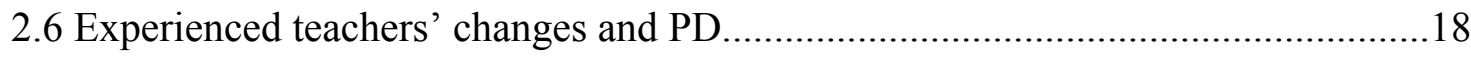

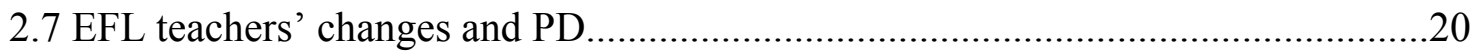

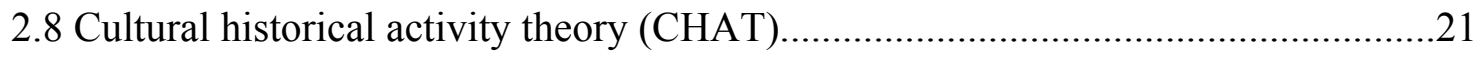

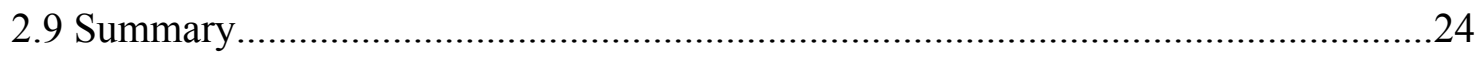

\section{Chapter 3: Methodology}

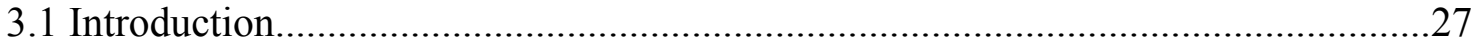

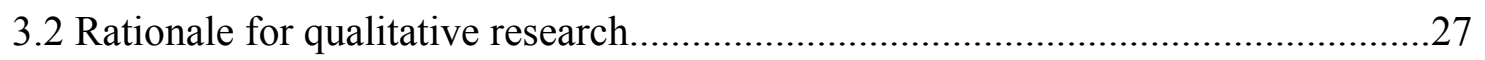




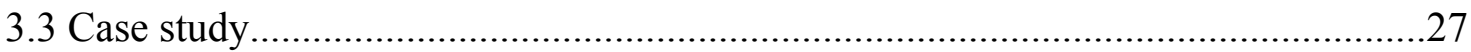

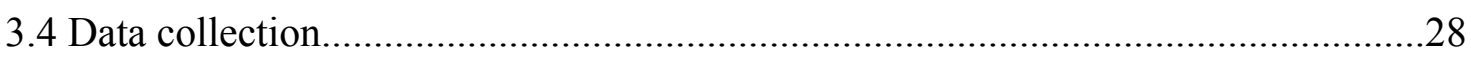

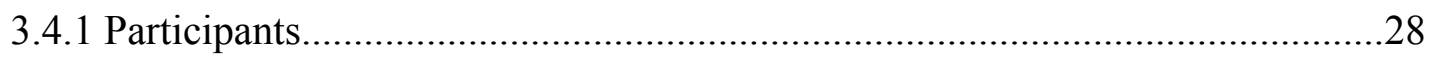

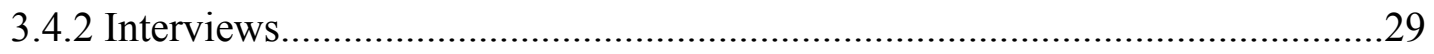

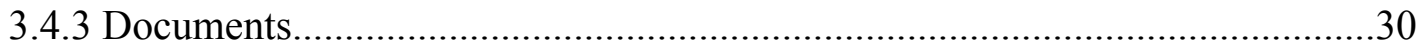

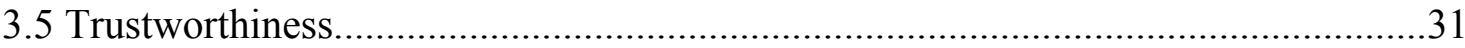

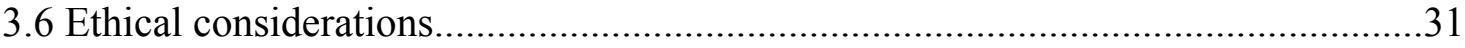

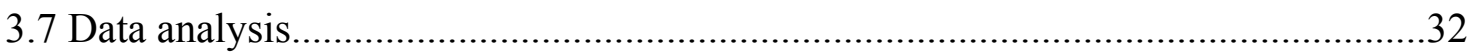

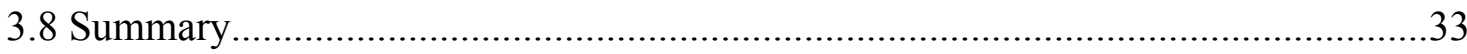

\section{Chapter 4: Findings}

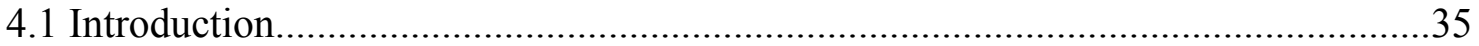

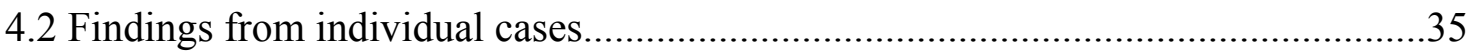

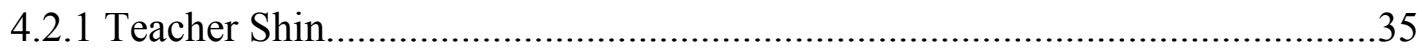

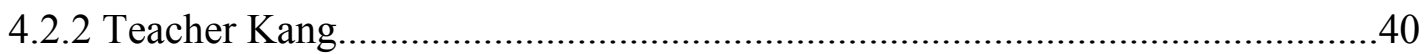

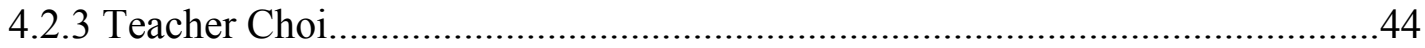

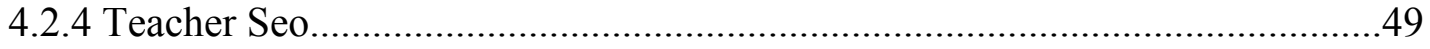

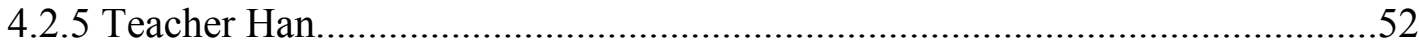

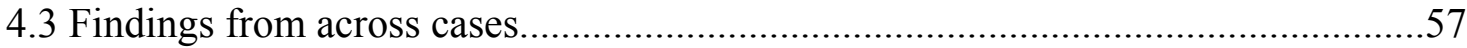

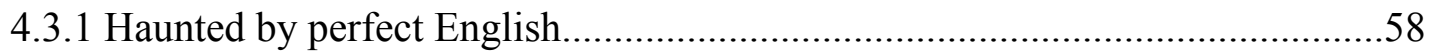

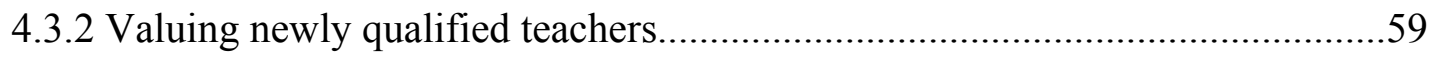

4.3.3 Isolated and stagnant teacher culture.........................................................61

4.3.4 Tension between PD goals and classroom reality.........................................64

4.3.5 Lack of support from policy and school.....................................................65

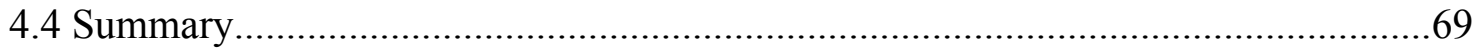

\section{Chapter 5: Discussion and Implications}

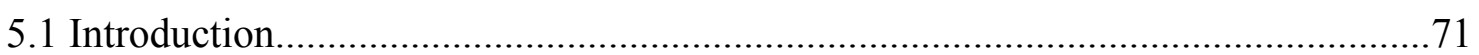

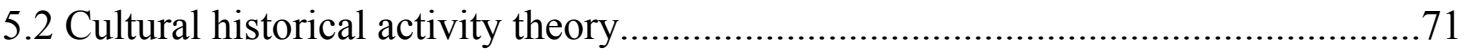

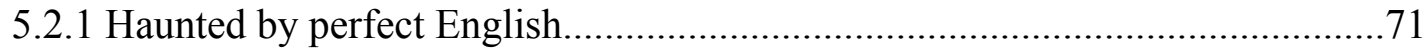

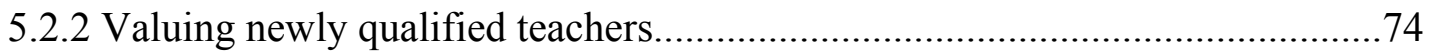

5.2.3 Isolated and stagnant teacher culture.......................................................... 77

5.2.4 Tension from conflicting goals and lack of support from policy and school...81 


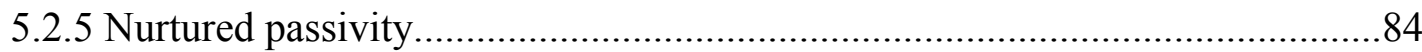

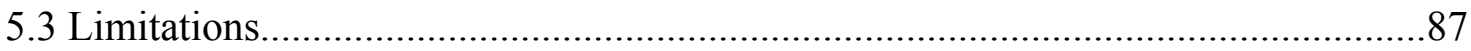

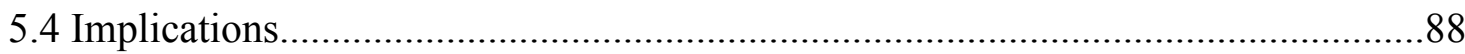

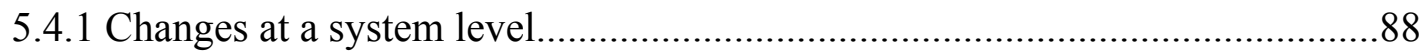

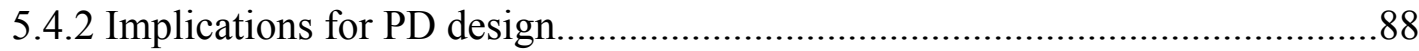

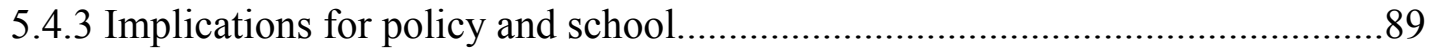

5.4.4 Implications for experienced EFL teachers..................................................91

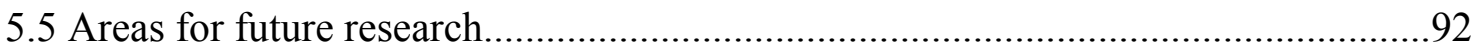

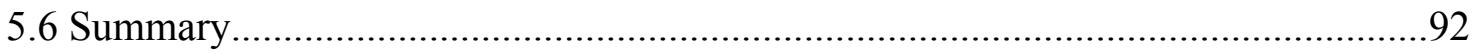

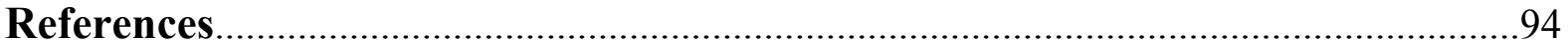

\section{List of Appendices}

Appendix A: Semi-structured interview questions.................................................110

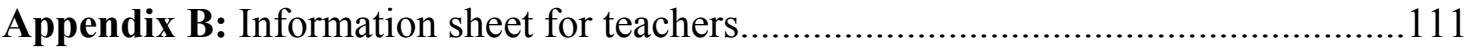

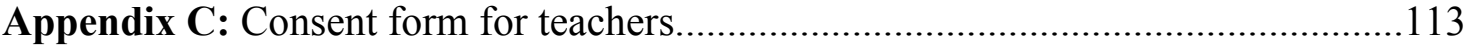

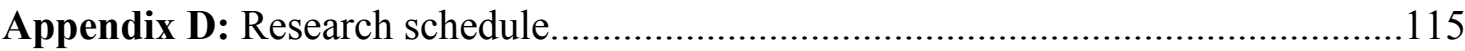

\section{List of Tables}

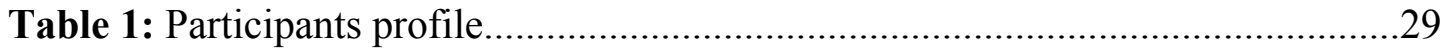

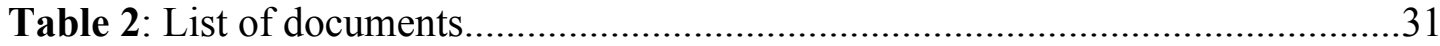

\section{List of Figures}

Figure 1: The structure of activity system (Engeström, 1987, p. 78) ..........................23

Figure 2: Haunted by perfect English in the activity system of experienced EFL teachers' PD experience.......

Figure 3: Valuing newly qualified teachers in the activity system of experienced EFL teachers' PD experience.

Figure 4: Isolated and stagnant teacher culture in the activity system

of experienced EFL teachers PD experience.

Figure 5: Tension from conflicting goals and lack of support from policy and school in the activity system of experienced EFL teachers' PD experience.

Figure 6: Outcome in the activity system of experienced

EFL teachers' PD experience. .85 


\section{Chapter 1}

\section{Introduction}

\subsection{Introduction}

There is a consensus in the literature that teachers are the most important single factor affecting student learning (Organisation for Economic Co-operation and Development (OECD), 2005). Based on the importance of the teachers' role, teacher professional development has been increasingly studied. For language teachers, both language and pedagogy are crucial professional development (PD) areas (Ur, 1990). In addition, for students who learn a language which is not used much outside of the classroom, teachers' use of language in the classroom is considered to be a significant way of providing language input (Nunan, 1991). A further reason why PD for English teachers is important in Asian countries is that English is used for professional purposes to gain higher social status in society. This professional driver is an added push for students to learn English for academic purposes (Tarone, 2005). South Korea is one of those countries (Ha \& Min, 2008) where 'English fever' is quite noticeable (Park, 2009). This heightened educational and societal attention has brought about an increased demand for high quality English teachers. This has placed greater importance on PD for English-as-a-Foreign-Language (EFL) teachers.

Diverse approaches to PD reflect the efforts of the Ministry of Education, Science, and Technology (MEST) in South Korea to improve the quality of in-service teachers and MEST hopes to see an improvement in students' learning from changes made to teaching approaches (MEST, 2013). While many studies investigate PD effectiveness, studies focussing on teachers' changes through PD have traditionally not received much attention.

However, a thorough understanding of teacher change is important. It may not be possible to improve teachers' practice without understanding what changes teachers have made to their practice as a result of PD and what they think about these changes. When teachers undertake PD, they are both learners of the content delivered in the PD programme and teaching practitioners who are considering how to apply their PD learning in their own classroom at the same time (Borko, 2004; Darling-Hammond \& Bransford, 2005). According to Timperley, Wilson, Barrar, and Fung (2007), teachers' changes depend on their black box, 
a concept referring to teachers' mental processes when deciding whether to apply their learning from PD to their teaching practices. The process of teachers' implementing changes to their practices as a result of their PD learning is not simple.

PD that is considered effective in one location is not guaranteed to be a success in other places without understanding teachers' contexts (Guskey, 2003). PD activities in countries where English is a foreign language are often based on current trends in English language teaching and affected by western-based English language education theories. The focus of research is mostly on mainstream teachers who teach English to students who have English as their first language, or teachers of English-as-a-Second-Language (ESL), who teach their dominant language to students in English-speaking countries (Karimi, 2011). However, in Asia, most EFL teachers are non-native speakers of English who teach English as a foreign language in non-English-speaking countries. Hence the approach to EFL teacher PD may be different from the approach taken with English mainstream teachers. Even among Asian countries with a similar background of EFL teaching, teachers' policy, school, and classroom contexts are different from each other.

Therefore, given that teacher change through PD is related both to teachers' inner processes and to external factors around teachers such as school environment and policy, investigating teacher change can provide crucial evidence to design more effective PD. It would be helpful to learn how teachers' teaching practice is influenced by PD and to use this information as a foundation for future PD design. However, limited research on teacher change and PD from the viewpoint of EFL teachers has been conducted in South Korea.

\subsection{Rationale for the study}

While there is prolific research on teacher change and also research on PD (Borko, Jacobs, \& Koellner, 2010; Desimone, 2009; Fullan, 2007), when it comes to teachers' changes in relation to $\mathrm{PD}$, researchers have paid more attention to the effectiveness of PD programmes rather than to understanding teachers' changes. That is, teacher change in the studies of the effectiveness of PD programmes have been limited to a measure for judging the PD effectiveness rather than a main focus to provide a deeper level of understanding of changes teachers made (Ross \& Bruce, 2007; Stein \& Wang, 1998). To understand teachers' changes arising from their involvement in PD, it is necessary to listen to teachers' own voices - how they think and feel. However, current studies rarely represent teachers' perspectives. Moreover, research on changes in the practice of EFL teachers in secondary schools is also scarce in South Korea. 
Another facet of the effectiveness of PD, its sustainability, has also received minimal attention (Fullan, 2007; Guskey, 2002; Zehetmeier, 2010). Teachers' changes have been investigated over short periods of time with most studies focussed on changes made immediately after PD such as a comparative research conducted in Canada on teachers' reported self-efficacy after taking PD (Ross \& Bruce, 2007). However, direct changes made as a result of PD can be affected by internal and external factors surrounding teachers. Therefore changes made right after PD may not be sustained in the classroom. Nevertheless, little research has been undertaken on how teachers' changes have been sustained a few years after PD. In addition, most research dealing with teachers' changes investigates one particular PD programme (Cheung, 2013; Saraniero \& Goldberg, 2011). This overlooks the fact that teachers undertake several types of PD activities over the course of their career. Therefore teachers' own articulation of the effect of a whole range of PD programmes in their practice is worth examining.

Experienced teachers have not been the focus of much research because in-service teachers in South Korea are regarded as a homogenous group. In the case of Seoul, most PD programmes are open to any teachers who volunteer to participate. The high level of job stability in the teaching profession in South Korea encourages teachers to remain in the profession longer than teachers in other countries (Seoul Metropolitan Government, 2013). Moreover, teachers with long experience are often overlooked as they tend to be regarded as expert teachers. However, as years of experience is just one element of expertise, changes within the experienced teacher group need to be specifically examined. Therefore understanding experienced South Korean teachers' professional changes would help to shape PD appropriate to their needs.

\subsection{Study aims and research questions}

This study investigated experienced South Korean EFL teachers' perceptions of how their teaching practice has changed over their career, and explored what kind of relationship exists between PD and their perceived changes. This study identifies factors reported to influence these teachers' changes in practice. The research question and sub-questions are presented below:

How do experienced EFL teachers perceive changes to their teaching practices as a result of PD?

1. In what ways do they report their practices as having changed over their careers? 
2. What changes do they attribute to PD?

3. What aspects of PD do they report as influencing changes to their practices?

4. What changes do they report sustaining over time?

\subsection{My position as researcher}

The researcher becomes a tool for the study in qualitative research (Harry, 1996). This means that what researchers think and believe might influence their study. Since it is not possible to exclude my subjectivity (Peshkin, 1988), I, as the researcher of this study fully acknowledge the fact that my experience as an EFL teacher in public schools in South Korea might affect this study and this is also included as a potential limitation in this study.

\subsection{The context of teacher PD in South Korea}

This study focuses on experienced EFL teachers in South Korea. Therefore it is necessary to understand PD contexts in South Korea in general and for EFL teachers in particular.

There are two levels of certification for public secondary school teachers: certification of secondary school teachers at level 2 and at level 1 (Coolahan, Santiago, Phair, \& Ninomiya, 2004). Secondary teachers start their teaching career with the level 2 certification after graduating from teachers' college and passing the national teacher examination. After an average of five years of teaching experience, teachers can attend a PD programme to attain the level 1 certification. This higher level of certification contributes to a higher salary tier. However, there is no relationship between achieving the level 1 certification and job security since public school teachers' positions are guaranteed by law until the age of 62 . Although teacher retention in South Korea is relatively high because of this job security, there is no higher PD certification after teachers reach the level 1 certification.

\subsubsection{General PD context}

From the mid-1990s in-service teacher education in South Korea has been viewed as a way of propagating a changed national curriculum and new educational policies, and as an opportunity for teachers to improve their professionalism (Coolahan et al., 2004). MEST (2013) has supported a variety of PD activities ${ }^{1}$ to enhance teachers' professionalism and thus to strengthen schools' global competitiveness. MEST diverses structure and management of

\footnotetext{
${ }^{1}$ Consensus has not been reached regarding terminology for PD in South Korea. In this study the term 'PD activities' will be used as a general and inclusive term for PD. Short-term PD of less than 1 month is called a 'PD course' whilst for long-term PD of more than 3 months 'PD programme' is used.
} 
PD to regional educational authorities such as the Seoul Metropolitan Office of Education (SMOE).

The most common PD activities available to teachers in South Korea are institutecentred. This kind of PD is usually done at venues outside of school such as regional institutes of teacher training under the direct control of the regional offices of education, universities entrusted with teacher training, or authorised private institutes for teacher training. Some face-to-face PD courses operate in schools for the convenience of teachers in schools far from the regional teacher training institutes. Lecture-style workshops and courses are the most popular PD structure and PD programmes incorporate discussion or presentation components from participating teachers. Online PD activities have been designed to free teachers from the constraints of time and place, and to encourage voluntary participation in PD. Online PD courses are usually lecture-style with little interaction required between the instructor and participating teachers or between participating teachers.

The second type is in-school PD. Although in-school PD like study groups can be organised informally, in-school PD activities initiated by regional offices of education. In case of SMOE, open-class and peer observation are two representative in-school PD activities (SMOE, 2009).

Both open-class and peer observation PD activities include classroom observation of other teachers' teaching practice. The difference is the purpose of each activity; the focus of open-class is on teachers' learning and improvement as a professional by conducting or observing a teaching demonstration (MEST, 2010). Open-class is described as the demonstration of teaching practice to other teachers and the purpose is to give teachers an opportunity to present their own teaching practice as an exemplary lesson. Open-class can be conducted at several levels: at an in-school level which is open for teachers in the same school; at district level for teachers in nearby schools; and at the regional office of education level for teachers from nearby schools and for facilitators from the regional office of education. While all teachers are required to conduct an in-school level open-class once a year, one teacher from each subject in each school is expected to conduct an open-class at the regional office of education level because open-class at the regional office of education level is regarded as an important event by the school. A teacher is chosen after discussion amongst teachers from the same subject area - it can be either a voluntary decision or a decision made after pressure from colleagues.

In contrast, peer observation is a formal classroom observation to assess a teacher's accountability as a teaching practitioner. This evaluation from colleagues is required as part 
of the national teacher evaluation. In addition, informal classroom observations are encouraged by SMOE as a way of peer learning. Regular meetings among teachers in the same grade or in the same subject are also included in this category.

Teachers can accumulate credits by taking PD courses and programmes (normally 1 credit per a 15-hour PD course). These credits are reported as part of the national teacher evaluation and school evaluation, which closely link to the incentive systems of performancebased pay for teachers and school-based merit pay (Ban, 2012; MEST, 2008a). To be ranked in a higher level of incentive systems, teachers are under pressure to take more PD than the required hours set by each regional office of education (Lim, 2013). In the case of SMOE, EFL teachers are recommended to take 60 hours of PD per year, and 30 hours for all other teachers (MEST, 2006). In contrast, participation in in-school PD activities does not accrue PD credits. With regard to content, teachers can take PD courses in their subject area such as English skill building and English teaching in the case of EFL teachers, or on general professional topics such as student discipline and counselling, or areas of personal interests such as music or art. Recently technology-related courses for teaching have been added based on increased attention to the use of information and communication technology (ICT) as educational tools.

The last type is PD in which teachers participate at their own discretion, such as pursuing a higher degree or participating in conferences. Teachers can also organise an informal study group within or outside of their schools and this kind of PD activity does not accrue PD credits.

As MEST has recently emphasised that PD should be closely linked to teachers' classroom practice, two PD initatives, teaching consulting and master teacher, have been newly introduced. Individual teachers can request a consultation with a teaching consulting group, organised by the regional office of education. The master teacher initiative is considered as mentoring, but as a newly adopted initiative, the numbers of qualified master teachers are limited. Both PD activities are intended to help individual teachers by providing advice and working with them to find possible solutions to current issues in the classroom.

\subsubsection{PD context for EFL teachers}

The demand on the practical use of English as a communication tool has resulted in a paradigm shift in English language teaching methodology, which has affected the goal of English education in South Korea (MEST, 2005). The transition in English language teaching methodology from grammar translation to communicative language teaching (CLT) has led 
to a significant focus on practical use of the four English language skills of listening, speaking, reading, and writing, but particularly on speaking skills. This is totally different from the focus on grammar and translation that EFL teachers had previously practised in the classroom. To enhance students' communicative ability in English, EFL teachers are now expected to meet new teaching competences based on CLT. Beginning in 2000, English speaking and Teaching in English have been included as components of the national teacher examination (MEST, 2008b). PD programmes for in-service EFL teachers also have a new focus on improving teachers' English communication ability. This change is likely to have had a significant effect on the professional efficacy of teachers who graduated before 2000 .

The new policy also encouraged EFL teachers to immerse students in English-only classes. As a result, English language proficiency at a level sufficient to teach and communicate with students in English became an important quality for EFL teachers. As EFL teachers' use of English for teaching became more desirable, the TEE (Teaching English in English) certification initiative was introduced in 2009 to encourage teachers to improve their teaching in English (MEST, 2013). There are two types of TEE certification: TEE-A and TEE-M. Teachers who have more than one year of teaching experience can apply for TEE-A certification. To achieve TEE-M certification, EFL teachers with more than ten years of teaching experience should pass several cycles evaluating their use of English in the classroom. Along with the TEE initiative, the regional offices of education recommend EFL teachers take more than 60 hours of PD every three years to improve English communicative ability and TEE ability (SMOE, 2009). Although the TEE certification is voluntary, this increased pressure on EFL teachers together with rapid changes in English language teaching trends have contributed to lower levels of EFL teacher retention compared to other subjects in South Korea (Gyeonggi-Do Education Information Archives, 2013).

\subsection{Structure of this thesis}

This thesis is organised into five chapters. Chapter One has introduced an overview of this study. The rationale for the study, research questions, and the context of the study has been explained. Chapter Two reviews the literature around PD and teacher change.

Beginning with the paradigm shift in the PD approach, the effective components of PD are described. The relationship between PD and teacher change in several points is discussed in detail. The chapter also introduces cultural historical activity theory (CHAT) as a theoretical lens of this study. Chapter Three describes the methodology employed in this study. The rationale for a qualitative multiple case study is discussed. Data collection procedures and 
how the data were coded and analysed are explained along with trustworthiness and ethical considerations. The results of the study are presented in Chapter Four. Findings from five individual cases - each teacher's changes and PD experiences - are thoroughly illustrated. Findings across the cases are developed into five themes and each theme is described. Chapter Five discusses the findings based on the framework of CHAT. Implications, limitations, and suggestions for future research follow.

\subsection{Summary}

This chapter presented the topic and the rationale for this study, and outlined the research aims and questions. The context of teacher PD in South Korea was also introduced as background for this study. The next chapter will discuss literature around PD and teacher change with a detailed discussion of sustainability of change, EFL teachers, and experienced teachers. 


\section{Chapter 2 \\ Literature review}

\subsection{Introduction}

This chapter introduces previous research around the topic of this study. Firstly changes in conceptions of teacher PD and constructs for effective PD are discussed. The next section presents literature on the scope and sustainability of teacher change. As this study focuses on experienced EFL teachers' perceptions, changes affecting experienced teachers and EFL teachers, related to PD, are specifically addressed. Lastly, cultural historical activity theory, the theoretical framework for this study, is introduced.

\subsection{Professional development}

Teacher PD is important because teachers are classroom practitioners who affect student learning (Borko, 2004; Fullan, 2007) and agents who implement and practice changes in educational policy (Laukkanen, 2008). As PD is "systematic efforts to bring about changes in the classroom practices of teachers, in their attitudes and beliefs" (Guskey, 2002, p. 381), the literature about PD is presented first to help understand its effect on teachers' changes over their careers.

\subsubsection{A paradigm shift in teacher PD}

Traditionally, the approach to teacher PD tended to be training, which is to equip teachers with the necessary skills to teach students (Richards, 2008; Wallace, 1995). The underlying premise in the training-oriented PD approach was that teachers had deficiencies and they needed some externally defined prescriptions to improve their teaching (Freeman, 2001; Richards \& Farrell, 2005). In traditional approaches to PD, teachers undertaking PD usually played a passive role; they needed to be receptive to learning and practicing new skills which educational policymakers determined. Therefore, teacher change, under the concept of training, was expected to follow the model of effective teachers established and suggested by the PD (Cochran-Smith, 2004). In Behaviourist terms, changes to teachers' behaviour were viewed as a positive response to the PD (Kumaravadivelu, 2006). 
While it was regarded as unsuccessful if PD content was not transferred into teachers' teaching practice, social constructivists consider that there is not one way of teaching and individual teachers have different definitions of effective teaching based on their own teaching context, students and culture (Singh \& Richards, 2006). They view PD as professional learning. Researchers advocating this view consider how teachers make sense of and develop their own way of teaching (Cochran-Smith, 2001). It is now believed that teachers - active practitioners and learners - make decisions in the classroom after filtering what they learned in their PD (Duffy \& Roebler, 1986). This is similar to Timperley et al.'s (2007) concept of teachers' black box, which is "situated between professional learning opportunities and their impact on teaching practice" (p. 7). Teachers reject, accept, or adopt new learning to make their teaching effective for their students. Teachers are now considered to play an active role in initiating changes in their teaching practice.

Moreover, teachers are not tabulae rasae; they are rather "boundedly rational" in that "individuals actively make use of cognitive strategies and previous knowledge to deal with their cognitive limitation" (Shulman \& Carey, 1984, p. 509). Teachers combine new learning from PD with what they already know and adjust the results of the new combination to fit their reality. In this sense, teachers are regarded as adult learners. Teachers' learning is "heavily influenced by an individual's existing knowledge and beliefs and is situated in particular contexts" (Borko \& Putnam, 1996, p. 674). Kwakman (2003) noted that teachers construct their own knowledge and direct their own learning to learn new ways of teaching, just like students. Therefore it is important to understand the process of teacher change after taking PD.

Instead of an outcome-oriented notion that changes are ideal and necessary to create a better teacher, PD is now considered to be a change process with greater focus on what is involved in the process. PD now is regarded more as learning and development and less as training.

\subsubsection{Characteristics of effective PD}

A general consensus now exists about effective PD components (Borko et al., 2010; Darling-Hammond, Wei, Andree, Richardson, \& Orphanos, 2009; Hawley \& Valli, 1999). School-based PD, PD that creates collaboration among teachers, ongoing PD, and PD that incorporates reflection and inquiry are included in as effective characteristics. School-based PD could make PD more effective because it is situated in teachers' own practice (Borko et al., 2010; Coolahan, 2002; Quick, Holtzman, \& Chaney, 2009). Gatt (2009) examined 
changes in perceptions and knowledge of fourteen teachers in a primary school who had participated in a three-year school-based PD programme to promote Drama. By employing a case study using interview, questionnaires, and informal conversations, Gatt concluded that participating teachers reported positive changes in perceptions, knowledge, and confidence in teaching. These changes were attributed to the conditions created by school-based PD that enabled teachers to experiment with the new PD learning immediately in the classroom where teachers could witness the results in the classroom. The benefit of simultaneous implementation of PD and feedback through school-based PD is one characteristic of effective PD (Desimone, 2009).

Encouraging teachers' collaboration is another characteristic of effective PD. This is related to active learning such as problem-solving through teachers' collaboration (Borko et al., 2010; Desimone, 2009; Mundry, 2005). Desimone (2009) emphasised the positive effects of PD that develops collaboration among teachers in the same school. Swafford, Jones, and Thornton (1999) studied the impact of a three-year PD programme on instructional practices of fourth to eighth grade mathematics teachers. The qualitative and quantitative data showed that the design of this PD programme which encouraged the teachers to collaborate and reflect led to improvement in their instructional practice and their enhanced self-confidence and autonomy. Teacher collaboration involves building a sense of community, one of the tenets of effective PD (Darling-Hammond et al., 2009).

Another feature that characterises effective PD is that it is ongoing (Borko et al., 2010; Darling-Hammond et al., 2009; Quick et al., 2009). Johnson, Fargo, and Kahle (2010) examined a three-year programme in which all the science teachers from one middle school participated. The PD programme consisted of a two-week PD session that took place every summer, followed by monthly PD sessions with a facilitator. Unannounced classroom observations of participating teachers over the three year PD programme showed that the teachers improved their teaching practice and their improved teaching was sustained even two years after PD implementation. Implementing the ongoing PD sessions every month for three years, rather than conducting PD in one two-week PD session each summer, contributed to teachers' improvement during and after implementing the PD. This study highlighted the importance of a sustained PD effort to improve teaching practice.

Effective PD also requires teachers to reflect and inquire into their own practice (Fullan, 2007; Desimone, 2009). In Qualters' (2009) study of a faculty development programme to promote collaborative dialogue, teachers had opportunities to reflect and inquire into their learning assumptions with other faculty members in a non-judgmental 
environment. This led to positive changes in teaching practice of the participating faculty groups. Quick et al. (2009) idenfied what characteristics of effective PD shown in literature were evident in actual practices when examining the impact of a PD programme on literacy instruction and concluded that reflection through coaching contributed to effective PD.

Regarding the structure of PD programmes, many researchers contend that reform type PD such as study groups may be more effective than traditional type PD such as one-off workshops or seminars, in terms of bringing about teacher change (Porter, Garet, Desimone, \& Birman, 2003; Stein, Smith, \& Silver, 1999). Aforementioned characteristics of effective PD are shown as components of reform type of PD.

One reform approach to PD which has been spotlighted is that of professional learning communities (PLC). PLCs are "an inclusive and mutually supportive group of people with a collaborative, reflective and growth-oriented approach" (Stoll, 2011, p. 104). Researchers advocating PLCs argue that PLCs have several characteristics that distinguish them from an ordinary group (Hipp \& Huffman, 2010; Hord, 2009; Stoll, 2011). Firstly, members of PLCs have a shared vision and values (Hord, 2009). Another prominent characteristic is collaboration. As well as working together as a collaborative team, they inquire into their learning and practices collectively for ongoing improvement (Hipp \& Huffman, 2010; Hord, 2009). PLCs encourage members to question the status quo and to be open to new possibilities and new experiences by sharing their own practice. Hung and Yeh's (2013) study of Taiwanese EFL teachers' changes through adopting a study group resulted in positive changes in their beliefs and practices by incorporating collective inquiry as a main focus of their study group. Shared leadership is also another PLC trait, with distributed responsibilities to members of PLCs for their learning and achievement of common goals (Hipp \& Huffman, 2010; Stoll, 2011). These characteristics of PLC are congruent with ones of effective PD.

In contrast, Shields, Marsh, and Adelman (1998) analysed the National Science Foundation's State Systemic Initiatives for the purpose of improving math and science education and showed that traditional PD conducted in the form of one-off workshops or seminars was not effective in fostering learning since such PD sessions were unlikely to alter teachers' beliefs fundamentally. Smith and Gillespie (2007) supported the importance of combining the characteristics of effective PD in PD design by arguing that traditional types of PD may be successful only if they are redesigned to meet the characteristics of effective PD. 
Effective PD is likely to have the following characteristics: it is based on teachers' practice within a school, it helps teachers collaborate, it is ongoing and consistent, and it incorporates teachers' reflection and inquiry. These characteristics of effective PD can be found in reform types of PD such as PLC rather than traditional types of PD.

\subsection{Changes in teachers and PD}

The teaching process is very complex. Teachers' professional choices can be described as "the integration of action and thought" (Freeman, 1992, p. 1). This suggests that it is not easy to change teachers' practice (Johnson, 2007) since it requires a transition from the "safe and familiar" to the "new and uncertain" (Gess-Newsome, 2001). PD is an affordable and easily accessed tool in order to push and prod teachers from their comfort zone to make changes in teaching practice (Borko, Davinroy, Bliem, \& Cumbo, 2000). PD can bring about two types of changes in teachers' practices - changes in cognition such as movement in teachers' knowledge, skills, attitudes, or beliefs (Cheung, 2013; Karimi, 2011; Luft, 2001) and changes in behaviour such as the use of instructional skills in the classroom (Desimone, Porter, Garet, Yoon, \& Birman, 2002; Diaconu, Radigan, Suskavcevic, \& Nichol, 2012).

Studies with a particular focus on either cognitive changes or behavioural changes to examine teachers' changes to their practice have limitations when attempting to address both areas of changes. Cognitive changes were evident in the participants in Cheung's (2013) study which used a survey to examine the influence of a four-week writing PD course on 28 Singaporean teachers of English. Cheung's study showed changes in the teachers' skills of teaching writing, and in their attitudes towards teaching writing. Karimi (2011) surveyed 60 junior high school teachers' self-efficacy, which were beliefs about their teaching ability. The findings showed that the teachers who undertook a PD programme which incorporated several PD models had higher levels of self-efficacy than the group who did not take the PD programme. However, neither study addressed how the particular PD programme affected the participants' behaviour. Desimone et al. (2002) studied 207 teachers' instructional practices as they participated in a PD programme designed to increase their use of specific strategies. Although Desimone et al. observed the participating teachers' changed instructional practices, the resulting changes in behaviour did not explain whether cognitive changes were engaged in the process.

It cannot be assumed that either cognitive changes or behavioural changes are the only measures of teachers' uptake of PD because cognitive changes do not imply behavioural 
changes and vice versa (Borg, 2003). Timperley et al. (2007) suggested three stages in the learning process for teachers. These stages involve changes in both cognition and behaviour: "cueing and retrieving prior knowledge", "becoming aware of new information and integrating this into their current values and beliefs system", and "creating dissonance with current position" (p. 7). As teachers reach a certain stage of the learning process, they may take one or more positions among six possible positions (Timperley et al., 2007). The six positions in relation to new theory and practice that Timperley et al. suggested are rejecting, continuing a current practice as if it is new, partly accepting, accepting as directed, implementing, and fully utilising.

First, teachers may reject or ignore the new theory and practice and continue with their existing practice, especially when they perceive a big gap between the new learning and their current teaching practice. In this case, changes in neither cognition nor behaviour may be involved. Kubanyiova (2006) studied both areas of changes in teachers who participated in PD and noted that although the teachers were motivated to be engaged in PD, the teachers' teaching context, teacher culture and an unsupportive system, hindered changes in cognition and behaviour. On the other hand, this rejection could also be interpreted as a change in teachers' cognition: teachers may resist new learning and decide to continue their current practices rather than adapt to new practices after considering their teaching contexts. Kennedy (1996) observed that Malaysian EFL teachers reverted to their traditional way of teaching because of their teaching context despite developing a student-centred view of language teaching during overseas PD in UK. Another possible interpretation is that teachers may be in transition towards implementing new knowledge, skills or perceptions into their behaviour in the classroom. That is, behavioural changes may not be realised despite cognitive changes.

Secondly, teachers may continue with their prior practice in the belief that it is a new practice (Timperley et al., 2007). Teachers in this position may be aware of the benefits of their new PD learning but these are not realised in a transformation of their teaching practice. Thirdly, teachers may select parts of the new theory and practice, and adapt elements of their current practice. Teachers' partial implementation may involve either changes in behaviour only or changes in both cognition and behaviour within their teaching context.

Among the six positions which Timperley et al. (2007) suggested, the latter three positions take account of whether the behavioural changes include changes in knowledge/skills or perception. The fourth position is when teachers implement the new ideas. However, part or thorough adaption at the observable level of teaching practice may be 
the result of forced external pressure from the school or policy rather than from changes in cognition, or it may be the result of negotiation with teachers about their own teaching context. Almarza's (1996) study of four student teachers in a postgraduate certificate in education course showed instances of behavioural changes as their performance was assessed, although the level of their cognitive change differed individually. The fifth position is where teachers actively engage with, own, and apply new theory and practice; and the last position which teachers may take is to demonstrate enhanced regulation of their own and others' learning. In these situations, teachers engage in thorough implementation of PD learning into their teaching practice. Therefore there should be a dual focus on teachers' cognition and behaviour to fully understand teacher change in teaching practice, and thus the impact of PD (Borko et al., 2000).

\subsection{Contextual factors and PD}

There is no one-size-fits-all PD (Garet, Porter, Desimone, Birman, \& Yoon, 2001). Even PD designed using principles of effective PD cannot guarantee positive results in teaching practice. PD which has led to successful results in one place may not be effective in another place. Ganser (2000) stresses, "context accounts for much of the success or failure of activities aimed at improving teaching" (p. 9). Although teachers may have a feeling of satisfaction and improvement while engaging in PD, it is contextual factors that may help or hinder the realisation of PD in their teaching.

Diverse factors affect teachers' PD learning and implementation in their classroom practice (Ingvarson, Meiers, \& Beavis, 2005; Lamie, 2004). Contextual factors which appear to affect teachers' changes include classroom factors, school factors, and educational policy factors (Lamie, 2004; Timperley et al., 2007). Classroom factors are related to students, classroom setting, and resources such as class size and the accessibility of teaching materials (Desimone, 2009; Lamie, 2004; Merilainen \& Pietarinen, 2002).

School factors are about school culture, which means interaction and networking among teachers, and about the relationship between teachers and school administrators. A congenial atmosphere and a collaborative teacher culture affect teachers' PD learning and implementation positively. A study of 21 primary mathematics teachers in the United States who participated in the Cognitively Guided Instruction PD programme to improve teachers' understanding of students' thinking found that all teachers made changes in their beliefs and incorporated the strategies of eliciting students' thinking into their teaching (Fennema et al., 
1996). This successful implementation was attributed to a collaborative culture amongst the participating teachers. Conversely, a study by Huberman and Miles (1984) revealed an absence of collaborative teacher culture which demotivated the participating teachers. Huberman and Miles observed:

when considering teachers as a group in the school culture, senior teachers were not only more resistant to change, they were also less likely to believe that it would work. Junior teachers who have attended training courses may also feel it is inappropriate to relate their experiences to senior teachers. (p. 130)

Support from school administrators is usually considered as an important contextual factor in that they can encourage teachers' active learning, and create a safe environment for teachers to experiment with their learning and incorporate it into their practice. Borko et al. (2010) point out that support from schools contributes to making PD effective. Research on PLCs also emphasises the significance of administrative support and teacher leadership from within the school (Hord, 2008, 2009; Stoll, 2011; Wells \& Feun, 2007). Chew and Andrews (2010) studied the implementation of a school improvement programme into schools both in Singapore and Australia, and revealed the important role of teachers as leaders. Their study showed how school administrators could support teacher leadership by providing resources such as time, space, and opportunities to share decision-making. Maughan, Teeman, and Wilson's (2012) study is in line with Chew and Andrews' findings by contending that head teachers' leadership can help to bring about positive changes.

The policy context is considered to be an external influence on PD provision. The examination-oriented curriculum in Asian countries such as China and Japan is perceived as a hindrance as it restricts teachers' teaching to exam preparation and allows teachers few chances to experiment using their PD learning in the classroom (Cheah, 1997; Rubdy, 2008). The dominating focus on exams was also seen to be a constraint in Wong's (2013) study of changes made by Japanese student-teachers after taking a PD programme overseas. Although the participating teachers showed changes to their beliefs, on their return to Japan they could not sustain these changes because of the focus on the public exam. As examination success is a high priority in South Korean education, it is likely to have an effect on teachers' changes through PD learning. The influence of Education policy affects teachers' PD learning and implementation of PD.

Top-down imposition of PD policies is perceived as a barrier preventing positive changes in teachers' practice (Leung, 2001). In a study of Japanese EFL teachers who had participated in PD overseas, Lamie (2004) showed that the imposed policies undermined 
teachers' implementation of new communicative teaching methods. An almost exclusive focus on examinations prevented teachers from making any changes to their practice.

Contextual factors from classroom, school, and educational policy have a significant impact on the process of bringing about changes in teachers' practice. Therefore consideration of these contextual factors in South Korea may help understand experienced EFL teachers' changes through PD in South Korea.

\subsection{Sustainability of teachers' changes and PD}

Studies evaluating the effectiveness of PD usually gather data during or right after a PD programme and use these data to conclude that the programme has stimulated change in the participants (Ross \& Bruce, 2007; Stein \& Wang, 1998). While these studies suggest a direct relationship between PD programmes and teacher change, the long-term effect of PD on teacher change is often not examined. Creating and sustaining change in teaching practice is not easy to accomplish (Pennington, 1995). Although meaningful changes have been made in teaching practice through PD intervention (Ross \& Bruce, 2007; Stein \& Wang, 1998), there is no guarantee that such changes are sustained over time. Therefore, research on the long-term effect of PD is necessary.

Although PD programmes include the consideration of how to sustain changes, few studies have focussed on the long-term effects of PD (Goldenberg \& Gallimore, 1991). Most studies have examined the sustainability of changes within a year after the PD programmes ended (Gatt, 2009; Goldschmidt \& Phelps, 2007) and some researchers investigated ongoing changes made to teachers more than a few years after PD participation (Franke, Carpenter, Levi, \& Fennema, 2001; Johnson et al., 2010). Research shows the quality of PD (Saraniero \& Goldberg, 2011), the responses from students (Gatt, 2009), and contextual factors (Zehetmeier, 2010) as influential elements in the sustainability of changes.

How a PD programme is designed affects the sustainability of teachers' changes. Saraniero and Goldberg (2011) used a mixed methods approach to investigate the effect of a two-year PD programme incorporating arts into the reading curriculum in the United States. Two groups of teachers took either a coaching-embedded workshop PD programme or a stand-alone workshop PD programme, and their PD learning was compared during and a year after the PD intervention. They concluded that the teachers' learning was evident from both PD programmes, but the teachers who participated in the coaching-embedded PD programme retained their learning longer than the teachers who participated in workshop PD alone. This 
study supported reform type PD such as coaching as an effective form of PD in terms of creating and sustaining teachers' changes.

Students' positive responses appear to impact significantly on teachers' continuous implementation of PD learning (Guskey, 2002). Guskey's assertion is supported by Gatt's (2009) study of fourteen primary teachers in Malta. The teachers' use of drama from PD one year after the PD ended was attributed to students' positive reaction.

The contextual factors affect not only teachers' changes to teaching practice but also the sustainability of those changes through teacher leadership (Chew \& Andrews, 2010; Maughan et al., 2012) and support from national or district policies (Owston, 2007; Zehetmeier, 2010). School factors of collaboration (Franke et al., 2001; Sarason, 1996) and building PLCs (Lerman \& Zehetmeier, 2008) are particularly crucial to bring about the sustainability of changes. Franke et al. (2001) investigated 22 mathematics teachers four years after a PD programme designed to improve teachers' understanding of how to use students' thinking as an instructional strategy. The teachers made changes in belief and practice: they listened to what students thought in the class and perceived that incorporating students' thinking in their teaching was beneficial to improve their teaching practice. The researchers concluded that the collaborative culture among teachers gave them opportunities to reflect on their teaching and led to the teachers' sustained changes.

The sustainability of teachers' changes after PD is affected by PD quality, students' reaction, and school and policy contexts. As this area has not been studied extensively, by focusing on experienced EFL teachers' PD experience over their career, my study may reveal more about teachers' perceptions of long-term changes resulting from PD.

\subsection{Experienced teachers' changes and PD}

Research on how teachers change over time suggests that teachers pass through different stages of development in their teaching career (Burden, 1990; Fessler \& Christensen, 1992; Leithwood, 1992; Steffy \& Wolfe, 2001; Steffy, Wolfe, Pasch, \& Enz, 2000). Although researchers have described stages of teacher development differently (Huberman, 2001), there is an agreement that teachers have different PD needs at different points in their careers (Killion \& Harrison, 2006). One example of this comes from Eros' (2013) study of second-stage music teachers who had 4 to 10 years of teaching experience. Through focus group interviews, Eros found that the teachers' PD needs at the time of the interviews were different from the PD needs they had in their early years of teaching such as classroom 
management and teaching skills. Based on this finding, Eros concluded that different types of PD would be needed to meet these teachers' different PD needs over their career. Margolis (2008) studied the career path of seven teachers with four to six years of teaching experience in the United States, who were at a similar development stage to the music teachers in Eros' study. Margolis found that assigning the role of a mentor might help these teachers to share their expertise with other teachers in the profession and yet continue their own learning. Although there is consensus on different PD needs depending on teachers' career stage, much of the research on teacher change has placed teachers at different stages into a single group (Eros, 2013) and few studies have investigated the experiences of teachers in later stages of their careers (Broad \& Evans, 2006). Most attention is given to pre-service or novice teachers. For this reason, my study focussed on experienced teachers who have more than 15 years of teaching experience to understand changes of this particular group of teachers through PD experience over their career.

Another issue in research on changes within the practice of experienced teachers is that teachers in later stages are more likely to have greater teaching experience, so it is commonly accepted that long-serving teachers are expert teachers. Teacher development models divide years of teaching experience into stages and suggest the last stage of development is one of mature practice (Burden, 1990; Katz, 1972). One of the characteristics of teachers in the mature stage is that they are likely to be autonomous (Glatthorn, 1984). In comparative studies, the term experienced teachers is usually used as the opposite term to novice teachers (Krull, Oras, \& Sisask, 2007; Luft, 2001). Some such studies have found, for example, that the level of experienced teachers' self-efficacy was higher than that of novice teachers (Tschannen-Moran \& Hoy, 2007) and that experienced teachers were more adaptive in implementing new changes than novice teachers (Luft, 2001).

However, some research shows contrasting results. In Lukacs' (2012) study of the relationship between teachers' demographic factors and the level of their change agency, a correlational study of 653 teachers showed that these teachers reported a lower level of change agency and lower levels of membership of the teaching community with increased age. Tsui (2003) points out that although the years of teaching experience is commonly used as a characteristic of experienced teachers, not all teachers with long teaching experience reach the level of expert teacher. Similarly, Steffy et al. (2000) contend that teacher development is cyclic rather than linear. In their life-cycle model, teachers experience six stages of teacher development - novice teacher, apprentice teacher, professional teacher, expert teacher, distinguished teacher, and emeritus teacher - depending on their tasks or roles. 
Whenever teachers encounter new tasks or new roles, they start from the stage of novice teacher. In this model, years of experience does not necessarily equate to expertise.

\subsection{EFL teachers' changes and PD}

Language teachers are different from other subject teachers. For teachers of English, their subject is not only content to teach but also a tool for instruction and communication. Other subject teachers, such as those who teach math or science, use their mother tongue (L1) as a mode of delivery. However, language teachers can choose either their L1 or the language their students learn, which is called the second language (L2). For teachers who teach English as a foreign language, there is a dilemma about which language to use for classroom teaching. In recent years, EFL teachers in Asian countries have faced increasing pressure both from policymakers and EFL education research to use English as the medium for teaching. This is considered to give students more opportunities to be exposed to and communicate in English (Littlewood \& Yu, 2011; Yamaguchi, 2002).

This expectation to teach English in English has brought about a change in the focus of EFL teacher PD towards improving the English language competence of teachers. An analysis of PD needs showed that non-native EFL teachers in Japan and South Korea have specific needs for language development (Igawa, 2008). In fact, language proficiency was the top priority for PD according to Hiver's (2013) study of seven EFL teachers in South Korea. This is an important finding in that language improvement of EFL teachers may be linked to their self-efficacy in teaching. A study conducted in Iran illustrated how increasing teachers' language proficiency led to higher self-efficacy in teaching (Eslami, 2008). Therefore, PD for EFL teachers frequently includes the development of their English language proficiency.

The majority of EFL teachers in Asian countries are non-native English speaking teachers (NNEST), and these EFL teachers aspire to speak English perfectly. This is what Phillipson (1992) describes as "the native speaker fallacy" (p. 185). He found that this unrealistic expectation persists despite the gradual acceptance of English as a Lingua Franca and the likelihood that the role of native English speaking teachers (NEST) would decrease in the future (Llurda, 2004).

This expectation that teachers will be expert English language users is also related to the roles imposed on teachers generally. González, Montoya, and Sierra's (2002) study of EFL teachers' needs as professionals in Colombia suggested three roles of teachers: as workers, as instructors, and as learners. They concluded that a holistic PD approach to these 
three roles is needed to balance the almost exclusive focus on the role of instructor. The disproportionate emphasis on teachers as instructors, combined with the Confucian perspective of teachers as 'knowers' in Asian countries, may consciously and unconsciously affect teachers in shaping their professional self-image.

In contrast to the teachers' own perceptions, some researchers contend that NNESTs have several advantages in teaching students, which native English speaking teachers (NESTs) cannot provide (Braine, 1999; Medgyes, 1994). NNESTs have a better understanding of their educational context. Speaking their students' L1 is a huge advantage that allows NNESTs to understand students' difficulties and make timely interventions to support students to understand complicated linguistic concepts. In addition, it is also noted that EFL teachers' experience as English language learners themselves can be a strength of NNESTs. However, there is little research on PD approaches that build on these assets of EFL teachers. Serdiukov and Tarnopolsky (1999) proposed an online PD model for NNESTs with a consideration of their distinct PD needs, but their model focussed on how to minimise disadvantages as NNESTs rather than on how to incorporate NNESTs' advantages into the PD model.

In addition to the "native speaker fallacy" (Phillipson, 1992, p. 185), there is a concern about a dominant "monolithic view of ELT [English language teaching] based on western conceptions of idealised practice" (Hayes, 2009, p. 9). ELT theories developed in western contexts are usually applied elsewhere without modification, and policymakers expect the direct application of these theories to bring similar results to those shown in western countries. However, theories about ELT developed in western countries may conflict with the culture and educational practices in countries where EFL teachers are. ELT theories may not be directly applied in Asian countries as a result of different teacher profiles and contextual factors (Anderson, 1993; Kirkpatrick, 1984). For example, communicative language teaching (CLT) methodologies are required according to the curriculum in South Korea. However, Li (1998) found that few teachers in Korea had incorporated CLT in their teaching practice despite taking PD related to the use of CLT classroom activities, and argued that this phenomenon resulted from the fact that educational theories in South Korea were different from those from western countries. The criterion of success for students is achieving high scores in school examinations and passing the university entrance examination, which emphasises grammar and reading comprehension while CLT methodology focuses on promoting the use of English through diverse communicative activities. This focus on written exams discouraged teachers to use CLT metnodology in the classrooms. EFL teachers work 
in a unique context where teaching is more complex as it is interwoven with language and culture. This complexity extends to PD for EFL teachers.

\subsection{Cultural historical activity theory (CHAT)}

The PD literature reviewed in this chapter shows that changes in teaching practice are affected by contextual factors, which include personal, organisational, and wider social influences (Timperley et al., 1997). Personal factors are factors exhibited by individual teachers such as personality and prior learning experiences. Organisational factors include school culture, classroom issues, and PD activities in which teachers are engaged. Lastly, wider social factors include those affecting teachers that are situated outside of organisations, such as educational policies or demands from society.

Studies about PD highlight different contextual factors depending on the different circumstances of PD learning in each study. Even the same contextual influences drawn from two different studies may be interpreted differently based on the study's own context. Although PD literature deals with contextual factors, the influence of contextual factors are often described in a simplified way such that each contextual factor seems to affect PD experiences independently. Enumerating each influencing factor on PD experiences does not fully reveal what really happens; there is a limitation in explaining interrelationships among contextual factors and effects from these interrelationships.

A useful theoretical framework for understanding diverse relationships around experienced EFL teachers' PD learning is cultural historical activity theory (CHAT). This framework was developed from social constructivist approaches to learning and thoroughly reflects the notion of learning as a social phenomenon (Douglas, 2011). As inquiry with a consideration of various aspects of the educational setting is one of the strengths of activity theory (Murphy \& Rodriguez-Manzanares, 2008), it allows the relationships between multiple contextual factors influencing PD learning to be examined. Kuutti (1996) defines an activity as:

a form of doing directed to an object, and activities are distinguished from each other according to their objects. Transforming the object into an outcome motivates the existence of an activity. An object can be a material thing, but it can also be less tangible (such as a plan) or totally intangible (such as a common idea) as long as it can be shared for manipulation and transformation by the participants of the activity. (p. 27)

In this study, experienced EFL teachers' professional development is an activity in CHAT. It is an activity where teachers themselves, PD, and contextual factors work together. The 
extent of PD learning and the application of PD learning in teaching practice can be explained through this activity. Therefore, CHAT is employed as a theoretical lens to explain the complex relationships between PD and teacher change in this study.

Engeström (2001) analysed first- and second-generation activity theory along with his framework of third-generation activity theory called CHAT. First-generation activity theory was developed based on Vygotsky's (1978) notion of artifact-mediated action in human activity (Engeström, 2001). What is important in the activity is that the action is mediated by artifacts, or material and psychological tools such as pencils and signs.

Second-generation activity theory, inspired by Leont'ev (1977), focused on collective aspects of an 'activity system' that different people with different roles are engaged in. Leont'ev also emphasised the rich social contexts in which the activity system is situated (Worthen, 2008). That is, an individual's goal-oriented actions should be understood only within the context of collective activity. Leont'ev proposed six essential elements of an activity system: subject, object, community, tools, rules, and division of labour.

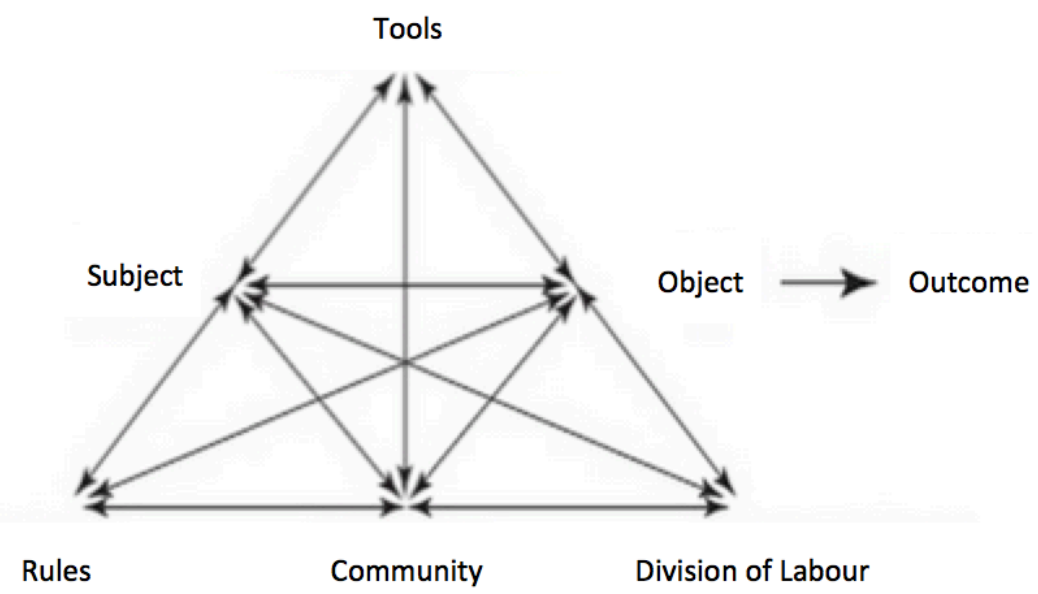

Figure 1. The structure of activity system (Engeström, 1987, p. 78).

Figure 1 is a representative activity triangle diagram presented by Engeström (1987), which describes these elements and their interconnections in the activity system. The subject is the participant in the activity system. The object is the motive or activity itself and the outcome is the ultimate goal that the subject wants to achieve. In an activity, the subject acts on the object to attain outcomes. Mapping the CHAT activity triangle to the activity system of experienced EFL teachers' professional development, experienced EFL teachers are the subjects of the activity system. The object is PD learning for building expertise in teaching 
EFL in order to bring about a change in practice, which is the desired outcome. The tools include a wide array of PD courses and programmes.

Three elements affect the subject's action towards the object. The first element is the formal and informal rules underlying what and how the subject acts on. Community represents a place the activity is located in and for. Division of labour means the vertical and horizontal distribution of tasks, power and status (Engeström, 2001). Accordingly, community in relation to experienced EFL teachers' professional development corresponds to teachers' groups, schools where the teacher is working, and PD providers. Rules are school and national educational policies whilst division of labour includes roles and hierarchies existing within schools and MEST. As illustrated in Figure 1, second-generation activity theory is used as an analytical tool for understanding complex human learning situations that can be observed in natural settings (Yamagata-Lynch, 2010).

Engeström (2001) developed third-generation activity theory called CHAT by pointing out the importance of contradictions arising within and between activity systems and reflecting multiple voices. Peruski (2003) contends that activity theory "views conflict as not so much rooted in the personalities of individuals, ... but as rooted in the systems in which individuals are a part of" (p.158). Engeström (1987) divided such contradictions into four categories: contradictions (a) within each element of the system, (b) between elements of one activity system, (c) between the object of an activity system and the object of a culturally more advanced form of the activity, and (d) between the activity system and other activity systems. Among the four categories, contradictions among activity systems are beyond the scope of this study since this study investigates one activity system of experienced EFL teachers. However, by employing a framework of CHAT, "the internal tensions and contradictions" (Engeström, 1999, p. 9) which arise from diverse factors involved in the process of changes in teaching practice can be examined.

Therefore this study has adopted CHAT to explain social, cultural, historical, and political dynamics brought from the interactions of elements and contributions of each element (Sannino, Daniels, \& Gutiérrez, 2009), and to understand tensions and conflicts in the activity system of experienced EFL teachers' PD learning at "micro and macro levels" (Leadbetter, 2005, p. 18).

\subsection{Summary}


This chapter has discussed literature around the topic of this study. It began by exploring the paradigm shift in the history of PD and then gave examples of constructs of effective PD. The next sections investigated the link between teacher change and PD, the scope of teacher change through PD, and sustainability of teacher change. After this, changes related to experienced teachers and EFL teachers were discussed and particular attention was given to changes that were likely to take place in the practice of experienced EFL teachers. The final section of this chapter introduced CHAT as the theoretical framework for this study in order to capture the complicated nature of teacher change through investigating teachers' PD experiences. The next chapter will discuss the research methodology used in this study. 


\section{Chapter 3}

\section{Methodology}

\subsection{Introduction}

This chapter discusses the methodology employed to investigate how experienced EFL teachers perceive changes in their teaching practice as a result of diverse PD experiences. A rationale for using qualitative methods to address the research questions is presented first. I then discuss the data collection methods and procedures, ethical considerations and issues of trustworthiness. Finally, how data were analysed for this study is outlined.

\subsection{Rationale for qualitative research}

Qualitative research is an inquiry process into how people understand social or human problems and form meaning from them (Creswell, 2007). This study focused on the changes made to teachers' practice after PD from their point of view. To look into their perceptions, it is important to "make sense of, or interpret, phenomena in terms of the meanings people bring to them" (Denzin \& Lincoln, 2011, p. 3) and a qualitative research approach can enable this.

Qualitative research "is an effort to understand situations in their uniqueness as part of a particular context and the interactions there" (Patton, 2002, p. 49). In addition, understanding complicated issues in situations, such as experienced EFL teachers' changes through PD experience over their career in South Korean context, "can only be established by talking directly with people allowing them to tell the stories unencumbered by what we expect to find or what we have read in the literature" (Creswell, 2007, p. 40). As teacher PD completely depends on the context (Freeman, 2002), changes to teachers' practice should be understood in their own contexts.

\subsection{Case study}

Case study methodology focuses on "a contemporary phenomenon within a real-life context" to address the question of "how" and "why" (Yin, 2009, p. 18). The distinctive characteristics of embedded contextual conditions are illustrated through cases (Creswell, 
2007). Stake (1988) stated, "the principal difference between case studies and other research studies is that the focus of attention is the case...the search is for an understanding of the particular case, in its idiosyncrasy, in its complexity" (p. 256). Case study methodology is appropriate to this study because it investigates how teachers perceive changes in their teaching practice related to their PD experiences.

Case study methodology makes it possible to conduct an in-depth exploration of each participating experienced EFL teacher as a bounded system in this study, which means a case to be studied such as an individual or event (Creswell, 2005). According to Hitchcock and Hughes (1995), in-depth understanding of each participating teacher can be developed as their individuality is maintained in a case study. Case study aims to get close to the thoughts of individuals, which is necessary to uncover the perceptions of experienced EFL teachers. Moreover, Denscombe (2007) contends that looking at the individual case through case study can "have wider implications and, importantly, that would not have come to light through the use of a research strategy that tries to cover a large number of instances - a survey approach" (p. 36), which is a prevailing research method in South Korea (Kim, 2006).

This study uses multiple cases which allowed me to identify issues within each case and then investigate common themes across the cases (Yin, 2009). Cross-case examination provided further insights into the central phenomenon of this study. Employing a multiplecase study approach strengthened the robustness, and hence the trustworthiness of this study (Yin, 2009), and this will be discussed later in this chapter.

\subsection{Data collection}

This study addressed the question of how experienced EFL teachers perceive their changes in teaching practice by undertaking PD. Data collection focused on eliciting the participants' reported changes in their practice following engagement in PD retrospectively. The participant recruitment process and the two data collection methods of interviews and documents are now presented in detail.

\subsubsection{Participants}

Participants were recruited through the researcher's networks on the basis of access and convenience. Two criteria for selecting participants were (a) Korean EFL teachers who had more than 15 years of teaching experience and (b) public school teachers who work at a secondary school (middle school and high school, students from 13 to 18 years) within Seoul 
Metropolitan Office of Education. Five candidates in five different schools were recruited and all of them met the criteria for this study. This was a manageable number because Creswell (2005) warns that including a large number of individuals can result in superficial perspectives rather than an in-depth picture. I contacted them via email or phone to invite their participation in the study, providing them with initial information about the study. All five teachers agreed to be part of this study. The participants were all female, aged in their 40s and 50s. Three teachers worked at a high school (students from 16 to 18 years) and the other two teachers worked at a middle school (students from 13 to 15 years) as described in Table 1.

Table 1.

Participants profile

\begin{tabular}{ccc}
\hline Participants & Years of teaching experience & Teaching level \\
\hline Teacher Shin & 23 & High school \\
Teacher Kang & 29 & High school \\
Teacher Choi & 17 & High school \\
Teacher Seo & 20 & Middle school \\
Teacher Han & 21 & Middle school \\
\hline
\end{tabular}

\subsubsection{Interviews}

This study employed one-on-one interviews as the main data collection method since interviews enable the researcher to look into thoughts, feelings, and behaviours which happened in the past (Patton, 2002). This was in line with what was sought in this study because changes in teaching practice and PD experience over more than 15 years were being explored.

To examine the teachers' perspectives in-depth, this study utilised a semi-structured interview. This gave participants enough room to express their thoughts while guiding the researcher not to stray from the purpose of the study. The semi-structured interview also allowed the researcher to have flexibility in asking further questions prompted by what participants said during the interview. In order to understand the effectiveness of the guiding questions (see Appendix A), the questions were piloted with one teacher who was not a participant in this study. The feedback from the pilot testing provided further editing guidance such as potential prompts for the interviews. To gather their authentic responses, the 
guiding questions were not presented to the participants before the interview. Although the interview focused on participants' PD experience and changes to their teaching practices, it was important not to influence their possible responses by presenting them with the questions beforehand.

A suitable date, time, and place for the interviews were arranged with each participant. Since the interviews were the major source of data in this study, it was crucial to find a quiet place where both the participants and the researcher would feel comfortable and free from distraction (Creswell, 2007), and where interview could be audio-taped. Interviews were conducted near each participant's school except for one interview: that interview was completed in the participant's classroom after school because of the difficulty in finding a suitable place outside of the school.

Before the interview, participants were given the chance to read the information sheet about this study thoroughly (see Appendix B), and to ask questions about the research. Then they gave their written consent to be part of this study (see Appendix C). The interviews were conducted in Korean to avoid any misunderstanding of the questions by the participants although they could speak English. This also helped the participants respond to the questions in detail and express their thoughts without any language barriers. Each interview lasted between 60 and 90 minutes and all interviews were audio-recorded. The possibility of power imbalance between the researcher and participants was reduced because the participants were teachers who were older and more experienced than the researcher, and respect for elders is part of Korean culture.

Each audio-recorded interview was transcribed verbatim in Korean. As the researcher transcribed the drafts of the interviews herself, the researcher's initial thoughts and reflection could be recorded simultaneously. Participants were given a copy of the transcript of their own interview for the purpose of checking the accuracy. They were asked to clarify or modify their responses on the transcript. Further questions were also sent to the participants to elaborate any unclear statements in the transcripts during the transcribing process. The participants made a few changes in their responses or added their comments on the further questions.

\subsubsection{Documents}

According to Merriam (1988), documents can "help the researcher uncover meaning, develop understanding, and discover insights" (p. 118). As another source of data for this 
study, participants were asked to provide documents related to their PD experience such as information about the PD programmes which they had taken, outlines or content of the PD programmes, and their reports of the PD programmes they had participated in. Documents which might show changes in their teaching practice through PD experience were also requested, such as teaching materials which they had made for their class, lesson plans, or personal journals about their teaching. When I sent the transcripts through to participants for checking, I also reminded them to send these documents. Three of five participants provided documents as described in Table 2.

Table 2.

List of documents

\section{Documents (provided)}

A list of PD courses/programmes (titles and durations)

Contents of PD courses/programmes

Handouts given during PD courses/programmes

Lesson plans

Handouts made for classroom activities

\subsection{Trustworthiness}

The use of multiple-case study, the different data sources, and member checking increased the trustworthiness of this study. Replicating the procedures in all five cases made this study more trustworthy (Yin, 2009). The two data sources of interviews and documents helped "the development of converging lines of inquiry, a process of triangulation" (Yin, 2009, p. 115, italics in original). Member checking also contributed to strengthening the trustworthiness of this study by ensuring the accuracy of the data (Creswell, 2005).

\subsection{Ethical considerations}

Ethical approval was gained from the Ethics Committee of the Faculty of Education at Victoria University of Wellington (FOE/2013/19869). However, recruiting teachers in Korea as potential participants in this study did not require specific permissions from the schools where teachers were working or other educational bodies. Since interviews were held either outside of school or in the participant's own classroom after school hours, the researcher's 
visit had no impact on other people in the schools. Therefore, gaining informed consent from each participating teacher was the most important ethical assurance for this study. All participating teachers were assured that their participation was voluntary and they had a right to withdraw until the data analysis was finished and they gave informed consent before the interview.

All information gained about participants was confidential and participants' identities were protected throughout the study. Before and after the interview the researcher assured participants of confidentiality. Pseudonyms were used from the beginning of the data collection and any information that could identify participants was deleted from the interview transcripts (Glesne \& Peshkin, 1992). The documents were kept confidential to the researcher and her supervisors. Any specific descriptors in the interviews and any information in the documents that may lead to the identification of participants, their schools, and people or organisations in the documents were withheld.

Participants' identities were further protected as participants were recruited from several schools and public school teachers in South Korea are required to move to another school every four or five years. Audio-recorded data, which were stored as an electronic computer file, were protected by using a password. The transcripts of interview data were secured in a locked cabinet and will be destroyed after 5 years.

\subsection{Data analysis}

Transcribing the audio-recorded interviews myself helped me to revisit the interview data and begin the analytical process. Korean transcriptions were used for the initial coding to maintain the credibility of the data. Vocabulary choice in translation may alter participants' original intentions or meanings and consequently influence the interpretation of these data (Denzin \& Lincoln, 2011). Notes were made in the margin to capture my thoughts, any understandings of what the interviewee meant to say, and emerging key words. During the coding process, quotations from the original Korean transcripts that linked to each code were highlighted with different coloured pens. The quotations were translated into English and grouped to guide the writing process.

Analysis of case study data takes an inductive process (Creswell, 2007). After reading through the data to obtain a general sense of them, the coding process of reducing the data into recurring descriptions and themes was followed. Based on Yin's (2009) data analysis 
techniques for multiple-case study, within-case analysis of describing each case and a thematic analysis across the cases, called cross-case analysis, were conducted.

Within-case analysis was conducted of the interview transcripts and documents provided by each teacher constituting individual cases. Through the investigation of the data, significant phrases were extracted and meaning was formulated from them. Patterns drawn from each case formed themes for initial coding and several times of rereading the transcripts confirmed the themes for each case. Finally, all five whole sets of interview data were reviewed to check the consistency of coding.

For the cross-case analysis, which is "a thematic analysis across cases" (Creswell, 2007, P. 75), my first consideration was of the themes which were commonly revealed from each within-case analysis (Yin, 2009). Then the whole set of interview data and emerging themes were revisited in order to find out potentially significant and meaningful themes which had not emerged from the individual case analysis. Overarching themes revealed from the revisiting process were presented in the cross-case analysis for the purpose of understanding the complexity of the cases rather than for generalisation (Creswell, 2007).

\subsection{Summary}

This chapter addressed the overall research design of this study in detail. A rationale for using qualitative case study methods and the processes of collecting data using interviews and documents were explained. Then ethical considerations to protect participants' confidentiality were discussed. Data analysis procedures of building codes and developing themes for individual and cross-case analyses followed. The next chapter will discuss the findings from this study, which is the exploration of how teachers perceived that their teaching practice has been affected by PD experiences. Findings from the individual cases will be presented in a descriptive manner and a more interpretive approach will be taken to explain findings from the cross-case analysis. 


\section{Chapter 4}

\section{Findings}

\subsection{Introduction}

This chapter presents the findings, firstly from the five individual cases and, secondly, across the cases. As each participating teacher is a case in this study, the main themes drawn from individual cases are discussed in order to show how each teacher's PD experiences affected their teaching practice in their own unique context. Each case includes excerpts from the corresponding participant's interview transcript to illustrate the discussion. Cross-case analysis revealed five themes of: (a) Haunted by perfect English, (b) Valuing newly qualified teachers, (c) Isolated and stagnant teacher culture, (d) Tension between PD goals and classroom reality, and (e) Lack of support from policy and school.

\subsection{Findings from individual cases}

This section presents findings for each individual case, organised through the unique themes emerging from each experienced EFL teacher's experiences. Verbatim quotes in each case have been used to illustrate the themes.

\subsubsection{Teacher Shin}

Shin had 23 years of teaching experience. She moved from teaching in middle school to high school when the demand for EFL teachers increased in 2000. Since that time she has doubted herself as an EFL teacher many times. "Regarding English teaching, I thought about what direction I would need to take and what English education should be necessary for our students to live in this generation." The main themes arising from the interview with Shin included the discrepancy between the topics emphasised in PD and those desired by classroom teachers, valuing novelty and the English skills of young and new teachers over her own experience, prejudice against taking long-term PD programmes despite the potential benefits, favouring ICT-related PD, difficulty in setting professional goals, and a perception that PD was unrelated to teachers' needs for PD. 


\subsubsection{Discrepancy between PD and classroom teaching}

Shin clearly acknowledged the gap between the PD that she had experienced and her actual classroom teaching. She felt that the Ministry of Education, Science, and Technology (MEST) emphasised the importance of teacher professional development and forced teachers to take PD courses. Shin believed that the focus for many teachers was on taking PD rather than teaching in the classroom, reporting, "Teachers prioritise participating in PD courses and seem to neglect classroom teaching". Shin implied that this approach to PD participation was unlikely to result in improving classroom teaching. Moreover, Shin reported that PD content did not seem to consider the different academic levels of students. Shin stated that "classroom activities presented in PD could not be applied to my students", who had low academic achievement. She added that "they [the classroom activities] seemed appropriate to students in International schools or independent private high schools", which meant schools with high achieving students. PD content seemed pitched towards an ideal classroom situation. The gap between PD and classroom teaching made Shin view PD as an additional responsibility.

\subsubsection{Valuing the skills of beginning teachers}

Shin constantly compared herself as an experienced teacher to young teachers. She believed that young teachers, rather than experienced teachers, should open their classes to observers because she thought that young teachers' open-class provided chances to see "what teaching methods the teachers' college is currently teaching", as "experienced teachers have been teaching in a traditional way", concentrating on grammar teaching that they learnt at university. When she observed young teachers' classes, she felt disempowered by their novel approaches to teaching.

Moreover, observing the English proficiency of young and new teachers seemed to lower Shin's self-efficacy as an experienced teacher. Her perception that her own English proficiency was less than theirs made Shin resistant to opening her class to observers.

[In open-class,] I have to use English. Therefore I do my best... However, in front of young teachers, although it does not matter if I make some mistakes when speaking in English, I felt a lower level of self-efficacy because of my imperfect English.

The differences between their approaches also showed while taking PD. The young teachers seemed to speak well in English compared to experienced teachers who "check if there are grammatical errors or not" so Shin assumed that young teachers had a better level of English than her own. 
In open-class situations, teachers were expected to conduct the lesson in English and the focus was less on classroom management - an area where Shin felt confident. During PD sessions, "experienced teachers tend to stay at the back" since "there are many teachers who have good English conversation skills and who have lived overseas". What Shin said shows that experienced teachers like Shin may feel small and discouraged from conducting openclass. Those feelings of inadequacy seemed to affect Shin's PD learning as an experienced teacher.

Interestingly, she said that these feelings did not affect her teaching when back at her school since "there are other things such as student discipline and counselling in school as well as teaching English". As an experienced teacher, she was confident in her classroom management and student discipline. That is, Shin seemed to have two different types of selfefficacy: in classroom teaching and in English proficiency. However, her low self-efficacy in English proficiency seemed to affect Shin more than her high self-efficacy in classroom teaching because Shin felt that deficiencies in her language proficiency were visible to others.

Shin thought highly of young teachers' capability in adopting new teaching skills and activities. She was not confident enough to include activities such as going out with students to interview other people in English, as "young teachers do" even when teaching extracurricular English classes, where she could include content outside that in the textbook. As Shin tried to make up for any weak points in her practice by incorporating ICT in her teaching, she wanted to have a young teacher as a mentor of ICT learning. This is the opposite to the traditional concept of mentor, in which older or more experienced people usually become mentors of the young and inexperienced. Shin felt that "young teachers can help me be exposed to good ICT materials". Therefore young and new teachers seemed to make Shin both less confident and envious simultaneously.

\subsubsection{Prejudice against taking long-term PD programmes}

Shin preferred to take only short-term PD courses, stating, "It is for maintaining my current knowledge level rather than improving". Although she perceived that long-term PD programmes could bring about substantial improvement in her practice, she did not have any long-term PD experience. Usually long-term PD required teachers to take leave from teaching and it was difficult to take six months off from her teaching. She would have to plan this in advance with school administrators because it would be necessary to hire a substitute teacher to replace her. Moreover, Shin had encountered some teachers who took long-term $\mathrm{PD}$ as a way of getting away from teaching in the classroom. As she did not want to be 
regarded as one of those teachers, saying that she still liked to be with her students, she was reluctant to take long-term PD programmes. Her negative impressions of long-term PD programmes seemed to outweigh what she saw as the potential benefits.

\subsubsection{Satisfaction from ICT-related PD}

Shin felt that the biggest change over her teaching career was that she cared more about her students' needs than in the past. She reported becoming more concerned about how students think and how to motivate them. She was unsure how PD she had undertaken in the past affected students since her PD had focussed on improving teaching ability. However, she could clearly see a positive reaction from her students when she applied her learning from ICT-related PD. As Shin found students becoming more engaged by her use of visual materials, she changed direction from participating in English PD towards PD focussed on ICT-related content. The documents of a list of PD courses she had taken confirmed that she had taken several ICT-related PD courses. Believing that it was easier to integrate new ICT learning into her teaching practice, Shin felt that she could catch up with current and new trends and that this might motivate her to take more PD. However, she reported that Englishrelated PD courses did not bring about the same level of changes in her teaching practice as ICT-related courses. Despite this, she took some English-related courses to remain up-to-date with current trends in English education and to fulfil her responsibilities as an EFL teacher.

\subsubsection{Tension between the goals of the curriculum and classroom teaching}

Although Shin was highly experienced, she still felt confused about which educational goals she should be prioritising.

Well... I don't know... whether getting a high score in the university entrance exam should be set as a goal of English education, as this requires English reading skills and grammar. I think that improving fluency is more important than getting the right answers in the examination. However, we have developed fluency as a show-piece rather than fluency in authentic situations. When I decide to teach in a certain way, I am confused about which goals I need to follow. ... I am even confused about whether I have a right to set this up by myself.

Shin thought that the EFL curriculum and the university entrance exam aspired to different goals. "The curriculum emphasises English conversation and English writing and those are not needed in the university entrance exam." The university entrance exam carried greater weight than the curriculum requirements. Shin's autonomy appeared to be restricted by the 
high-stakes examination system and she was caught between different goals set by different authorities.

If I teach a class which I personally think is ideal, I question if my way of teaching is ideal to my students in their current situation. The biggest issue in high schools is the university entrance exam, so teaching in an individual teacher's own way ... might be possible in the classroom of first graders of high schools, but for second and third graders ... so it is getting more difficult [for individual teachers to differentiate using different teaching styles].

The high-stakes university examination affected Shin and her teaching practice, so that she could not think of any PD programme to recommend to other teachers. As long as the focus in high schools was on the university entrance exam, it was difficult for her to engage in PD with an expectation that she would learn anything useful from that PD.

\subsubsection{PD related to teachers' needs}

The regional office of education and the school encouraged EFL teachers to take as many PD courses as possible. Therefore, Shin's documents showed how she undertook a combination of PD she wanted to take and PD she took because of this pressure. Even PD courses she was motivated to take, did not necessarily meet her teaching needs. Although Shin considered her students' needs and suitable ways of teaching for her students, she found PD courses were either too simple, different from her expectations, or had content that was unrelated to the PD title. These PD experiences made her think that PD courses were offered only for the purpose of allowing teachers to accumulate PD credits.

It was important to Shin for there to be an environment in which experienced teachers were encouraged to take PD based on their own choices. Although taking PD was compulsory, she hoped PD courses would allow for the diverse needs of teachers, such as incorporating music into PD courses. She compared teachers' motivation to attend PD to students' motivation to learn. "I wish PD would encourage teachers to take PD in the same way as teachers do with students [to motivate them]." She believed that the function of PD should be to motivate teachers rather than to improve their teaching.

She wished that PD would reflect and address difficulties which teachers in the classroom experienced. Although PD was nominally customised, she thought that even customised PD courses were designed by others who anticipated teachers' needs rather than analysing in-service teachers' needs after talking with them. As a result she reported that many PD courses were unrelated to what in-service teachers needed in their classroom. 


\subsubsection{Summary}

Shin's interview revealed a discrepancy between the PD she had experienced and her classroom teaching and this made her consider PD as an additional burden, rather than as a useful activity. Although Shin had extensive teaching experience, she felt both intimidated and admiring of newly qualified teachers because of their use of new teaching methods and their high level of English proficiency. While she had a negative attitude toward long-term PD programmes, she liked to participate in ICT-related PD as a way of covering her weak points in English and engaging her students. Different educational goals set by different authorities made it hard for her to prioritise goals as a teacher whilst undifferentiated PD programmes seemed to negatively affect her motivation to take PD.

\subsubsection{Teacher Kang}

Kang had 29 years of teaching experience both in the middle and high school. "There were no PD activities when I came into the teaching profession. When the regional office of education started to offer PD courses, I thought how great it was and tried to take as many PD courses as possible." Therefore Kang had eagerly taken diverse PD courses from the regional office of education in her early years of teaching. Kang had worked as a PD instructor as well as a classroom teacher during her teaching career. The themes drawn from Kang's interview were: a focus on students from PD activities, dissatisfaction with formal PD, valuing inschool professional learning communities (PLC), leading by example, and lack of support for teacher trainers.

\subsubsection{A focus on students through PD activities}

The purpose of open-class is to share teaching practice. For observing teachers it can be an opportunity to gain teaching ideas and tips. Therefore, whenever Kang used to prepare for an open-class, she wanted to incorporate as many ideas and tips as possible for the benefit of observing teachers. While Kang felt rewarded by thinking that she helped other teachers, she recalled those times that she "was exhausted at the end of the open-class". She came to realise that open-class was a "one-off show" which "could not be linked to either the curriculum or the assessment". This realisation came from taking a six-month PD programme of workshops and onsite classroom observations. Workshops covered teaching methods and teaching skills and were linked to classroom practice. Classroom observations with pre- and post-discussions were planned based on one-to-one mentoring. All instructors were native 
English speakers. This PD programme made Kang aware that students should be at the centre of teaching rather than the teacher. After taking that PD, she realised that she had been focussed on how to present her way of teaching more interestingly to the visiting teachers rather than focussing on students in her class.

He [the instructor] said to me that I was too ambitious in my lesson plan. He said that I needed to give more time for students to fully explore the content. I did not know that I packed too much in one lesson before working with him.

For Kang, performing open-class had few benefits for her teaching practice. Rather it made her develop an "open-class mentality", which meant focussing on presenting seemingly interesting and new activities and techniques to other teachers. The PD programme Kang participated in brought awareness of the importance of student-centred teaching. She reported that this programme had substantially affected her fundamental beliefs and as a result she continued to sustain her new focus on students' learning.

Kang said that she had long been concerned about her English language competence as English made her feel "burdened and inferior". Through her own efforts and PD participation, she had gained confidence in her English proficiency and her concern moved from her own English language ability to her students' learning through her. However, Kang worried that "my students may pick up and learn my English, which includes mistakes and errors" since she was not a native English speaker.

She had a chance to talk with a professor in the English education field and this opportunity gave her a new perspective. "[The talk with the professor] freed me from aspiring to be perfect in English language. ... [The professor] said that I could become a model of a non-native language learner to my students. That was the wakeup call.” The informal talk with a professional brought a fundamental change in her view of English as a non-native English speaker. It allowed her to focus on how to "let my students know the joy of learning" rather than being concerned about her own English proficiency.

During her career, Kang moved from teacher-centred teaching to student-centred teaching and recast her English ability as an opportunity to model to students how to learn English rather than viewing it as a burden. These two big transitions in her teaching practice came about because the PD programme and the informal interview gave her a chance to question her beliefs about teaching and raise her awareness of her role as a non-native English teacher. 


\subsubsection{Unsatisfactory formal PD}

The content of PD courses did not link to what Kang taught in the classroom. She believed that PD lacked rich content to discuss and had no relation to what happened in her classroom. Kang also reported that some PD courses facilitated by native English speaker instructors brought a cultural gap because their perception of students and English teaching did not seem to be based on the Korean context. Therefore, Kang did not feel encouraged to participate in PD.

Kang also reported that most of the PD courses seemed to focus on teachers' language improvement. Although language competence of the teachers had improved, she said that the language proficiency of the teachers was not the only component of effective EFL teaching.

Kang commented that PD led by the regional office of education usually contributed to teachers losing autonomy. What Kang meant by decreased autonomy was that "there are not many things I can do in the program design". According to Kang, teachers were rarely asked to take an active role in PD courses. Moreover Kang's general dissatisfaction with the public sector influenced her to take a negative attitude toward new initiatives. She reported that the top-down nature of PD needed to be changed to motivate teachers to take PD courses.

\subsubsection{Valuing in-school professional learning communities (PLC)}

Instead of attending formal PD arranged at the regional level, Kang focussed her attention on informal PD activities within her school by organising a study group of colleagues to read a diverse range of books. This enabled Kang and participating colleagues to share their feelings, ideas, and issues which were happening with the students in their school. Her leadership of this informal community arose from her beliefs about teaching. She felt that teachers should be able to expand the content of the textbook in order to let students understand how much fun learning can be. Through her school PD community, Kang believed that the teachers "truly learned from each other" through "peer learning or peer collaborating". Moreover, what she liked about this study group was that it was based on the voluntary participation of teachers in her school. Kang's approach to a study group with her colleagues includes similar characteristics to those of a PLC. Her study group had a clear vision to expand their knowledge through extensive reading. She reported that teachers in the study group collaborated as a team and linked the content of their reading to their own students as a way of inquiry.

The PLC led by Kang seemed to provide what formal PD could not offer. Kang's commitment to the benefits of in-school PD was obvious, as she continued to organise and 
sustain this type of PD activity despite moving to another school. However, while Kang advocated in-school PLC, she was pessimistic about scaling up her informal PD in case the regional office of education required all schools to implement a similar type of PD. She stated, "Then it would become a PD activity in which teachers have to participate rather than one they would like to participate in".

\subsubsection{Leading by example}

Kang's teaching practice was strengthened by positive students' responses. Her changed belief about teaching came about through witnessing students' excitement with their learning progress. "I could see that my students felt rewarded through learning with me... that feeling still thrills me and makes me energised."

She did not stop there; she wanted to share this experience with other teachers and assist them as an experienced teacher. For example, she let other teachers come to her classroom at any time. "I don't set up a specific day for open-class." Teachers came to Kang's classroom while she was teaching. She said that there was no additional preparation because of other teachers' visits as she was no longer performing but rather focussing on students' learning. She said, "I show the reality of my teaching. If there is a student who is sleeping, visiting teachers may see how I deal with that student". After class, she talked with the visiting teachers about her class. This was about sharing issues on the spot rather than propagating new tricks and tips through teaching in open-class, as she felt it was unrealistic to try and include something new in every class. This learning opportunity was helpful not only to other teachers but also Kang herself. Kang's openness seemed to represent her leading role as an experienced teacher. "They [other teachers] can trust me as a leader and keep participating in the PD [in-school PLC].” Kang's voluntary decision to open her classroom showed a good peer learning model to other teachers.

\subsubsection{Lack of support to be a teacher trainer}

Her long teaching experience and Kang's willingness to take a leading role among her colleagues seemed to equip her to work as a teacher trainer. Although she wanted to know more about how to help other teachers such as through mentoring and modelling effective ways of giving feedback, she felt that the current PD system could not fulfil her PD needs. Even though she was often invited as a PD instructor, she reported that she received limited support to work more effectively as an instructor. It totally depended on her own capability. 
A master teacher initiative was planned to enable experienced teachers like Kang to take a leading role in schools. However, Kang did not show any interest in being a master teacher. She thought that the current master teacher initiative needed to have a solid structure to affect teachers' teaching practice positively. She remarked, "Some teachers asked me why I did not apply for master teacher. But what I want to accomplish is working together with teachers in my school. I think that this will be more substantial”. For Kang it was important to learn more about how to support other teachers as an experienced teacher. However, she did not feel that PD courses including the master teacher initiative could satisfy her needs to develop as a leader.

\subsubsection{Summary}

Through Kang's interview, her student-centred way of teaching and her realisation of her potential as an NNES teacher resulted from her undertaking PD activities. She reported that her increased awareness of these concepts had become the backbone of her teaching. While she participated in regional PD activities, she was generally dissatisfied with the structure and content of formal PD. She disliked the fact that it was compulsory and felt that it was only weakly linked to classroom teaching. Kang valued in-school PLC based on her long time experience of this type of PLC as the weak points of formal PD seemed to be resolved through studying and sharing ideas in in-school PLC. She also practised peer learning by opening her classroom to others voluntarily. Lastly, Kang hoped that PD courses could be customised for experienced teachers, like herself, who wanted to help other teachers.

\subsubsection{Teacher Choi}

Choi was a high school teacher with 17 years of teaching experience. As well as diverse PD experiences, she had a Master's degree in English education. The interview with Choi included the main themes of: valuing overseas PD programmes, regarding PD as a stimulus rather than as a learning opportunity, a preference for face-to-face PD, implementing PD at an individual level, and mixed feelings about evaluating her teaching.

\subsubsection{Valuing overseas PD programmes}

Not having any experience in English-speaking countries used to make Choi anxious and lowered her feelings of self-efficacy in teaching in the early years of her teaching career. She was especially diffident about her "Korean-style English pronunciation". She said, 
"Although students did not ask me whether I had been in any English-speaking countries, I myself was not confident. I wanted fill that gap with teaching skills and by bringing interesting activities into the classroom". Choi's willingness to overcome perceived weaknesses in her language proficiency through improving her teaching motivated her to take a variety of PD programmes. By participating in three long-term PD programmes conducted overseas, led by the regional office of education, she had the chance to be exposed to English-speaking cultures and to estimate whether her level of English language ability was appropriate for teaching English. Communicating with lecturers and teachers in the programmes made Choi realise that her level of English proficiency was not bad and she gained confidence about speaking in English. PD was more meaningful to her in terms of providing an opportunity to assess her level of English rather than for improving her English proficiency or teaching practice.

\subsubsection{PD as a stimulus}

Early in her career, Choi's approach to PD was to improve her teaching skills and English skills. Choi felt that PD to strengthen her teaching skills was needed to fill the gap between her learning at university and what happened in the actual classroom. She perceived that the level of her students was too low to apply what she had learned at university. As a beginner teacher, she expected PD courses and programmes to help her teaching improve in order to meet her students' needs.

However, many years of PD experience had reshaped Choi's view into seeing PD as a stimulus for moving beyond the status quo. Although PD learning did not link to her classroom teaching, she still believed that PD helped her "keep awake although what PD suggested did not seem to be what I wanted to find. ... I could learn something which I would not know unless I took that PD". Choi considered PD as "encouragement" that she should not stop improving her English skills. Her PD experiences of building English skills suggested that it was difficult to improve her English ability through short-term PD courses such as "conversation opportunities two hours a day for a week only". She no longer thought that PD was a tool for improving her teaching skills and English skills.

Choi was not particularly motivated to take PD because she had concluded that learning from PD could not be used in her practice. She seemed to find it extremely difficult to employ what she learned from PD in her teaching especially when she taught third graders in high school as these students focus on preparing for taking the national university entrance exam. The textbook for the third graders in high school is actually a workbook published by 
the Educational Broadcasting System (EBS) and 70 per cent of the workbook content is reflected in the national university entrance exam. She sighed, "Ah... as far as third graders in high school, the textbook is no use ...All students rely on EBS only...” Therefore, Choi felt her role was restricted to helping students become familiar with question types and teaching reading skills. This was different from the PD content that covered how to teach speaking and how to promote group work. This reduced her motivation to take PD courses for their content.

The rigid role of a teacher of third graders in high school seemed to change Choi's practice totally.

When teaching first or second graders right after the third graders, I must take PD. If not, the way of my teaching... it is even strange to me... Students sometimes said that I was teaching like an instructor in a private institute.

By this, Choi meant she rarely interacted with the students, focussing more on lecturing on about how to answer questions on the exercise sheets and develop reading skills. Therefore, when she stopped teaching third graders she took "any kind of PD with great effort" in order to return to her former style of teaching practice. The clear goal of taking PD to discard teaching practice for third graders seemed to help Choi revert to her preferred way of teaching. However, it might not have a substantial influence on improving her teaching practice because she did not care about the PD content.

For Choi, there were several reasons why she treated PD as a stimulus: PD courses did not affect her skill improvement; her limited role when teaching third graders meant that taking PD was unnecessary. She regarded PD as a stimulus to refresh her teaching practice when she returned to teaching younger students.

\subsubsection{Favouring face-to-face PD}

Choi seemed to prefer face-to-face PD than online PD because she could concentrate on the content more. However, taking face-to-face PD was not easy because of her workload at school, which included extra-curricular classes and her role as a homeroom teacher. As face-to-face PD was usually held in the regional teacher training institute, to attend these PD courses, Choi needed a whole afternoon's leave. When she decided to take a certain PD course in spite of these physical constraints, she had made a decision that it was worth taking. Therefore she did not think that taking face-to-face PD was a waste of time since "I sacrificed many things to take" a certain PD course. However, Choi felt sorry for other teachers because whenever she attended PD, it inevitably led to changes in other teachers' timetables. She also 
felt sorry for her students as she left school in the middle of school hours. This guilty feeling became another motivation to learn from PD more actively. Therefore Choi "tried to learn more... tried to listen and speak more... tried to do whatever the instructor said and get more teaching materials while attending PD". After coming back to school, "I share the materials with other teachers because I feel guilty that I received those materials by attending PD”. Besides, having the chance to network with other teachers seemed to be another important reason to take face-to-face PD courses. She reported that she could share issues in her teaching and her school and get tips from teachers from other schools.

Despite favouring face-to-face PD, Choi took online PD more than face-to-face PD because of distance and time constraints. She perceived that online PD was mostly ineffective - she found it easy to become distracted and there was only limited information available to guide her in choosing courses. Another reason for taking online PD was to get PD credits which her school and the regional office of education required. Therefore she did not review the PD content from these courses after they finished. "I do not have time to go back ... It is time to move forward to the next one." Accumulating PD credits was also perceived by Choi to be useful as they are a prerequisite for taking long-term PD programmes overseas. Hence this gave her motivation to take PD courses although their medium was online.

While Choi was willing to take face-to-face PD, the constraints of time and distance made her take online PD instead. As a result, she did not experience what she perceived as the advantages of face-to-face PD - active participation and having informal talks with teachers from other schools.

\subsubsection{Taking initiative individually}

Choi had had a positive and rewarding experience of working with one of her colleagues. As they taught in the same grade, they developed the idea of incorporating an English essay writing component in the curriculum. Given that exams include multiplechoice type and short sentence type of questions, essay writing is usually not a part of EFL teachers' teaching practice in South Korea. She recalled how much she had enjoyed this time since "it made me think of myself as a professional. Organising this [English essay writing component] with my colleague empowered me. I liked doing things together".

In spite of this positive experience, there were some obstacles in continuing similar work in the following year. Firstly, Choi and her colleague encountered difficulty in incorporating the essay component into the students' assessment. Another obstacle was that it 
was not easy to find a new partner to work with since teachers who teach the same grade are changed every year. Choi said,

It is not easy to ask others to do the same thing with me... In addition, I would have to take charge because it was my idea to work together. Then it becomes a bigger project, than I planned.

She emphasised that embedding a writing component had been possible when she was lucky enough to find a partner. Therefore, she took the initiative at an individual level rather than working with other colleagues.

Doing this kind of thing by myself is less burdensome because I can be more flexible in the number of students' writing tasks. [As this was limited to only the classes I taught,] I do not need to worry about how to include these [activities] in students' assessment.

Choi said that it was difficult to build common ground with other teachers to initiate and include such activities in their curriculum.

\subsubsection{Mixed feelings on being evaluated}

Choi did not want to be evaluated in case her current teaching was not as good as she perceived. For example, although she knew that a teaching consultant would point out good and bad aspects of her teaching precisely, she was afraid of knowing her real teaching ability and of potentially getting hurt by the consultant's comments.

Frankly speaking, it [avoiding opening her class] is a kind of self-defence because I am satisfied with my current status. Of course, it may be good for me if other parts of my teaching practice would be revealed to be improved, but... I am...very... scared.

This fear of evaluation seemed common to teachers because Choi said that post-discussion of open-class rarely dealt with teaching practice in detail. Instead, Choi remarked that "teachers know teachers", which meant that observing teachers including teachers from other schools empathised with Choi's situation; preparing for an open-class was stressful and open-class was not voluntary. Therefore, praise and encouragement rather than critique and reflection were prevalent. This did not lead to learning on either side for Choi or the observers.

Despite understanding the potential benefits from evaluation, Choi did not want to be evaluated by a teaching consultant. She was also not satisfied with a superficial level of discussion about her teaching practice with other teachers. These mixed feelings made her self-monitor her teaching through watching a video recording of her open-class. Through watching her own teaching practice, she realised "how I taught in the classroom. [For 
example,] I talked to students in this way [when giving instructions] and I should have done differently in this part".

\subsubsection{Summary}

Choi's overseas PD experiences helped her gain self-confidence by affirming her English proficiency. However, PD courses had limited influence on Choi overall. Her reasons for taking PD included keeping stimulated and encouraged because PD content rarely linked to her teaching practice, especially given the unique context of teaching third graders in a high school. While constraints of time and distance led Choi to take online PD as an alternative to face-to-face PD, she preferred the latter because of external motivation generated from the guilt of leaving her colleagues with extra work. She particularly enjoyed having the chance of networking with teachers from other schools. She set up curriculum initiatives and incorporated them - but only in her own teaching practice. Difficulty in finding a same-minded partner and little flexibility in working with others meant her initiatives could only be conducted at an individual level. Choi also had mixed feelings about being evaluated: whilst she wanted to receive a thorough and detailed evaluation about her teaching practice, she expressed fear of being evaluated as an unsuccessful experienced teacher.

\subsubsection{Teacher Seo}

Seo had 20 years of teaching experience and started her teaching career as a high school teacher outside of Seoul. When she moved to Seoul, she was assigned to a middle school by the Seoul Metropolitan Office of Education. Her personal responsibilities raising two children affected her PD participation because she could not find time to take PD activities when her children were young. The interview with Seo revealed several themes: becoming a learner of PD, implementing PD within her comfort zone, fearing face-to-face PD, conflicting perceptions of English proficiency, and maintaining a positive attitude towards peer observation.

\subsubsection{Becoming a learner of PD}

Seo was in favour of taking PD courses and thought that they were helpful in improving her English and teaching skills. When she took PD, she seemed to change her role from one of teacher to being a learner. Rather than positioning herself as a teacher and 
thinking about how her learning from PD could be related to her teaching, she engaged fully with PD content as an adult learner. Seo's learning from the PD activities had a limited relationship to her current teaching, unlike her feelings right after undertaking PD activities. She reported, "I should have included what I learned from PD, but I could not apply everything [learned from PD courses] in my teaching. This was not easy". However, rather than criticising the PD content, Seo responded as if it was her responsibility to incorporate all PD learning into her teaching. She seemed to think that it was up to her to find ways to link PD learning to her practices by herself - like students in her classroom.

\subsubsection{Implementing PD within her comfort zone}

Seo perceived that applying PD learning in her teaching practice was sometimes ineffective. In her case, she tended to decide the effectiveness of PD learning before witnessing the effects of her practice on her students' learning. The textbook content to be covered in a semester did not give Seo enough time to experiment and explore how new implementation could work in her classroom. If her attempts at implementing new learning impeded the pace of teaching the content in the textbook, she considered them ineffective. She stated, "I adopted an activity using group work but stopped using it. I thought that I might not be able to teach all the chapters in the textbook". Given that it usually takes time for new PD learning such as classroom activities or teaching methods to be thoroughly implemented in teachers' practice, it seemed unlikely that Seo would incorporate new PD learning into her teaching practice.

Seo reported that the textbook was most important in her teaching. Seo said, "I try to include as much content from the textbook as possible in my lesson because I believe that students should know at least the content of the textbook". After a few attempts to implement PD resulted in incongruence with her teaching and her beliefs about teaching, what she learned from PD was discarded. Her teaching practice could only be modified when what PD offered matched with her beliefs.

In addition, Seo believed that she should "control her students' learning in the classroom". Although one online PD course changed her thinking by making her realise the importance of giving students enough time to do an activity by themselves, she stopped applying this method in her teaching because she felt insecure about letting students do activities by themselves. As Seo could not manage her students in the classroom when using the new PD learning, she discontinued it and regarded it as an ineffective method. This showed that PD learning was inconsistent with her beliefs. Alternatively it may indicate that 
Choi would benefit from PD that specifically focussed on facilitating group work or other skills required for the management of communicative activities.

Seo's application of PD learning can be explained as modifications within her comfort zone. Consequently, the changes in Seo's teaching practice were limited and fundamental changes seemed rare. Although she did not incorporate much PD learning into her teaching, she said that she liked to take PD as refreshment and for encouragement.

\subsubsection{Fearing face-to-face PD}

Despite Seo reporting the importance of taking face-to-face PD, she described being "fearful" of such PD for two reasons. Firstly, her fear came from travelling to "the remote location of the teacher training institute" as it was a long way from her school. To take PD, Seo needed to commute more than three hours after teaching classes every day for a month and it made her feel stressed and exhausted. Secondly, she reported "the fear of speaking in English in PD courses". She did not want to reveal her English ability, which she perceived as inadequate, by speaking in English in public. She also stated, "Sometimes I could not understand what the native English speaker instructor said". Therefore Seo did not view interactions provided by the PD courses as beneficial. Taking online PD courses was her strategy to avoid speaking in English and it was evident from the documents of a list of PD courses she had taken. She showed satisfaction in taking online PD courses, which usually have a lecture-style format. Although Seo thought that the teacher training institute offered a wide range of PD courses which she was interested in, the constraints of distance and fear of speaking in English kept her from taking face-to-face PD.

\subsubsection{Conflicting perceptions of English proficiency}

Seo's assessment of her level of English proficiency depended on whom she talked to: her students or other EFL teachers. She reported that her level of English proficiency was adequate to teach middle school students. In her classroom, the low level of students' English ability kept her from using English for instructions and communication. She said, "I cannot use English because my students could not understand my English instructions". On the other hand, she did not want to conduct open-class because she had to reveal her English speaking ability in front of other teachers. Seo's low self-confidence in English speaking was also shown in her reluctance to participate in English-medium PD courses. When she participated in a face-to-face PD course, she liked to talk informally with other teachers in Korean while the instructor was not present. This suggests that Seo regarded other teachers as evaluators 
while she thought that her students were not in the position of evaluating her English proficiency. She said, "I feel less and less confident in teaching English as I gain more teaching experience". Having long teaching experience did not positively affect her selfconfidence because she seemed to equate self-confidence as a teacher with achieving a high level of English proficiency.

\subsubsection{Maintaining a positive attitude towards peer observation}

Seo preferred the idea of peer observation to open-class since open-class usually had a wider audience including teachers invited from other schools. Although Seo was open to the possibility of learning through the colleagues' observation, she tended to believe that she knew her teaching better than anyone. "I know how I teach fairly well, but I may be able to realise something that I have not noticed before peer observation". Whilst generally unwilling to conduct open-classes, she seemed to feel safer being observed by colleagues in her school. At the same time, Seo was concerned about the atmosphere in her school, which did not seem to promote peer observation. She questioned, "I am not sure whether other teachers would like this [peer observation]".

\subsubsection{Summary}

Seo seemed to switch to a learner's role when participating in PD experiences. She tried to take responsibility for incorporating PD learning rather than criticising what was lacking in PD courses. Seo's efforts to apply PD learning in her teaching practice seemed to be restricted to those that were congruent with her beliefs. This meant that PD had a limited effect on her beliefs. She evaluated her level of English proficiency according to her audience. While she was confident in working with students, it was the opposite when she had to speak in English in front of other teachers. Along with the remoteness of the teacher training institute, her low self-efficacy in English influenced her choice of online PD over face-toface PD. She was open to the idea of peer observation based on its potential benefit in her teaching.

\subsubsection{Teacher Han}

Han had 21 years of teaching experience in middle schools taking diverse PD activities over this period. She believed that it was necessary to take PD continuously since she felt unable to rely on anyone other than herself at school. "It is difficult to accumulate 
know-how in the English teaching profession because students, textbooks, and schools are changing almost every year." Han explained that PD activities which she had taken had little relationship to her teaching context. Han felt that there was a lack of authenticity in the PD she could access and the PD did not meet her needs. As an experienced teacher, she was reluctant to show her classroom teaching and expose her own English proficiency to others. She also thought that there was little professional support in her school. Han's major concern was the disconnection between PD learning and her teaching practice.

\subsubsection{Inauthenticity in PD}

PD activities did not seem to meet Han's needs. When she was talking about PD related to English grammar teaching, what she wanted to know was how to teach English grammar to students. However most PD that mentioned English grammar teaching was designed to teach English grammar to teachers rather than dealing with "how to teach and present English grammar to students".

Han was also concerned about the quality of the instructors. English native speakers who were instructors "taught teaching skills of English as the mother tongue rather than EFL". Although some in-service teachers were selected as PD instructors, Han did not trust the quality of these instructors selected from the regional office of education. "For the regional office of education, teachers are accessible human resources to use" so they just ask some teachers to run PD courses, who "want to be instructors, or were selected without clear criteria".

Han thought that the PD content which those instructors presented did not seem to come from their own teaching experience or relate to hers. She reported, "They seem to prepare PD content for its own sake. It is new teaching methods and activities for them because they present things which they have not applied to their own teaching practice yet". Therefore the PD content seemed "great, but only theoretically, not practically". She was not convinced that teaching methods or activities learned from PD could be applied in her classroom teaching because PD instructors could not provide evidence of its applicability. Other instructors who were in-service teachers prepared PD content based on their own teaching context rather than the participating teachers' teaching context. For example, the instructor "presented the use of pictures to make students write a story in English, while my students need to know how to make a sentence".

Han further criticised the lack of authenticity of other PD activities. She said that PD activities led by the regional office of education seemed divorced from Han's real classroom 
contexts and needs. One PD activity encouraged teachers to organise a project group which the regional office of education would fund if the project proposal were accepted. However, Han said that results of these projects were rarely evaluated. These projects were assumed to be effective without any assessment to confirm the results. Han also thought that teachers participated in the projects to achieve a non-pedagogical purpose such as promotion. She said that she had witnessed some teachers putting classroom teaching and students' learning aside to focus on a project. She said, "I do not want to participate in projects because they do not match the goal that I pursue. ... Projects should be solely for helping teachers in schools..." The focus on outcome rather than content showed a lack of authenticity and discouraged her from participating in projects.

She also pointed out the lack of authenticity in peer evaluations. While the purpose of peer evaluation was to improve one's own teaching practice through classroom observation, Han thought that teachers did not practise this as it was intended. "As teachers do not want to criticise others, they just tick 'good' in each item on the evaluation sheet."

PD content remote from Han's classroom teaching, PD instructors with a focus different from her needs, and a lack of authenticity in PD activities negatively affected Han's motivation for taking PD. As a result, it seemed to Han that PD rarely influenced her teaching. Nevertheless she took PD regularly because gaining PD credits was a component of the national teacher assessment and a teacher's total PD credits were evaluated within the school assessment process.

\subsubsection{Lack of a helping hand}

In spite of being an experienced teacher, Han wanted a helping hand. However, Han felt that there was limited support from within her schools or the regional office of education. She did not consider that working with a consultant to improve her teaching was useful, or expect any support from her school administration, or the regional office of education.

Nevertheless, Han felt that she needed someone to help her improve her teaching. "If someone observed and coached me objectively, I would be able to improve faster as a teacher." One of her past efforts was to work with a teaching consultant. A teaching consulting system was introduced whereby veteran subject teachers helped teachers address any problems they were facing in their practices. However, this did not have a positive effect on Han's teaching. Han commented that "there was not much professional dialogue" and the consultant only offered superficial levels of advice such as correcting typos in Han's lesson plan. Furthermore, Han was confused in the discussion sessions because she could not 
understand which criteria derived from "a manual for effective teaching if there is one" and which derived from "the teaching consultant's personal taste". The consultant seemed to assess her teaching subjectively. The superficial discussion and unclear criteria were totally different from what Han had expected from the consulting. This experience made Han doubt the quality of a teaching consultant and Han did not plan to work with a consultant afterwards.

Regarding school support, she was cynical about the principal's and vice-principal's roles in the school. She described them as people who stayed away from classroom practice and she said that she had never met a principal who wanted to help teachers improve their practice:

Researcher: "A principal could play the role of master teacher in school."

Han: "They can't. They don't like to do anything related to practical things."

She did not seem to expect school administrators to care about teachers' teaching or support teachers' improvement.

Lack of support from the regional office of education was also mentioned. Han was disappointed that the regional office of education did not help teachers prepare to work with new initiatives. She said, "If administrators in the regional office of education want us to implement new things in the classroom, those things should be provided as a full package and should have been piloted in the field [schools] beforehand". It seemed that insubstantial external support, ineffective teaching consulting, disillusionment with school support, and implementation of initiatives without adequate preparation led Han away from formal PD activities; rather she made an effort to learn, improve, and develop as a teacher by herself.

\subsubsection{Concern about showing her English teaching}

As Han got older and more experienced, she became less confident in showing her teaching practice to other teachers and was increasingly concerned about teaching in English. She was afraid that other teachers might be disappointed and think she had not reached the level of expert despite her long teaching experience.

When I was young, it was okay to open my class because I thought that I still had the potential to be better and I had enough time. However, as I am getting older, I would not want my way of teaching to be analysed or criticised in detail.

In her 30s, Han suggested to a colleague that they should attend each other's classes and discuss how to improve lessons. She described the suggestion as "a brave decision" since she viewed peer observation as a positive step in spite of the fear of opening her class. However, 
her colleague seemed to misunderstand Han's intention as if Han wanted to show off her teaching. The rejection from her colleague kept her from trying out peer observation in case her passion might be misunderstood as arrogance.

Han made another effort to open her class when working with the teaching consultant mentioned earlier. As Han voluntarily participated in the activity of being evaluated despite her fear of criticism, she expected an in-depth analysis of her teaching. However, the consultant "finished the discussion session noncommittally by saying that I did well rather than critiquing or providing an analysis of what went well or not". She thought this was because the consultant had "Korean sentiments", which meant that the consultant was reluctant to offer harsh criticism of others for fear of hurting their feelings.

Moreover, Han joined several informal study groups with teachers in other schools, which aimed to improve their teaching practices. However, none of these study groups incorporated observation of each other's classes. Han felt that opening a class to others was unwelcome and a sensitive issue for many teachers.

The rapid change in focus of English education in Korea towards English communication skills has meant that many teachers are not ready to deliver English lessons in English in class and nor was Han. She said, "In our day, English speaking was not emphasised, [we] usually focussed on English reading... Uh... so... As my English speaking proficiency is low... I keep studying English". Han's current level of English proficiency was a result of mixed factors of personal effort and PD, but she emphasised her own effort. Although Han believed that her English proficiency was sufficient to teach, she still felt that her overall English proficiency needed improvement. This may have been her humility about expressing her own capability, or this feeling of deficiency may have resulted from being a non-native EFL teacher. Han stated that "native speakers of English are the only rivals to non-native EFL teachers", which made it seem that Han made comparisons between nonnative EFL teachers and native English speakers of English.

Han was reluctant to open her class because she did not want to reveal her actual teaching ability as an experienced teacher. From failing in her efforts to incorporate openclass in her teaching practice, she learned that opening a class was not a feasible way to enhance her teaching practice. Moreover, Han's worries about having perfect English persisted despite her extensive experience as an EFL teacher.

\subsubsection{Resistance to change}


Han perceived that only one PD programme had changed her attitude. "What I learned is that... I need to inquire into my teaching and my way of teaching may not be the best... [which] made me humble..." The format of the programme was four days of workshops of EFL teaching theories and then one day of a presentation and discussion session, during which the participating teachers presented how to incorporate their learning into their own teaching practice. This five-day format was repeated for 3 weeks. Although she felt "distressed as hell", she remembered this PD as prompting her to "inquir[e] into her teaching practice a lot" and she began "seeing how other teachers use their learning". The PD component of connecting her own teaching practice with theory affected her attitude toward teaching.

However, even this PD programme failed to change her teaching practice. In the interview she reported that she persisted in her beliefs in textbook-based teaching and the importance of grammar teaching. Han maintained her teaching practice on the premise that it was too difficult to change. Han stated, "Making changes in teaching practice can be compared with changing one's personality. As we know, personality cannot be changed easily". In other words, her PD experiences rarely brought fundamental changes in her teaching practice and her beliefs. Therefore Han could not find any significant link between her PD learning and her teaching practice. For Han, the purpose of taking PD was to maintain her current status and she did not hesitate to say, "PD is not necessary to improving teaching practice".

\subsubsection{Summary}

The interview with Han revealed that Han did not consider that PD was useful in bringing about changes in her teaching. PD content was often inconsistent with her actual needs in the classroom. She noted that ill-prepared PD instructors and inauthentic PD activities were mismatched with her needs. She perceived that she did not have sufficient support from her school and the regional office of education. Han, as an experienced teacher, felt constant anxiety about opening her class and about needing to have perfect English. These experiences led Han to think that her teaching practices were rarely influenced by PD.

\subsection{Findings from across cases}

This section illustrates findings across the individual cases. The cross-case analysis in this study provides insight into the changes made in these experienced EFL teachers' practice 
through PD experience over time by exploring themes that recurred across all the individual cases. Five themes were: (a) Haunted by perfect English, (b) Valuing newly qualified teachers, (c) Isolated and stagnant teacher culture, (d) Tension between PD goals and classroom reality, and (e) Lack of support from policy and school.

\subsubsection{Haunted by perfect English}

Concern about their own proficiency in English never seemed to end for these experienced EFL teachers despite the long list of PD courses they had taken. They perceived that they possessed a low level of English. Moreover, their negative perceptions of non-native English speaking teachers (NNEST) compared to native English speaking teachers (NEST) also contributed to their feeling of distress about their English and prevented them from acknowledging their strength as teachers. This also made it difficult for them to focus on extending their teaching skills.

These experienced EFL teachers reported that they felt uneasy when they had to use English in the presence of other teachers such as when conducting open-class because they perceived they had a low level of English proficiency and they felt inadequate. They assumed that the observing teachers would judge how well they spoke in English. This low level of self-confidence in their English ability was also evident when they reflected on PD courses which required teachers to speak in English. For example, Seo reported that she was reluctant to speak in English during PD courses because her low level of English speaking ability might give an impression to other teachers that she was an underperforming teacher.

Experienced EFL teachers were afraid that they did not fit the image of EFL teachers expected by their students and society. Teachers who could communicate well with native English speaking teachers seemed to be regarded as teachers who could teach well by these EFL teachers. Speaking skills were especially easily observable and comparable. Han reported, "It is easy to find out who speaks English well by seeing them talking with native English teachers". Comparing their oral English skills with those of other teachers seemed to have a profoundly negative influence on experienced EFL teachers' self-confidence.

Participating teachers' concern about their English pronunciation also showed how important observable English ability was among EFL teachers. Choi reported, "I do not like my Korean-style English pronunciation" and Han said, "Experienced teachers need to improve their English pronunciation first to give a good first impression to students". 
It was hard for these teachers to resist comparing themselves to other EFL teachers because there were four or five EFL teachers in one school on average. Experienced EFL teachers seemed to regard other colleagues as threats rather than collaborators. The worries about their own English skills and continuous comparison with the speaking skills of other EFL teachers overwhelmed these experienced EFL teachers and contributed to their low sense of self-efficacy in English. Han admitted that EFL teachers even considered native English speakers who had no teaching background as their competitors in teaching English. This showed an excessive focus on English ability among experienced EFL teachers. Therefore the language proficiency of NNESTs was regarded as almost insurmountable regardless of the PD activities they had undertaken.

Kang was a notable exception. She reported that for many years she had focussed on improving her English proficiency thinking that this would have helped her teaching. However, her diverse PD experiences revealed that achieving native-like English was impossible and this need not be a significant factor in teaching her students. Although she took as much PD as she could and was even called "the queen of taking PD", Kang reflected that the impact of PD on improving her English ability was insignificant. "It seems that I followed a false dream to be a native English teacher by taking PD. Now I realise that it is better to focus on how to teach English to students, not myself'. Viewing herself as an English learner the same as her students rather than a teacher who knows everything, she could change her focus from her own English proficiency to what and how to teach her students. Although Kang's transformation can be attributed to her high level of selfconfidence and high level of English ability, which was different from other participating teachers, focussing on teaching seemed impossible for all the participants unless they could first overcome concerns about their English proficiency.

\subsubsection{Summary}

Experienced EFL teachers in this study were excessively concerned about acquiring perfect English and their failure to achieve this undermined their self-confidence. The recent emphasis on speaking and oral fluency in South Korean education led these experienced EFL teachers to constantly compare their English ability with that of colleagues and NESTs. This over-emphasis on their own English language ability led them to overlook their skills as professional teachers.

\subsubsection{Valuing newly qualified teachers}


During the interviews it was noticeable that the participating teachers compared themselves to newly qualified teachers and perceived that they were less adept than newly qualified teachers at using English and adopting new teaching methods such as technology in the classroom. Undermining their own long teaching experience further lowered their selfconfidence and inhibited them from taking a leading role among EFL teachers in their schools.

Observing newly qualified teachers' English use in open-class and PD courses, experienced EFL teachers perceived their own English skills as limited in comparison. Shin mentioned that she envied young teachers' bravery in organising activities which exposed students to authentic English such as going out with students to have interviews with English speakers. Regarding PD courses, Seo reported that she did not feel comfortable attending the same PD as newly qualified teachers because of their high English proficiency. Shin also said, "They [newly qualified teachers] could respond to the instructor right away. But it took time for me to think about words and grammar..."

As well as admiring their English ability, the participating experienced EFL teachers seemed to value the fresh ideas of novice teachers. These teachers' teaching methods and technology were regarded as being abreast of new trends in English language teaching. Their skilful use of ICT impressed Choi who remarked, "I would like to learn their skills of using computer programmes for teaching, such skills as editing”. Han and Shin reported that they were impressed by new and seemingly innovative classroom activities and teaching methods of newly qualified teachers. Their judgements made them reluctant to conduct open-class since their way of teaching did not have anything new to offer. In their perception, conducting open-class meant incorporating new methods or approaches into their existing teaching practices even though those new methods or approaches were not part of their normal practice. Therefore preparing for open-class was regarded as a burden and Han described open-class as an obligatory PD activity that had to be done annually.

Furthermore, experienced EFL teachers were not working in an environment in which their experience was valued. They commonly reported that their extensive teaching experience helped them develop skills in student discipline and counselling. Shin stated, "I did not feel so inferior [to newly qualified teachers] when I returned to my class after attending PD sessions" because she was confident in her skills in student discipline and counselling, which were not specific to teaching English. However, in-school PD activities such as open-class and peer observation combined with speaking-focussed initiatives put experienced EFL teachers in situations where their English ability received more attention 
than teaching itself. Therefore, experienced EFL teachers' skills in managing students, accumulated over many years of teaching, were overlooked.

The extensive experience of these experienced teachers seemed to impede their openness. Han said, "I want others to keep their expectation about my teaching as an experienced teacher [by not showing my teaching practice]". Han's concern was that others might have thought that she did not teach well in spite of her professional experience. Unlike the other participating teachers, Kang reported that she invited new and less-experienced teachers to her class to observe and discuss her teaching practice. They discussed issues such as English teaching and how to manage classroom issues on the spot, for example dealing with a student who was sleeping in the classroom.

These experienced teachers generally refused to take a leading role as they did not think that they deserved to be leaders among EFL teachers in their schools. Despite Kang's reported pride in taking a leading role voluntarily through creating a study group among colleagues and inviting other colleagues to her classroom, the limited leadership roles assigned to experienced EFL teachers also showed disregard for their experience. Seo and Choi reported that they had not thought that becoming the head teacher of an English department was an important role among EFL teachers. They perceived this role as managerial rather than leading professional learning among EFL teachers. These experienced teachers (except Kang) tended to be unwilling to take a leading role.

\subsubsection{Summary}

Experienced EFL teachers in this study thought that they were falling behind the current English teaching trends and, despite their long experience, their self-confidence in using English continued to drop as a result of comparisons with less-experienced teachers. Newly qualified teachers' use of ICT also appeared to undermine experienced EFL teachers' extensive teaching experience. This made the experienced teachers feel vulnerable and that they had lost ground as professionals. They questioned their professional expertise and became reluctant to promote their skills or take a leading role. Therefore they perceived that new teachers were more valued than experienced teachers.

\subsubsection{Isolated and stagnant teacher culture}

Teachers' interviews also revealed a unique EFL teacher culture in Korean schools. Although participating teachers were from different schools, a stagnant teacher culture 
pervaded all their schools. This culture seemed distinguished by individualism rather than collaboration in teaching. There was also a prevalent resistance against accepting new methods or practices, as experienced teachers felt more confident about maintaining their existing practice.

Firstly, experienced EFL teachers assumed that teaching was an individual and private matter. Keeping their classroom door shut was a normal practice in schools. Therefore there was little communication among EFL teachers. When asked in the interview about what they shared with other teachers, they only came up with sharing teaching materials or handouts for classes. Teachers reported that the main purpose of staff meetings was administration rather than discussing classroom teaching. This culture did not allow for sharing their classroom experiences. Seo said,

I used to ask senior teachers how they dealt with students or how they planned their classroom teaching when I was in my early years of teaching. Now I don't do that as I have some years of teaching experience.

It seems that Seo thought asking others might not be seen as a professional behaviour.

Moreover, these participants seemed to equate sharing to evaluation. This is one reason why they were reluctant to conduct open-class. Han said that teachers did not share any judgements of others' teaching materials because "it becomes evaluation if I say they [teaching materials] were good or bad. If I share teaching materials with colleagues, how they use them is up to the individual". Therefore there was no communication related to teaching practice among teachers. Teachers did not talk about their teaching practice voluntarily because they did not want to be evaluated. They also did not ask about others' teaching practice since they did not think that they deserved to evaluate others.

For participating teachers, it was difficult to escape from the firmly established isolation of their teacher culture. They reported that their attempts to be collegial had been criticised when they were in the early years of their career. Han said,

When I suggested to one of my colleagues that we should observe each other's teaching regularly, she refused and said to me that I must be proud of my teaching to think of opening my classroom door to others. ... If that had happened, my teaching might be different now.

Efforts to bring about changes were constrained by the rigid culture and the resulting professional isolation led teachers' concerns about the opinions of other EFL teachers in the school to become magnified. Therefore when Choi incorporated some PD learning at an individual level, she did not consider asking other teachers to work with her. Choi said, 
First of all, it was hard to find the same-minded colleague. Moreover, it would be hard to reflect content of the new project in the exam when not all the teachers who teach the same grade agreed to participate.

When these teachers were asked how they viewed developing a professional learning community (PLC) in their schools, they welcomed the idea but simultaneously doubted whether other teachers would agree to the idea. As new innovations could not penetrate into the established teacher culture, teachers became more accustomed to the existing culture. This teacher culture did not encourage teachers to be active or dynamic in seeking learning opportunities to improve teaching practice. Rather they accepted the status quo.

In this culture, it was difficult to introduce or implement new PD activities. Although two types of in-school PD - open-class and peer evaluation - were mandated by the Ministry of Education, Science, and Technology (MEST), the characteristics of those PD activities were contrary to the prevailing teacher culture. This led teachers to view those in-school PD activities negatively. They avoided participating in open-class. Seo reported that she did not want to conduct open-class as she did not like to reveal her teaching practice. In the case of peer evaluation, Han observed that teachers only did the minimum that they were required to do such as filling out an evaluation form. Discussion sessions after open-class or peer observation did not result in professional discussions about teaching practice because experienced teachers embedded in this culture were worried that discussion meant evaluation and invasion of teachers' privacy. They were afraid of giving honest comments since these may have hurt others' feelings so they avoided talking about others' teaching practice. Han stated, "[Invited] teachers commented that my open-class was great or that it must have been difficult to prepare this open-class... nothing further than that". Therefore Han reported that she did not expect genuine critique from post-discussion sessions. In such an environment it was difficult for in-school PD to bring about substantial learning to teachers and ultimately affect teaching practice positively.

\subsubsection{Summary}

The isolated and stagnant teacher culture was evident and prejudiced teachers' attitudes towards PD. Teachers had a conception of sharing that was limited to sharing materials. Other than that, they rarely shared teaching practices because they viewed sharing as evaluation rather than learning for improvement. Therefore discussion and reflection could not proceed to a deeper level. 


\subsubsection{Tension between PD goals and classroom reality}

The participants constantly reiterated that there was a gap between PD content and what they were teaching, and this discrepancy made experienced EFL teachers confused about goal-setting. The participating teachers tended to set their goals in compliance with the demands of classroom teaching and examinations, and did not consider the PD goals to be achievable.

PD is designed to support teachers to achieve goals of the national curriculum.

Documents shared by the participating teachers showed that the current PD focussed on enhancing teachers' English fluency and implementing communicative language teaching (CLT) into classrooms. On the other hand, because of high-stakes examinations, the main focus of classroom teaching was on preparing middle and high school students for written tests. Therefore, grammar and reading were considered important preparation for written tests, especially for students sitting the national university entrance exam. In contrast, speaking and conversation based on CLT methods did not seem important to these experienced EFL teachers. Although MEST offered PD about how to include CLT in classroom teaching, PD learning did not seem applicable in actual classroom teaching. A tension between these two different goals made these teachers confused about how to align their teaching practice.

Experienced EFL teachers focussed on the goal of classroom teaching, which was preparing students for examinations. As teachers grounded in the classroom, their immediate focus was on their students' needs. Moreover, experienced EFL teachers found it hard to ignore students' demand for exam preparation. Teachers were also faced with students' and parents' negative reactions against any new ways of teaching drawn from PD as Shin stated that "parents of students do not seem to like it if a teacher has a unique way of teaching". Therefore PD learning which could not bring immediate results was regarded as ineffective. Seo reported that she returned to her existing practice after a few attempts of learning from PD. Kang's attempt to incorporate PD learning was confined to an after school class because she did not need to prepare those students for an examination. Choi said,

My plan this year is to help my students to write a short essay. ... I cannot do this every class $\ldots$ if there is enough time after covering textbook content for an exam, I ask my students to write a short essay in English... This has only happened twice this semester...

Choi's intentions to develop her students' English essay writing were rarely realised in the classroom because English essay writing was not included in the examinations. Examination questions usually consisted of multiple-choice or short-answer questions. However, Choi 
persisted as it was apparent from the documents related to PD that English essay writing was encouraged by several PD courses.

It was not easy to balance the ideal and reality even for these experienced teachers. Shin noted how difficult she found it to apply PD learning in her classroom, when this learning seemed to be different from what she required for her classroom teaching. Even Han cynically mentioned that PD was no use in terms of improving teaching practice. These teachers struggled to find a link between PD learning and their teaching practice. Experienced EFL teachers perceived that the importance of PD was in participation rather than in learning and so it did not matter whether PD goals were achieved or not. The participating teachers took PD to expose themselves to current trends in English language teaching and to remind them of the importance of being up-to-date as EFL teachers rather than to achieve substantial learning. They took PD as the system required.

\subsubsection{Summary}

The different goals suggested by PD and classroom teaching made these teachers confused about setting goals for teaching. This led these experienced EFL teachers to doubt the value of taking PD and to regard PD goals as unrealistic.

\subsubsection{Lack of support from policy and school}

This study showed that these experienced EFL teachers felt the lack of support from policy and schools in matters relating to their PD experience and learning. Three issues regarding policy support were: (a) lack of any assessment of experienced EFL teachers' PD needs, (b) top-down PD that treated teachers as passive participants, and (c) limited leadership roles for experienced EFL teachers. In terms of school support, these experienced EFL teachers either perceived that there was none or they perceived the bureaucracy surrounding school support as a burden.

It did not seem that teachers' needs were considered when designing PD. Despite MEST's efforts to meet teachers' needs, lack of consultation with teachers led to gaps between PD content and support for classroom teaching. Some participating teachers insisted that a thorough needs analysis was necessary. Shin reported that what policy described as "customised PD" was far from what that term suggests because the individual teaching context was ignored. Another effort of MEST was to offer PD courses in schools near where teachers work to minimise the constraint of distance. However, as only a few PD courses 
were available, similar content was repeated every year, and there was no time to take PD because of workload, few benefits arose from this proximity. When Seo mentioned PD running in nearby schools, she reported, "The PD content offered was the same as last year, so I did not take it this year. I hope that the PD course next year has different content". Seo also mentioned that she had not been asked about her PD needs despite attending PD courses at nearby schools.

Teachers' interviews also revealed that MEST seemed to regard teachers as passive participants to be trained. According to these teachers, MEST initiated new educational policies without thorough consideration of the teachers' requirements. Choi reported,

As the lowest position, what can we [teachers] do? ... I sometimes feel embarrassed in front of students because of the changing policies ... If teachers understood the educational policies thoroughly, we could convince students why these policies were necessary. But sometimes I heard about the initiatives from media like TV. Then how can I make students follow them?

MEST's apparent relegation of teachers to consumers of PD made teachers feel that they had little to offer and they were demotivated to participate in PD.

Shin perceived that teachers were required to take corresponding PD courses to catch up with new initiatives only after they had been announced. This made her feel frustrated because she struggled to understand their purpose. Choi said that they had no choice but to comply since teachers were regarded as being on the lowest rung of the teacher education system. Han also reported,

After a few years of abrupt implementation of the new initiative, we might get some materials from other teachers as a result of their brave attempts. However, in the meantime, we felt vulnerable and struggled in front of students. Students also became victims of the new initiatives.

MEST did not help teachers to understand the rationale behind taking open-class and peer observation thoroughly. They imposed compulsory open-class as "an event to be practised once a year". These teachers' perceptions of using only English in open class and the necessity of incorporating new classroom activities were affected by MEST's top-down PD enforcement. As their practice in open-class was not the same as their normal practice, these teachers did not perceive this as a learning opportunity, but rather a burden on them. Nominal peer observation was also reported. Han said, "Teachers go to other teachers' classroom briefly and fill out the peer-evaluation form". Choi mentioned that she tried to incorporate what she would plan for open-class in her existing teaching practice, but she did not value the post-discussion. Choi reported, "After open-class, I watch the video clip of my open-class to 
reflect... Other teachers usually just give compliments about my overall teaching performance". The discussion was not critical enough for her to see strengths and weaknesses in her teaching practice.

From the participating experienced EFL teachers' perspectives, it seemed that MEST limited its responsibility to offering PD programmes and did not consider how PD learning could be applied into the classroom. While teachers' attendance at PD courses was regarded as important and EFL teachers were forced to take 60 hours of PD every year, the results of PD learning seemed less important. There was no evaluation of how teachers' PD experience linked to teaching practice and even further to students' learning in the classroom. As Choi and Seo mentioned that they did not have time to review what they learned in PD after returning to the classroom, systematic implementation of PD learning seemed unknown. Choi said, "After taking one PD course the next step is to take the next one".

Furthermore, it seemed to be assumed that teachers would apply PD learning in their classroom. Seo said, "Some PD learning looked interesting and suitable to my students... I included it in my teaching a few times, but it sprang back to the way I have always done". The absence of follow-up PD made Seo discard the changes after a few attempts rather than retaining them since learning and application were solely up to her own effort. Unlike Han's hope of having someone observe her newly adopted changes with an objective viewpoint, teachers' own beliefs and definition of effectiveness were usually the only criteria to judge the usefulness of PD learning in the classroom. These experienced EFL teachers even reported confronting objections to new practices from their students. Unless teachers had a firm belief in the changes they made in their practice, it was easy to revert to their prior teaching practice. Seo reported,

[After taking PD related to English,] every year I tried to use English. ... While teaching chapter 1 and 2 [of the textbook], I tried to use English, but students did not or could not understand what I said, I had to switch to Korean [for the rest of the school year].

The success and failure of incorporating PD learning into the classroom was solely the teachers' responsibility.

Lack of school support was another issue especially for experienced EFL teachers. As schools were also subject to the national school evaluation, schools tended to urge teachers to take more than the recommended number of hours of PD (Ban, 2012) to gain the school a high score in the teachers' PD participation component. Other than that, schools did not seem to give much thought to the professional learning of their teachers. Taking PD was solely 
dependent on individual teachers. Schools did not mediate teachers' struggle between PD goals and exam-oriented classroom teaching goals. Moreover, schools did not support teachers to do experiments and to implement PD learning into their classroom. Seeking school support was regarded as an administrative liability. After I exemplified possible kinds of school support, Choi reported,

When I incorporated a new writing project, which I and my colleague agreed to do, my school was not aware of our project. ... If they had known, they might have asked me to make reports. I did not want to get any support from school.

She did not perceive the school as a helping hand.

As fellow teachers did not seem to be perceived as team members by teachers within a particular school, the teachers were not motivated to work together. Participants' interviews did not reveal any school-led PD initiatives. Schools did not seem to create an atmosphere for teachers to share their PD learning with other teachers. Han mentioned, "I have never met a principal who wanted to help teachers' teaching and learning". In her perception, principals seemed to close their door on teaching when they took on the role of administrators.

Schools appeared to take a similar position to MEST's by not sharing PD responsibility with experienced EFL teachers. Even the position of head of the English department was limited to managerial work rather than promoting learning for better teaching practices of EFL teachers within schools. Choi said, "We [EFL teachers] take turns in the role of the head teacher". The role did not require experienced EFL teachers to take action based on their accumulated teaching experience.

\subsubsection{Summary}

Lack of support from policy included absence of any teachers' needs analysis. PD courses were offered based on what MEST assumed to be the needs of teachers. Being placed in the position of passive participants of PD made teachers feel vulnerable in the classroom. Teachers were expected to follow suggestions from MEST without thorough preparation. While assuming authority for PD planning, MEST did not seem to be accountable for the translation of PD learning into teachers' teaching practice. PD learning and its application in teaching practice solely depended on individual teachers without any external support. Furthermore, the concept of school support was unfamiliar and teachers had negative attitudes towards the idea of school support. 


\subsection{Summary}

In this chapter, findings from five individual cases and across cases have been presented. Given that these experienced EFL teachers' PD experiences were diverse over their career, interviews from each teacher revealed unique themes based on their own context for teaching, which were related to teachers themselves, their school, and educational policy. Their preferences and opinions about PD were different from each other's and some themes were unique to a specific teacher.

As well as the voices of individual cases, findings across cases were described in this chapter. Experienced EFL teachers were excessively preoccupied with having perfect English and their imperfect English reduced their self-confidence as teachers. Instead of realising their value as experienced teachers, they perceived newly qualified teachers as more capable teachers by emphasising the importance of their higher English proficiency and their use of new methods and strategies. As they became more experienced, these teachers were assimilated into an isolated and stagnant teacher culture. They became increasingly resistant to sharing their teaching practice and considered sharing to be another form of evaluation. Experienced EFL teachers tended to focus on the classroom teaching goal of students' exam preparation. This led PD goals, which are different from classroom teaching, to be discarded by these teachers. These teachers perceived that support from policy was lacking in several areas: Policy did not help teachers learn or implement PD thoroughly. The current system, with few follow-up PD programmes, appeared to restrict them to the role of followers. Finally there were few chances for EFL teachers to become leaders. Support from schools was not apparent and some of the teachers did not perceive that school support was necessary. The next chapter will discuss findings across cases through the theoretical lens of CHAT with reference to literature. Implications and limitations of this study will be also discussed. 


\section{Chapter 5}

\section{Discussion and Implications}

\subsection{Introduction}

This chapter discusses findings of this study, which investigated experienced EFL teachers' perceptions of changes to their teaching practice after PD, using the theoretical lens of cultural historical activity theory (CHAT). Findings are discussed based on the following cross-case themes: (a) Haunted by perfect English, (b) Valuing newly qualified teachers, (c) Isolated and stagnant teacher culture, and (d) Different goals and lack of support related to conflicts between policy and teachers' practices. A new theme of nurtured passivity emerged across from all the themes previously discussed. The later part of this chapter deals with the limitations and implications of this study.

\subsection{Cultural historical activity theory}

CHAT helps not only explain each element in the activity system related to teachers' adoption or rejection of PD learning in their teaching practice, but also captures the complex relationship among these diverse elements (Roth \& Lee, 2007). In this study, experienced EFL teachers' PD experience is considered as an activity system in CHAT where the subject, the experienced EFL teachers, works on the object of PD learning to achieve the outcome of bringing about changes in their teaching practice.

\subsubsection{Haunted by perfect English}




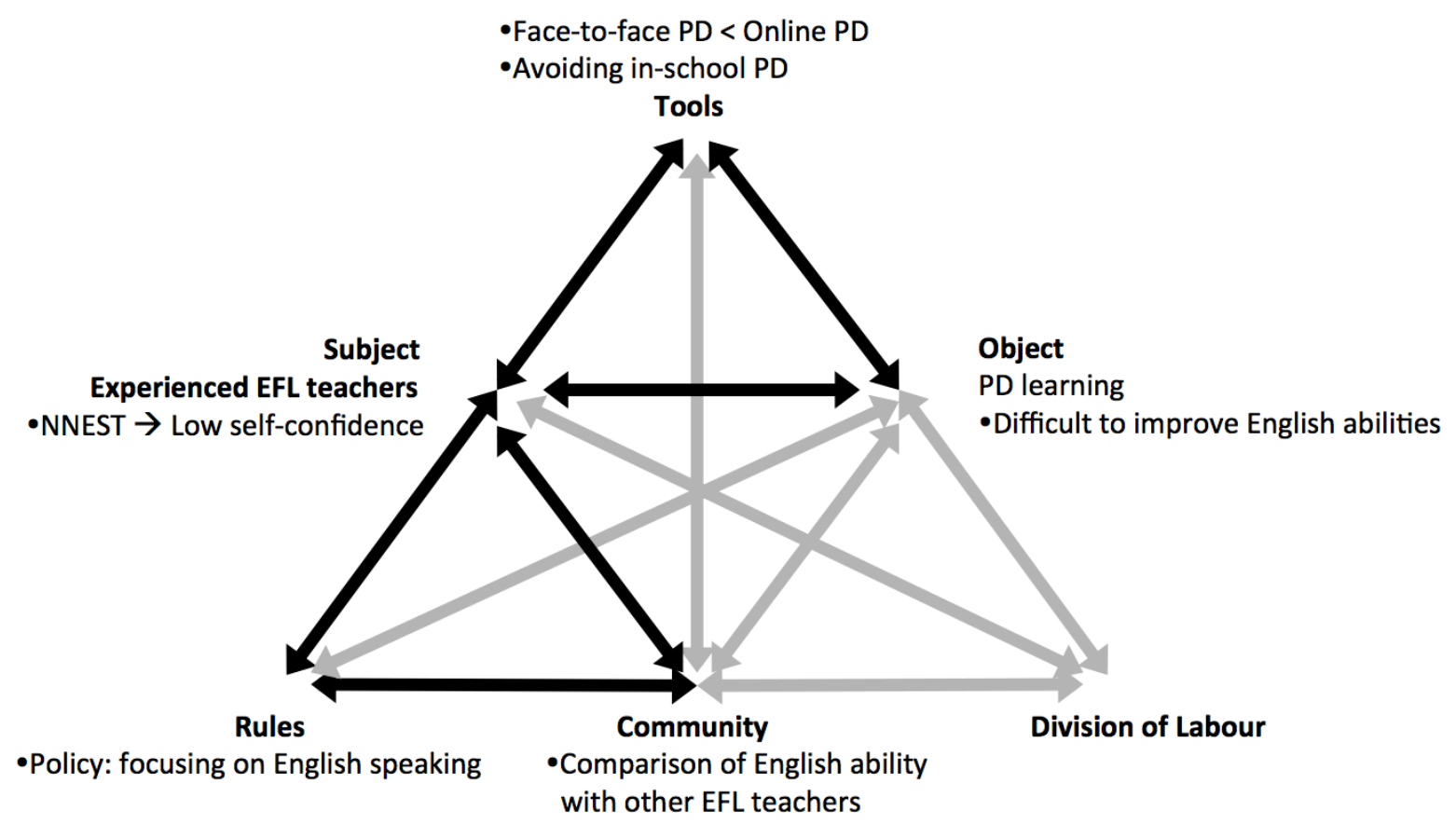

Figure 2. Haunted by perfect English in the activity system of experienced EFL teachers' PD experience.

Figure 2 is adapted from Engeström's (1987) activity triangle of CHAT and represents the activity system of experienced EFL teachers' PD experience with a special focus on the theme of Haunted by perfect English. The focus of the Ministry of Education, Science, and Technology (MEST) on English speaking - which can be considered a rule in Engeström's model - contributed to these experienced EFL teachers' low level of selfconfidence. This rule led members of the EFL teacher community to constantly compare their English ability with that of other teachers, which undermined the self-confidence of experienced EFL teachers. This affected these experienced EFL teachers' choice of types of PD, which corresponds to tools in Engeström's model. The experienced EFL teachers tended to favour online PD over face-to-face PD, and avoided in-school PD. Consequently, it was difficult to improve the English ability of these experienced EFL teachers through PD, even though this was the object of the activity system.

It seemed to the subject - experienced EFL teachers - that the policy initiated by the MEST drew attention to their English ability which was constantly compared with that of other colleagues. This finding is translated into these non-native English speaking teachers' (NNEST) focus on attaining native-like English. It was evident from the documents that most of their PD courses were about improving teachers' English skills such as a title of PD course, 
English communication. These findings reflect Murdoch's (1994) contention that NNEST's views of their own competence are significantly influenced by their own English language proficiency as they value high levels of English ability over other characteristics of an EFL teacher.

The focus of PD on improving English teachers' ability to a level approaching that of native English speaking teachers (NEST) gave teachers the impression that being a NNEST was a disadvantage instead of helping teachers recover and build their lowered selfconfidence. EFL teachers' feelings of imperfection in English shown in this study is in line with what Medgyes (1994) called an NNEST "inferiority complex". In addition, studies about EFL teachers in Asian countries show a similar fear of incompetence in English from teachers. Igawa's (2008) survey of the PD needs of 38 NESTs and 6 NNESTs also found that language competence was one of the top three PD needs, but one confined exclusively to NNESTs. Thai teachers' perception of linguistic superiority of NESTs was found in Phothongsunan and Suwanarak's (2008) study.

Medgyes (1994), however, argues that both NEST and NNEST have their own strengths and weaknesses. Regarding NNEST's fortes, Braine (1999) and Medgyes (1994) contend that NNESTs' understanding of multicultural issues and their versatile multilingualism are beneficial to students. NNESTs can create good rapport with students by employing students' L1 (Inbar-Lourie, 2001) and have a better understanding of students' difficulties in learning English derived from understanding the cultural differences between western culture and the culture in their own country (Phillipson, 1992; Tang, 1997). Another advantage as NNEST is that they can act as English learner models for the students given they are also English language learners (Medgyes, 1983; Tang, 1997). There are parallels between the findings in these studies and the experiences of one teacher, Kang, in this study who became comfortable in her NNEST status through realising the benefits it provided for her students.

However, the elements of rules and community in this activity system did not support these experienced EFL teachers to embrace the advantages of being NNEST evident elsewhere in the literature. Rather the contextual factors had a negative influence on these EFL teachers. The high social value of English and power-relations accorded through being fluent in English continued to underpin these NNEST's desire to attain NEST-like English ability in a manner common in many Asian countries including South Korea (Park, 2009).

These experienced EFL teachers' lowered self-confidence in speaking English led them to misconceive that their teaching ability was the same as their English ability. They 
perceived that they could not teach well since they did not have good English. They lost selfconfidence in both their English proficiency and their teaching ability. Their lowered selfconfidence led them to take PD selectively within their comfort zone in order to hide their English ability.

They preferred online PD which generally involved no spoken interaction as a way of relieving their anxiety about their English proficiency. However, interaction with and feedback from others, can be beneficial (Gass \& Mackey, 2006; Long, 1996; McKay \& Schaetzel, 2008; Reigel, 2008) in bringing about change in their English ability, especially their speaking skills. This could have been achieved in this study by teachers' participation in face-to-face PD and conducting open-class. The findings from this study suggest that it is important to help teachers increase their self-confidence enough to think that revealing their English ability would help enhance their English proficiency. Hence PD, as the element of tools within the activity, was not effective to improve the English ability of these experienced EFL teachers.

Too much concern about their English proficiency prevented these teachers from looking beyond the improvement of their own English ability; they could not envision how to connect their English ability to their teaching practice. Their misalliance of their English ability with their teaching ability made them believe that they would be able to teach better if they had greater English competency. Therefore these teachers perceived that enhancing their own English proficiency was the ultimate goal of PD.

\subsubsection{Valuing newly qualified teachers}




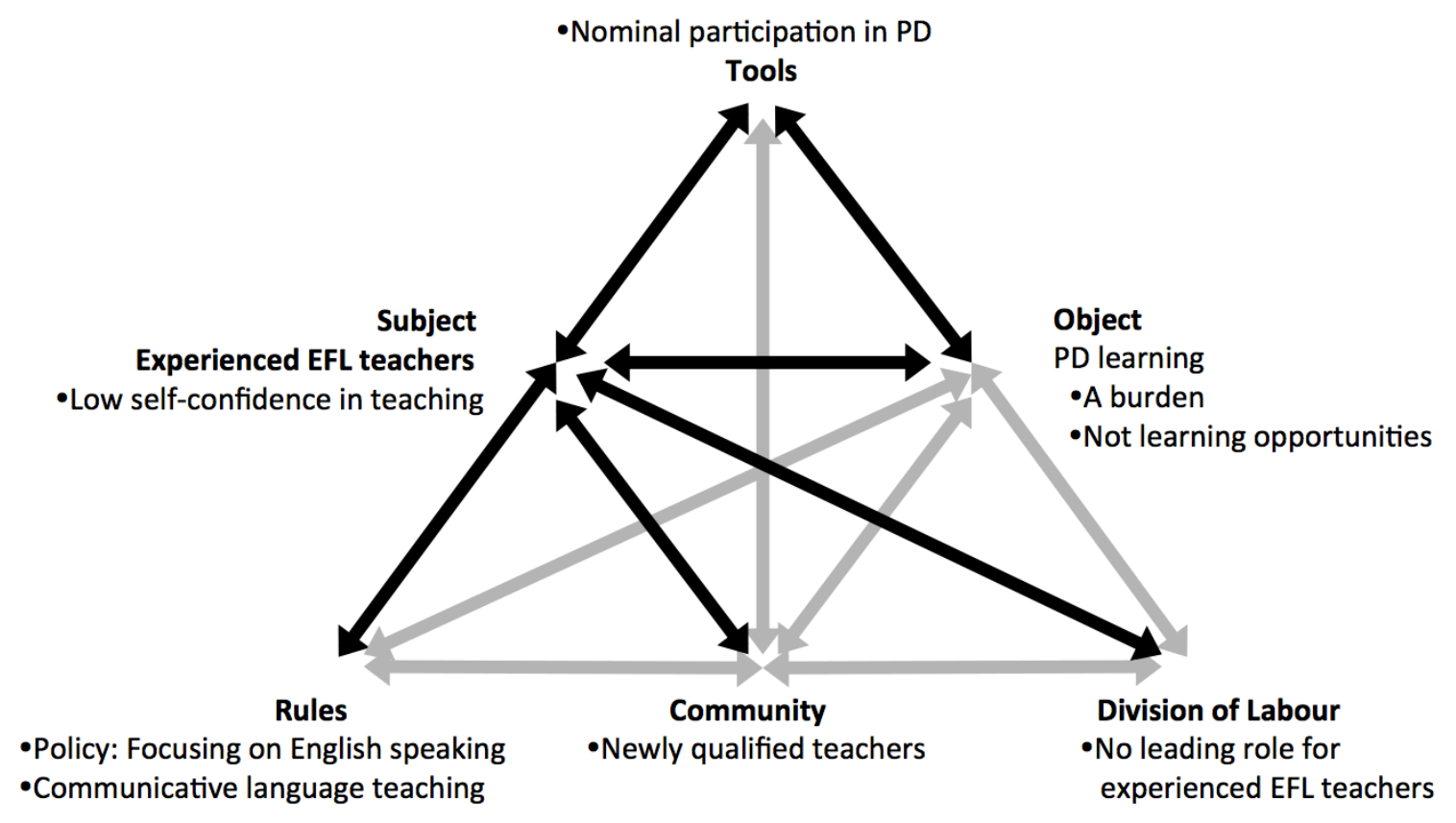

Figure 3. Valuing newly qualified teachers in the activity system of experienced EFL teachers' PD experience.

As shown in Figure 3, the rules created by MEST's focus on English speaking and the shift of English language teaching methods towards communicative language teaching (CLT) had a negative influence on these experienced EFL teachers' self-confidence in teaching. This led them to create barriers between themselves and newly qualified teachers within the wider teaching community. They developed inferior feelings in the absence of MEST or their school hierarchy creating leading roles for these experienced EFL teachers, within the element of division of labour. Their lowered self-confidence, in comparison to newly qualified teachers, affected the subject's choice of tools - their selection of different types of PD. As a result, these experienced EFL teachers regarded PD as a burden instead of a learning opportunity thus preventing them from achieving the object of the activity system: new learning.

Despite PD to prepare these experienced teachers for the implementation of new MEST policies, they thought that they were at a different starting point from newly qualified teachers. This meant that PD did not have a substantial influence on helping their adaptation to new changes.

The finding that these experienced EFL teachers perceived newly qualified teachers as a separate group from them and as ideal teachers contrasts with the literature on teacher communities. Experienced teachers in a teacher community usually act as leaders based on 
their expertise gained from their teaching experience (Andrews \& Lewis, 2002; Manthei, 1992). Wenger (1998) explains the experienced members of a community as old-timers. In a teachers' community of practice, these old-timer teachers help newly qualified teachers, or newcomers, smoothly settle into the new community (Rogoff, 1990). Studies of mentoring within teaching usually position experienced teachers in a mentor position with the underlying assumption that experienced teachers are expert teachers (Feiman-Nemser, 2003; Huling-Austin, 1992).

However, Fessler and Christensen (1992) and Furlong and Maynard (1995) suggested that teachers experience several stages in their professional lives and Tsui (2003) notes that experience is not the only factor to decide expertise in teaching. Tsui identified the characteristics of expert teachers compared to non-expert teachers. Expert teachers see tasks and problems as opportunities to increase their expertise and maximise their professional learning while non-expert teachers regard tasks and problems as should-be-solved; they try not to change their existing practice, and develop routines to minimise the occurrence of problems. Therefore, expert teachers constantly reflect on and inquire into their practices to avoid staying in automaticised routines (Farrell, 2013). Experience can be meaningful only if teachers learn from it rather than repeat it (Bereiter \& Scardamalia, 1993). In this sense, the experienced EFL teachers in this study are consistent with what Tsui defines as experienced non-expert teachers as they "rely more on routines and solve problems at a superficial level" (p. 194).

These experienced EFL teachers attributed their low status to the limited value placed upon their long teaching experience by the new policies - or rules. There were few chances to share their forte of maintaining student discipline and classroom management. Since inschool PD focused attention on teachers' demonstration of new teaching methods conducted in classes where the medium of instruction was English, presenting other teaching strengths was not regarded as valuable during open-class demonstrations. They felt that they had no opportunity to make sure their long experience was valued.

In CHAT theory, the division of labour addresses vertical and horizontal power relations among groups in the community element of the activity system (Engeström, 2001). In this study, it was evident that the Seoul Metropolitan Office of Education (SMOE) and school administrators had not created leadership roles for experienced EFL teachers even though experienced teachers could be recognised and respected in a teaching community through their leadership roles (Feiman-Nemser, 2003; Manthei, 1992). Staff meetings unrelated to improving teaching practice did not provide these experienced EFL teachers with 
a chance to act as leaders. Without any recognition of their value as experienced teachers in the community, these teachers felt that they were regarded as having old and out-dated ways of teaching in comparison to newly qualified teachers.

What is significant is that the experienced teachers in this study also accepted this: for example, Han avoided conducting open-class due to her perception that her teaching practice lacked up-to-date ideas. As well as the contextual factors which did not help these teachers value their own strengths as experienced teachers, their reluctance to take on leadership also undermined the value of their long teaching experience. As most of the teachers, except Kang, perceived they did not have the same ability as newly qualified teachers, they wanted to hide their teaching practice or disguised their teaching practice by designing one-off lessons as a show for open-class rather than as an example of their usual teaching practice.

\subsubsection{Isolated and stagnant teacher culture}

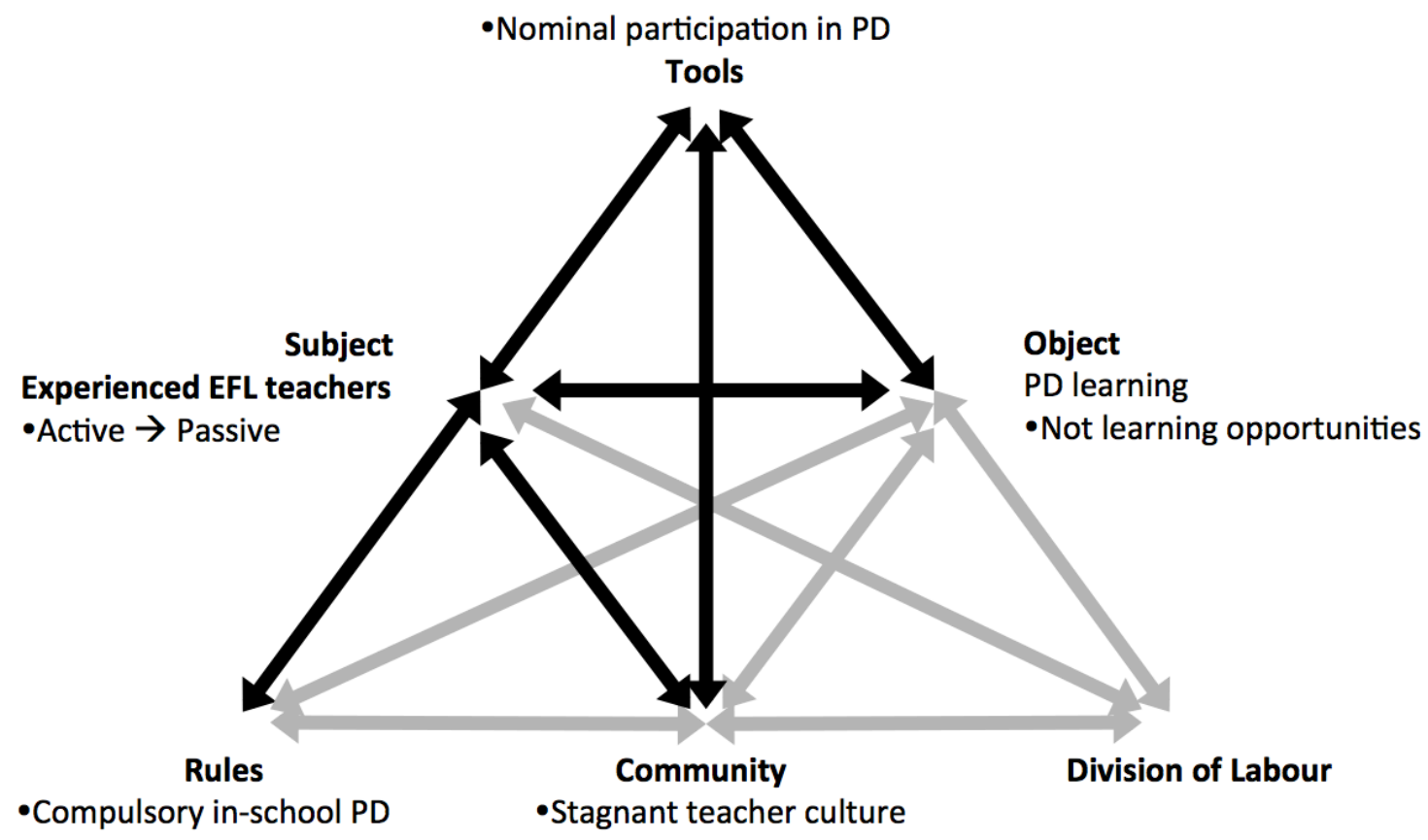

Figure 4. Isolated and stagnant teacher culture in the activity system of experienced EFL teachers' PD experience.

The pressure from the rule requiring experienced EFL teachers' compulsory participation in in-school PD conflicted with these experienced EFL teachers' ingrained passivity. This strong urge to maintain the status quo developed as individuals were assimilated into the isolated and stagnant community of experienced teachers. In-school PD 
required teachers to share their teaching practice and collaborate with other teachers. The different nature of in-school PD from their teacher culture led these experienced EFL teachers to only engage in in-school PD at a superficial level. Therefore in-school PD did not bring about substantial learning.

The view that teachers tend not to change in general is widely presented in the literature (Hohn, 1998; Morimoto, 1973; Williamson \& Blackburn, 2010). Whether it is a case of implementing innovations or adjusting to new change, resistance is understood as an inevitable process in change (Hall \& Hord, 2001) although the degree of resistance may vary (Morimoto, 1973). This study identified that resistance to change as a result of PD was not what teachers had brought with them when they entered into a teaching profession as described in Figure 3. When their attempts to incorporate innovative teaching methods or classroom activities and requests for collaboration were rejected in the early years of their teaching career, these participants realised how difficult it was to change the existing teacher culture. According to Wenger's (1998) community of practice, newcomers try to assimilate into the community of practice by learning how to behave in the organisational culture. Consistent with Wenger, the teachers in this study also showed that they became assimilated into the prevailing culture as they become more experienced, but in a way that fossilised their teaching practice. Their defeated motivation to incorporate PD learning led them maintain the status quo.

Potential benefits of sharing described in the literature include opportunities for teachers to reflect on their own teaching by having others' perspectives on their own practice (Leander \& Osborne, 2008), and initiating learning for changes in teaching practice through collective participation of teachers (Garet et al., 2001), especially collaboration among same subject teachers (Hindin, Morocco, Mott, \& Aguilar, 2007). However, in the culture experienced by these teachers, openness was not encouraged so passive teaching beliefs created in their early years of teaching had not been questioned over their career. Moreover, it is difficult for these participants to initiate learning through collective participation as comparison and isolation led these experienced teachers to perceive their colleagues as competitors rather than collaborators. The findings of this study support Lortie's (1975) assertion that a culture of isolation allows only limited peer interactions and inhibits professional learning.

Although some of these experienced EFL teachers made attempts to include their PD learning in their teaching practice, these attempts remained at an individual level rather than at a departmental or school level. Because they were accustomed to working in isolation, they 
seemed to think that collaboration was less effective than working alone; working together with other colleagues was considered as bothersome and complicated work. Another issue this culture of isolation brought is that experienced EFL teachers' beliefs on teaching were not questioned by others and so they came to believe that their own way of teaching was effective. Their own interpretation of effectiveness increased their resistance to change because they felt that accepting changes meant losing their ground. For example, Seo felt nervous when students seemed to become out of her control when adopting group-work in her practice because it did not match her teaching belief that teachers should have control over students.

These experienced EFL teachers' conscious comparison with other members in their EFL teacher community strengthened the nature of their isolation. Korean people have a tendency to worry too much about what others think about them (Merkin, 2009). By comparing types of self-construal (Markus \& Kitayama, 1991) between American and Korean, Merkin (2009) found that Koreans have interdependent self-construals, meaning they were more dependent on the thoughts and feelings of others than were Americans. Norton and Toohey (2001) contend that how individuals are labelled by others' perceptions can be a decisive factor in shaping their identities. In this study, others' expectations of the participants as experienced EFL teachers affected them and undermined their self-confidence as teachers. Furthermore, they regarded asking for advice and talking about the issues they faced in the classroom as unprofessional. This furthered their avoidance of collaboration. As another example, even though these teachers favoured the notion of a PLC as an in-school PD activity, they could not initiate these because they were concerned about other colleagues' opinions about PLCs.

The effect of this teacher culture seemed highly intense. Even though these teachers made changes in their teaching practices, they were not sustained and rather easily discarded. This also implies that policymakers and PD providers did not address the impact of this inactive teacher culture thoroughly for these teachers to manage potential obstacles situated in the teacher culture. They did not think that PD could lead to improvements in their teaching practice. Rather they took PD to accumulate PD credits.

In terms of in-school PD, both open-class and peer observation PD activities have characteristics of sharing with others and reflecting on practice through others' perspectives. These characteristics are close to a reform type of PD and are considered to make PD more effective in bringing changes in teaching practice (Ball \& Cohen, 1996; Garet et al., 2001; Stiles, Loucks-Horsley, \& Hewson, 1996). However, experienced EFL teachers in this study 
did not regard in-school PD as a learning opportunity. Rather the conflict between in-school PD and the teacher culture hindered teachers from participating in in-school PD.

The implementation of policy requiring in-school PD without taking account of teachers' status in this rigid teacher culture led to rejection from these experienced EFL teachers. This finding is supported by Sikes' (1992) and Smit's (2003) contentions that experienced teachers do not prefer imposed educational initiatives which may challenge their deeply rooted beliefs accumulated over their long teaching experience. Peery (2004) points out that PD activities which help teachers' skill building and inquiry skills are of no use without understanding 'why' and 'how' those PD activities improve teaching. Teachers in this study could not explain why these PD activities were necessary and how they might have been helpful to their teaching practice. They did not seem to have a thorough understanding of how to reflect on their own teaching and critique others' teaching practice. As Bransford, Brown, and Cocking (1999) identified, teachers' initial understanding is crucial to help them "grasp the new concepts and information that are taught" and if not, teachers "may learn them superficially and revert to their preconceptions in real situations" (p. 10). The imposition of policy initiatives can make teachers feel threatened and return to their existing practice (Smit, 2003). Smit supported Morimoto's (1973) argument that teachers did not have enough time "to understand and to affirm the new learning as something desirable, and as something of our own choosing” (p. 225). In this study experienced EFL teachers' attitudes towards new policy initiatives were negative and so they avoided participating in PD that supported those initiatives.

In addition to in-school PD that conflicted with the teacher culture, the requirement the rule element in CHAT - that teachers participate in in-school PD led teachers to follow the rule but only nominally. Teachers created a different identity for open-class to avoid negative evaluation from their peers (Mackenzie, McShane, \& Wilcox, 2007). This was a socially constructed self to protect themselves from revealing their authentic teaching ability. What was revealed in open-class might be different from their usual teaching practice. In addition, they believed that "poorly framed feedback" in discussion was not helpful in improving teaching practice (Hendry \& Oliver, 2012, Conclusion, para. 1). Although Gosling (2005) contends that peer observation can increase the quality of teaching, it is important for the observers to have an understanding of how to critique and how to give feedback. The findings from my study are congruent with Cosh's (1999) study that learning from peer observation was not genuine as participants did not want to offend their counterpart. This did not give teachers a chance to reflect on their teaching practice and did not make the link to 
learning (Cosh, 1999). For teachers in this study, the lack of useful feedback received during in-school PD sessions meant that they did not engage in learning about their own practice.

Although in-school PD has characteristics of effective PD such as sharing and inquiring into teaching practice (Borko et al., 2010), in-school PD experienced by these experienced EFL teachers in South Korea was not effective. This highlights that there is no one-size-fits-all PD and contextual factors, especially the unique teacher culture in the case of South Korea, must be taken into account when designing PD.

Ironically, these experienced EFL teachers were caught between the value of their immersion in a stagnant teacher culture and the value they accorded newly qualified teachers. These teachers showed complex responses - they followed the practices of the community they belonged to and did not want any change in their existing practice. At the same time, they valued newly qualified teachers and wanted to learn from their teaching practices which seemed concurrent with societal expectations for English teaching. As a result, they valued newness but rarely practiced it in their own teaching.

The pervading isolated and stagnant teacher culture within which these experienced EFL teachers worked, led them to become increasingly passive over the course of their careers as they were acculturated into the community, with the notable exception of Kang.

\subsubsection{Tension from conflicting goals and lack of support from policy and school}

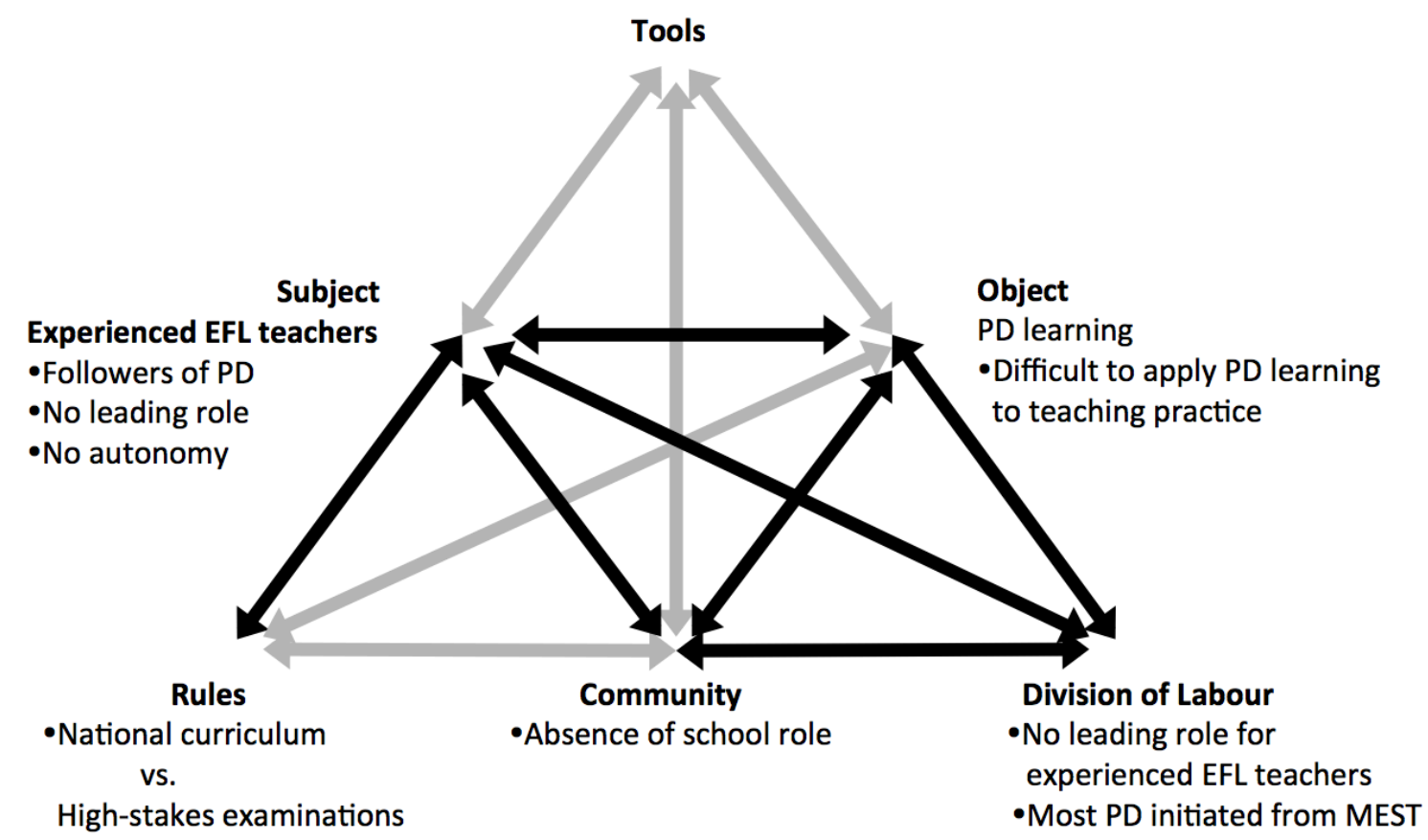


Figure 5. Tension from conflicting goals and lack of support from policy and school in the activity system of experienced EFL teachers' PD experience.

The PD goals resulting from the national curriculum and the participating teachers' experience-driven exam-focussed teaching goals were conflicting rules, simultaneously imposed upon experienced EFL teachers. This conflict was exacerbated by the absence of a school leadership role for experienced teachers in the community element, and an uneven division of labour down the hierarchy from the PD providers - MEST and SMOE - to schools and then to teachers. These three elements of conflicting rules, a dysfunctional community, and an uneven division of labour had a negative impact on the subject. That is, these experienced EFL teachers were regarded as followers of policy; they were situated in a condition where they could not employ their autonomy; and they were rarely designated a leading role. This inhibited these experienced EFL teachers from applying their PD learning to their teaching practice (see Figure 5).

Lack of support from policy and school, coupled with experienced EFL teachers' confusion from trying to reconcile two conflicting goals resulted in a sense that experienced EFL teachers did not hold a significant place in the education system hierarchy. Although teachers play important roles in the educational system as agents who take charge of students' learning on the front line (Hattie, 2003; OECD, 2005), this study shows that the PD providers did not recognise the contributions of schools and teachers appropriately, through the distribution of labour.

These experienced EFL teachers perceived that the PD providers did not seem to understand what teachers wanted from PD. Despite the importance of identifying teachers' PD needs in order to improve their teaching practice (Black, Harvey, Hayden, \& Thompson, 1994), PD providers tended to anticipate what teachers might need in the classroom. This is in line with Moeini's (2008) assertion that conducting a teachers' needs analysis as the first step in designing PD was usually neglected. Because their needs were ignored, the experienced EFL teachers in this study perceived themselves as followers expected to accept what they were told to do without expressing their true PD requirements. Hjelle's (2001) study of elementary school teachers also drew a similar finding that teachers were asked to accept changes with no regard for their actual needs.

This distribution of labour is consistent with a rigid hierarchy in the South Korean educational system (Kim, 2005). Whilst PD providers decided what to include in PD, teachers were obliged to follow their suggestions as a mandatory rule. As a result of PD 
providers limiting their role to offering PD and not including teachers' perspectives on their PD needs, teachers tended to take PD in order to fulfil the requirements for PD credits rather than to improve their teaching practice. These findings suggest that PD participation should not be the only measure for judging PD effectiveness.

Although Blanchard (2006) argues that "effective organisational leadership is more about managing the journey of change than announcing the destination" (p. 205), how to achieve PD learning was left to individual teachers. Policymakers assumed that teachers would apply PD learning in their classroom and this view reflects the traditional approach of PD, which does not guarantee success (Waldron \& McLeskey, 2010). That is, teachers are solely responsible for applying PD learning in their classroom teaching. However, especially in the isolated and stagnant teacher culture shown in this study, it is difficult to implement and sustain new PD learning into teaching practice without external support from policy such as follow-up PD. This is unsurprising given Smit's (2003) study of teachers' emotional responses to policy change which illustrated that policy initiatives were not simply received and applied in teachers' teaching practice. During those times, teachers felt vulnerable (Guskey, 2002), particularly because there was no follow-up PD. This is congruent with Rust and Dalin's (1990) argument that follow-up PD components are important to help teachers implement and sustain their PD learning as new changes take time to be implemented thoroughly in teachers' practice through trial and error (Dass, 1998).

In this study, it was evident that the PD providers did not consider what happened to teachers after they had completed their PD programme. This may have had an influence on the development of conflicting goals for teachers. This separation of goals has also been found in other countries and considered as an obstacle hindering improvement of teaching practice (Hu, 2005; Menking, 2001; Yan \& He, 2012). In this study, the existence of these parallel goals - the national curriculum and the high-stakes examination - diverted teachers' efforts and made them disregard PD and prioritise achieving classroom teaching goals. From the document analysis it was evident that the focus of PD was mostly to improve their English skills and to engage teachers to prepare for teaching CLT. On the other hand, teachers' interviews revealed that their teaching in the classroom was significantly different from what was covered in the PD. This finding supports Silver and Steele's (2005) contention that immediate classroom priorities outweigh policy goals. PD providers did not recognise teachers' confusion and struggle arising from these divergent goals. Moreover, teachers, rather than PD providers, are the subjects likely to be blamed if implementing PD learning in teaching practice is not successful. It would be easy for outsiders to misconstrue the situation 
and assume that the experienced EFL teachers are failing to take advantage of effective PD programmes offered by PD providers.

In the South Korean context, in-school PD was initiated and designed by PD providers, not by teachers. Furthermore, their approach to developing and implementing PD appeared to limit the professional autonomy of experienced EFL teachers, thus inhibiting these "teachers' willingness, capacity and freedom to take control of their own teaching and learning" (Huang, 2005, p. 4). Enabling the development of professional autonomy may be crucial for experienced EFL teachers to value their own teaching expertise and to accept their role as leaders within their schools. Moreover, experienced EFL teachers were not invited to contribute to the PD design process as co-planners although such a role would allow experienced EFL teachers to develop their professional autonomy by showing their expertise and expressing their professional opinions (Hjelle, 2001).

The SMOE's power also restricted the autonomy of individual schools (Kim, 2005). Although much literature deals with the importance of schools using their autonomy to develop contextually relevant school-based PD (Meier, 1995; Timperley et al., 2007), schools in South Korea play a minor role in implementing PD initiatives. PD initiated by a school was almost unknown in this study and schools did not appear concerned about their teachers' PD participation other than that they met requirements to complete a minimum number of hours. Without schools playing an active role in the provision and support of PD, these experienced EFL teachers did not perceive their school as offering a helping hand for improving their teaching practice - a significant community element in the activity.

These teachers felt it was difficult to apply their PD learning to their teaching practice due to the competing goals of implementing new initiatives alongside the pressure to prepare students for the national examination. In addition, teachers' feedback on the difficulty of applying their PD learning was not reflected back to policymakers.

\subsubsection{Nurtured passivity}




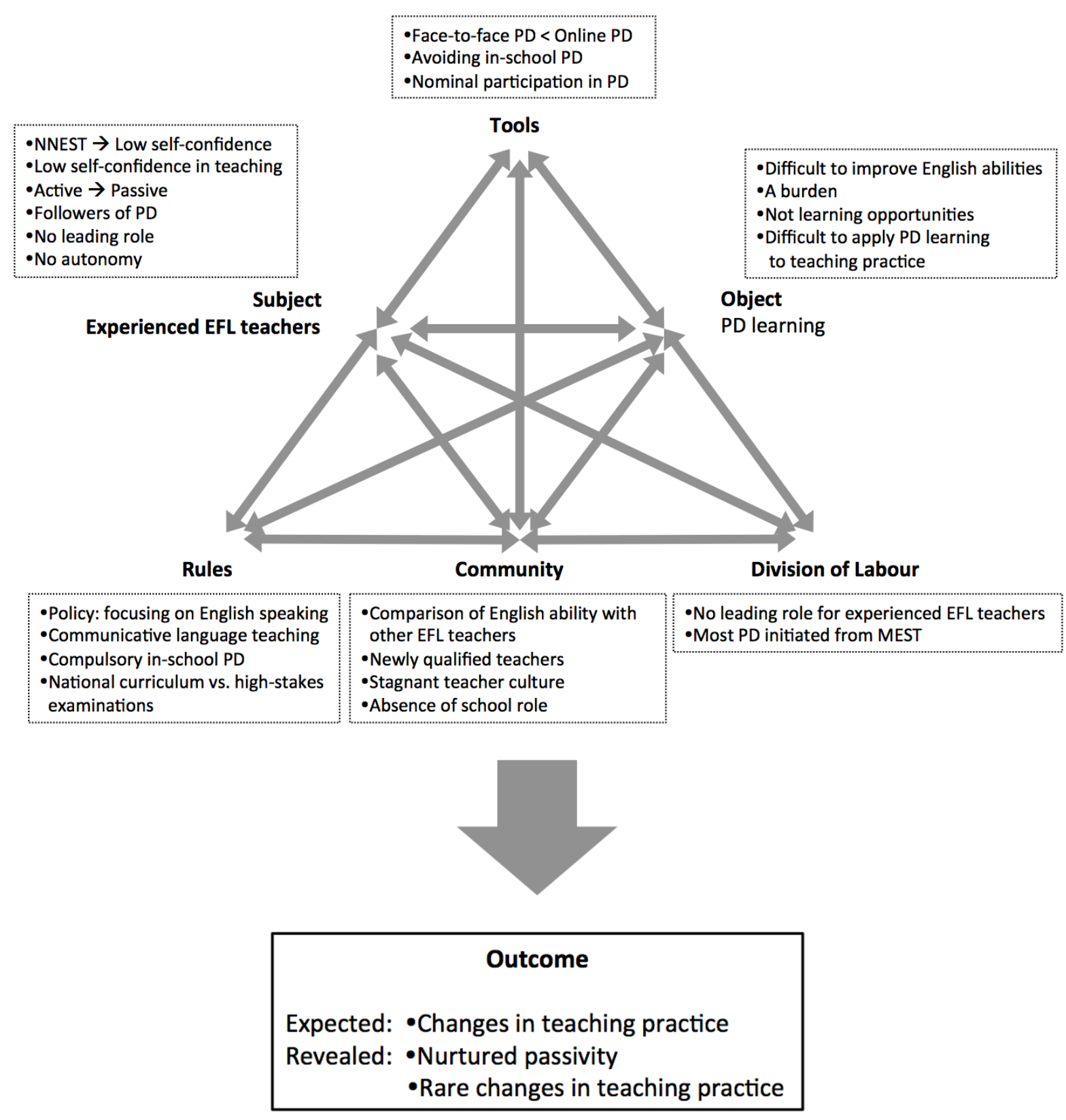

Figure 6. Outcome in the activity system of experienced EFL teachers' PD experience.

Figure 6 shows that the influences from the elements in the activity system of the experienced EFL teachers' PD experience, discussed throughout the previous sections of this chapter. The complex relationships between the elements in this activity system can be further explained through Engeström's (1987) multilevel contradictions. Engeström proposed four types of contradictions based on the scope of conflicts from primary to quaternary with the first two levels of contradictions highlighted in this study. A primary contradiction occurs within a single element in the activity system. For example, the tension between the goals from the national curriculum and from the exam-focussed teaching goals caused a primary 
contradiction within the element of rules. A secondary contradiction occurs between elements in the activity system. For example, a conflict between the subject element and the community element was revealed in the section 5.2.2 where it was highlighted that these experienced EFL teachers perceived newly qualified teachers as a different group of teachers. A secondary contradiction between the subject element and the rules element was also evident in these experienced EFL teachers' nominal engagement in in-school PD, as discussed in section 5.2.3. The clash between stagnant culture and the nature of in-school PD also showed a secondary contradiction between the element of community and of tools (see section 5.2.3).

The influence both from the elements and the primary and secondary levels of contradictions in the activity system showed that contextual factors hugely affected these experienced EFL teachers' PD experience and their teaching practice. The effect of these contextual factors on experienced EFL teachers can be described as "nurtured passivity": these teachers' passivity was learned and nurtured by diverse factors - the rules, community, division of labour, and tools in the activity - around them.

Experienced EFL teachers in this study became assimilated into a teacher culture which discouraged collaboration with other colleagues and the adoption of new methods. The elements of the rules, community, and division of labour had a negative impact on their selfconfidence as experienced EFL teachers. Their lowered self-confidence was partly contributed to passivity. This finding is supported by Lamie's (2004) contention that a lack of self-confidence results in resistance to change and the notion of passivity of teachers shown in this study is consistent with resistance to change noted elsewhere (Stivers \& Cramer, 2009; Williamson \& Blackburn, 2010).

Taking PD did not help these experienced EFL teachers break out of their passivity since, without support from the PD providers - MEST and SMOE - and their school, their PD learning could not be sustained enough to increase their self-confidence. They, again, retreated into the culture of isolation to become complacent, which led to further passivity, congruent with Saraswathi's (1991) assertion that resistance intensifies resistance, especially without sufficient support (Nodeson, Beleya, Raman, \& Ramendran, 2012). With few positive factors, a cycle of nurtured passivity continued in the activity of these experienced EFL teachers' PD experience. Knight (2009) describes this as an "attempt, attack, and abandon cycle" (p. 512). In this cycle, teachers' attempts to implement a new practice are not successful because of the lack of support. Then the practice is attacked by the unsuccessful results and regarded as ineffective. As teachers have no sufficient reason to hold the practice, 
they then abandon it. Knight points out that it is difficult to see sustained change in this cycle, offering an explanation why the effect of PD on these teachers' practice was not substantial in the South Korean context.

The findings from this study also revealed that EFL teacher PD in South Korea is attempting to change its traditional approach to a reformed approach to PD. Teacher PD in South Korea seems to advocate the reformed approach to professional learning; MEST and SMOE have tried to include reform types of PD courses and programmes, which were evident from the document analysis. However, the positioning of teachers as passive recipients of $\mathrm{PD}$ are congruent with the traditional approach to $\mathrm{PD}$. This traditional approach to PD may have offered "a quick fix for teachers' inadequacies and incompetence" (Dass \& Yager, 2009, p. 100) but could not bring about fundamental changes in these experienced EFL teachers' teaching practice.

\subsection{Limitations}

There are some limitations to this study. First, findings from this study cannot be generalised as this study employed qualitative methodology. The five participants were recruited through the researcher's network within one regional office of Education and were chosen according to their willingness to participate in this study. This process may have skewed the data gathered.

Another limitation is that this study is based on teachers' self-report. Teachers' interviews were inevitably a main source of data collection because this study examined the impact on participants' teaching practice of their PD experience over time, and not at a specific time or through participation in a specific programme. Although documents were collected as a way of strengthening the trustworthiness of this study, the fact that findings were subject to teachers' perceptions without support from observation should be considered. However, an in-depth and rich description of teachers' inner voice has emerged because teachers' perceptions were fully explored, which is rare in the field of teacher PD research in South Korea.

Beyond these methodological issues, my teaching background as an EFL teacher in South Korea could be construed as another limitation since what the participating teachers talked about in the interviews resonated with me. I acknowledge the influence of my teaching background on this study and I attempted to use my own experience as a tool for understanding the participants' perceptions during the interviews and data analysis. 


\subsection{Implications}

There are a number of implications arising from this study. Those implications are: (a) recommendations for system-level changes, (b) PD design focusing on experienced EFL teachers' needs and strengths, (c) support from policy and school to create a positive PD learning environment, and (d) recommendations for experienced EFL teachers. The following sections outline the details of each implication.

\subsubsection{Changes at a system level}

The perspective of CHAT revealed that every element within the activity affected teachers' PD experience negatively. Moreover, the holistic exploration through CHAT (Roth \& Lee, 2007) indicated that addressing only one element might not lead to changes in the whole system as the elements were intertwined with each other. Congruent with Blumenfeld, Fishman, Krajcik, Marx, and Soloway's (2000) assertion that a successful innovation considers the aspects related to the innovation concurrently, a system-level approach to deal with all elements simultaneously would be needed in order to bring positive changes in experienced EFL teachers' practice. CHAT suggests that activity systems are dynamic and are able to be transformed through tensions and contradictions (Engeström, 2001). Therefore, tensions revealed through this study may motivate changes to the structures of PD in order to bring about changes in teaching practice. Further, addressing these tensions may contribute to a paradigm shift from PD as training to PD as professional learning in South Korea.

\subsubsection{Implications for PD design}

It is important to address how to improve experienced EFL teachers' limited selfconfidence before addressing how to raise their actual English ability. If policymakers, schools, and EFL teachers can recognise the strengths of NNESTs including their strengths as teachers within their school context, teachers' lowered self-confidence might be increased. For this, PD courses need to help NNESTs build upon these strengths. This means that PD designed for early career and more experienced teachers may need to be differentiated. Once their level of self-confidence has been boosted through these PD activities, experienced EFL teachers may then perceive PD focused on English ability as a learning chance and be more willing to reveal their weakness in English ability in PD courses. Creating a relaxed atmosphere for PD could also help them focus on learning rather than comparing themselves with other teachers. 
Given that experienced EFL teachers in South Korea rarely engage in reflection, PD activities incorporating building reflection and inquiry skills could be beneficial. This may help these teachers revisit their existing beliefs and current teaching practices which have developed over many years (Richards \& Farrell, 2005). For such PD to be effective, these teachers will need to understand the rationale before any introduction to reflection strategies. PD incorporating inquiry and reflection is also significant for experienced teachers because such teachers can be reinvigorated as teachers by trying new methods and materials and taking risks (Chisman \& Crandall, 2007).

Such an approach could help equip teachers with tools to develop their teaching practice independently. Through acknowledging their deeply rooted beliefs, experienced EFL teachers may be able to realise changes to be made in their own teaching. Exercising reflection and inquiry in one's teaching practice may also prompt these teachers to explore new opportunities such as seeking learning opportunities from PD voluntarily. Constant reflection on their own teaching practice might encourage isolated teachers to move beyond their familiar routines (Tsui, 2003). Then, they may aspire to becoming an expert in teaching rather than an experienced non-expert (Tsui, 2003).

The current concept of customised PD in South Korea could be improved by conducting a thorough PD needs analysis with experienced EFL teachers. This may find specific English language areas to be tackled enabling PD courses to be more specialised and fine-tuned. Such PD may be more attractive to experienced EFL teachers and result in more substantial learning compared to PD prepared for the general population of EFL teachers. Teachers' feedback, as another form of needs analysis, could provide insights to improve the PD courses and inform the design of successive PD courses.

It could be useful to expand the scope of open-class to include more diverse topics such as classroom management. With a variety of topics to choose from, experienced EFL teachers may be more likely to demonstrate their accumulated teaching expertise in student discipline and classroom management with confidence. Then these teachers may perceive open-class as a learning opportunity to improve their own teaching practice for students' learning rather than worrying about their English speaking ability. Consequently their teaching expertise in generic teaching abilities is likely to be recognised and valued.

\subsubsection{Implications for policy and school}


MEST may need to help teachers understand the rationale of in-school PD initiatives and prepare them thoroughly before implementing in-school PD. Workshops providing information about PD initiatives and providing supplementary materials and guidelines may be of particular use. The foundation of these plans would be to help teachers have a positive attitude toward new PD initiatives rather than imposing further compulsory PD on them. In the case of open-class, developing awareness of benefits of open-class may give teachers room to think about how to use open-class more purposefully to improve their teaching practice. Alongside this, PD courses about how to conduct classroom observations and how to give constructive feedback to colleagues may support more effective open-class activities. If teachers understood and were well-prepared for new policies, they may be more willing to participate in in-school PD.

In the case of PD outside of schools, a thorough follow-up PD from MEST, in collaboration with schools, could help teachers to sustain PD gains. This may help MEST recognise potential issues raised by individual teachers while implementing PD learning and identify possible solutions appropriate for teachers' own context together with the teachers. Ultimately follow-up PD could be a way to transform PD courses for the general teacher population into customised PD courses for individual teachers.

It is recommended that policymakers present clear goals for teachers' PD participation. It is important to take account of teachers' struggles arising from the tension between the PD goals and exam-oriented classroom teaching goals so that teachers are not placed in a position where electing exam-oriented classroom teaching goals is in opposition to adhering to the national curriculum. Aligning PD and curriculum initiatives with the prevailing examination culture may give teachers a coherent vision to follow.

Teachers' participation in PD is unlikely to lead to improvement in teaching practice unless classroom needs are acknowledged in the design of PD activities. This also means that policymakers would be advised to recruit teachers into the PD design process. PD activities designed by practising teachers are likely to appeal to teachers and thus affect teachers' practice more significantly.

If MEST made efforts to distribute leadership roles to experienced EFL teachers within schools, these teachers could have more chances to demonstrate their professional autonomy and their value as experienced teachers in school. They may feel rewarded and recover self-confidence by leading other teachers as experienced teachers. Creating accountability as leaders may also help experienced EFL teachers overcome their nurtured passivity. 
However, forcing experienced EFL teachers to take a leadership role may not bring substantial changes. The atmosphere of valuing experienced EFL teachers' long experience might be a prerequisite to encourage them to take a leading role voluntarily. In-school PD could facilitate this by giving them chances to show their strong points from their accumulated teaching experience. Then their self-confidence could be increased and consequently they would become leaders naturally within their teacher community. By equipping experienced EFL teachers with well-planned in-service PD activities to support their leading role, they could lead collaboration and mutual learning among teachers including newly qualified teachers.

Schools could help teachers' PD learning by inquiring how to support their teachers. Creating an atmosphere for their teachers to explore what the teachers learned from PD autonomously with enough time may contribute to bring about changes to teachers' teaching practices. In the absence of school support perceived by experienced EFL teachers in South Korea, it might be a wise move for schools to recognise and use the expertise of experienced teachers in some facets of teaching. If their leadership was supported by their schools, it could create congeniality among teachers within schools. Schools may also be able to engage in their teachers' PD learning and initiate school-led PD for their teachers.

\subsubsection{Implications for experienced EFL teachers}

It could be beneficial for experienced EFL teachers to become aware of their passivity and to make an effort to engage in new learning. For example, their valuing newly qualified teachers' ability may trigger them to improve their teaching. Therefore it would be recommended that experienced teachers who are unfamiliar with reflection and inquiry to begin to use strategies such as Choi's use of the video clip of her own teaching in this study, to reflect on their own teaching, given the benefits of these skills were evident in the literature (Farrell, 2013; Tsui, 2003). If teachers could become accustomed to reflecting on their teaching practice, this could help them give intrinsic motivation to take PD rather than just to accumulate PD credits. This may need support from policy and schools as discussed in the previous section. However, experienced EFL teachers' own willingness to change may be also crucial. For example, whilst giving teachers time to understand the rationale behind open-class may be a prerequisite, it might be not be enough to bring about successful learning because open-class is a MEST-initiated PD. In this circumstance, teachers could think about how to maximise PD learning by themselves. Through sharing their opinions and experiences 
of open-class, all EFL teachers within a school may set aims for open-class based on the consideration of their students at their own school. Having a common goal could also give them a reason to work collaboratively. If experienced EFL teachers could lead this process, their leading role would also be highlighted and valued.

\subsection{Areas for future research}

Potential areas for future research include longitudinal research to track experienced EFL teachers' changes in teaching practice through, for example interviewing and observing their changes at regular intervals such as after 5, 10, 15, and 20 years of teaching. The data from the longitudinal research may suggest which areas of PD have most effect on teaching practice and which areas of PD needed to be more focussed on in the South Korean context.

As this study focussed mainly on teachers' perceptions, combining classroom observations of participating teachers in future research would have the potential to examine actual changes. Moreover, research on the same topic with teachers of other subjects and other teacher groups in a different context could also provide interesting findings to compare and contrast with the findings of this study.

Research using the theoretical framework of CHAT provides another area for future research in teacher PD. As this study focussed on the activity system of experienced EFL teachers, the activity system of policy and school related to PD and teachers' changes in teaching practice respectively are other potential areas of interest. This may provide a more balanced view and holistic interpretation by looking into the whole system of teacher PD.

Lastly, as this study identified the complex relationship among elements in CHAT, indepth studies on each element revealed from this study such as teacher culture or teacher leadership in the South Korean context could open another possibility for future research. There is also scope for an evidence-based examination of the internal and external nature of the attributions in relation to changes or lack of changes following EFL teachers PD programmes.

\subsection{Summary}

In this chapter the framework of CHAT was used to discuss the findings. Emphasis on English speaking and fear of evaluation through comparison lowered these teachers' selfconfidence. They could not value themselves as NNEST and their diverse experiences of PD could not help them to overcome their feeling of inferiority compared to NEST. 
New English language teaching methods were unfamiliar to these experienced EFL teachers. Consequently, this led these experienced EFL teachers to perceive newly qualified teachers as ideal teachers of English. The nature of isolation and stagnation in the teacher culture made experienced EFL teachers become more passive. As this teacher culture was in conflict with the initiatives for in-school PD, these teachers tended to avoid taking in-school PD and did not link in-school PD to a way of enhancing their teaching practice.

Two different goals imposed on teachers made it difficult for these teachers to take PD with a clear vision of how it would help improve their practice. A lack of support in terms of needs analysis and follow-up PD did not help these teachers commit to ongoing PD or sustain their PD learning in their teaching practice. The lack of support to develop professional autonomy and to take a leadership role resulted in nominal adherence to inschool PD requirements.

CHAT revealed the negative confluence of several contextual factors on teachers' teaching practice; teachers' passivity was nurtured and repeated in the activity system of experienced EFL teachers' PD experience. More importantly, this study showed that the relationship among contextual factors was complex in experienced EFL teachers' PD experience and teaching practice.

Implications arising from this study suggest that PD design would need to focus more on how to improve experienced EFL teachers' self-confidence and take into consideration of their long teaching experience. Another suggestion is that the regional office of education should ensure enough time is given for preparing and implementing in-school PD. It is also recommended that the regional office of education should trust these teachers' capacity in some facets of teaching areas and distribute leadership to them. Schools would need to take a more active role in order to support teachers' PD learning. Lastly practitioners would also need to be aware of their own potential nurtured passivity and make an effort to move beyond this. Limitations of this study and potential areas for future research were also discussed. 


\section{References}

Almarza, G. (1996). Student foreign language teachers' growth. In D. Freeman \& J. C. Richards (Eds.), Teacher learning in language teaching. Cambridge: Cambridge University Press.

Anderson, J. (1993). Is a communicative approach practical for teaching English in China? Pros and cons. System, 21, 471-480.

Andrews, D., \& Lewis, M. (2002). The experiences of a professional community: teachers developing a new image of themselves and their workplace. Educational Research, 44(3), 237-254.

Ball, D. L., \& Cohen, D. K. (1996). Reform by the book: What is - or might be - the role of curriculum materials in teacher learning and instructional reform? Educational Researcher, 25(9), 6-8.

Ban, J-C. (2012), 교원 성과상여금 제도의 효과성 분석 및 지급방안 연구 [The effect of performance payment system for teachers]. Seoul: Ministry of Education, Science, and Technology.

Bereiter, C., \& Scardamalia, M. (1993). Surpassing ourselves: An inquiry into the nature and implications of expertise. Chicago: Open Court.

Black, D. R., Harvey, T. J., Hayden, M. C., \& Thompson, J. J. (1994). Professional development for teachers. International Journal of Educational Management, 8(2), 27-32.

Blanchard, K. (2006). Leading change at a higher level. New Jersey: Pearson Education Ltd. Blumenfeld, P., Fishman, B. J., Krajcik, J. S., Marx, R. W., \& Soloway, E. (2000). Creating usable innovations in systemic reform: Scaling up technology-embedded projectbased science in urban schools. Educational Psychologist, 35(3), 149-164.

Borg, S. (2003). Teacher cognition in language teaching: A review of what language teachers think, know, believe and do. Language Teaching, 36(2), 81.

Borko, H. (2004). Professional development and teacher learning: Mapping the terrain. Educational Researcher, 33(8), 3-15. doi:10.3102/0013189X033008003

Borko, H., \& Putnam, R. (1996). Learning to teach. In D. Berliner \& R. Calfee (Eds.), Handbook of educational psychology. New York: Macmillan.

Borko, H., Davinroy, K. H., Bliem, C. L., \& Cumbo, K. B. (2000). Exploring and supporting teacher change: Two third-grade teachers' experiences in a mathematics and literacy staff development project. The Elementary School Journal, 100(4), 273-306. 
Borko, H., Jacobs, J., \& Koellner, K. (2010). Contemporary approaches to teacher professional development. In P. Peterson, E. Baker, \& B. McGaw (Eds.), International encyclopedia of education ( $3^{\text {rd }}$ ed., pp. 548-556). Oxford, England: Elsevier.

Braine, G. (1999). Non-native educators in English language teaching. Mahwah, NJ:

Lawrence Erlbaum Associates.

Bransford, J., Brown, A., \& Cocking, R. (1999). How people learn: Brain, mind, experience, and school. Washington, DC: National Academy Press.

Broad, K., \& Evans, M. (2006). A review of literature on professional development content and delivery modes for experienced teachers. Toronto: Canadian Ministry of Education.

Burden, P. (1990). Teacher development. In W.R. Houston (Ed.), Handbook of research on teacher education (pp. 311-328). New York, New York: Macmillan.

Cheah, Y. M. (1997). Shaping the classrooms of tomorrow: Lessons from the past. In G. M. Jacobs (Ed.), Language classrooms of tomorrow: Issues and responses. RELC Anthology Series 38, (pp.16-35) Singapore: SEAMEO Regional Language Centre.

Cheung, Y. L. (2013). The impact of an in-service professional development course on writing teacher attitudes and pedagogy. Journal of Pedagogic Development, 3(1), 11-16.

Chew, J. O. A., \& Andrews, D. (2010). Enabling teachers to become pedagogical leaders: Case study of two IDEAS schools in Singapore and Australia. Educational Research for Policy and Practice, 9(1), 59-74.

Chisman, F. P., \& Crandall, J. A. (2007). Passing the torch: Strategies for innovation in community college ESL. New York, NY: Center for Advancement of Adult Literacy. Retrieved from http://www.caalusa.org/eslpassingtorch226.pdf

Cochran-Smith, M. (2001). Reforming teacher education: Competing agendas. Journal of Teacher Education, 52(4), 263-265.

Cochran-Smith, M. (2004). The problem of teacher education. Journal of Teacher Education, 55(4), 294-299.

Coolahan, J. (2002). Teacher education and the teaching career in an era of lifelong learning (OECD Education Working Paper No. 2). Paris: Education Directorate, OECD. Retrieved from http://www.olis.oecd.org.helicon.vuw.ac.nz/OLIS/2002DOC.NSF/LINKTO/EDUWKP(2002)2. 
Coolahan, J., Santiago, P., Phair, R., \& Ninomiya, A. (2004). Attracting, developing and retaining effective teachers, country note: Korea. Paris: OECD. Retrieved from http://www.oecd.org/edu/teacherpolicy

Cosh, J. (1999). Peer observation: A reflective model. ELT Journal, 53, 22-27.

Creswell, J. W. (2005). Educational research: Planning, conducting, and evaluating quantitative and qualitative research. New Jersey: Pearson Prentice Hall.

Creswell, J. W. (2007). Qualitative inquiry and research design: Choosing among five approaches. Thousand Oaks: Sage Publications.

Darling-Hammond, L., \& Bransford, J. (Eds.). (2005). Preparing teachers for a changing world: What teachers should learn and be able to do. San Francisco, CA: JosseyBass.

Darling-Hammond, L., Wei, R. C., Andree, A., Richardson, N., \& Orphanos, S. (2009). Professional learning in the learning profession: A status report on teacher development in the United States and abroad (Technical Report). Dallas, TX: National Staff Development Council.

Dass, P. M. (1998, April). Professional development of science teachers: Results of using the Iowa Chautauqua model in Collier Country, Florida. Paper presented at the National Association for research in Science Teaching Annual Conference, San Diego, USA.

Dass, P. M., \& Yager, R. E. (2009). Professional development of science teachers: History of reform and contributions of the STS-based Iowa Chautauqua program. The Science Education Review, 8, 99-111.

Denscombe, M. (2007). The good research guide: For small-scale social research projects. New York: Open University Press.

Denzin, N. K., \& Lincoln, Y. S. (2011). The SAGE handbook of qualitative research. Thousand Oaks: Sage Publications.

Desimone, L. (2009). Improving impact studies of teachers' professional development: Towards better conceptualizations and measures. Educational Researcher, 38(3), 181-199. doi: 10.3102/0013189X08331140.

Desimone, L. M., Porter, A. C., Garet, M. S., Yoon, K. S., \& Birman, B. F. (2002). Effects of professional development on teachers' instruction: Results from a three-year longitudinal study. Educational Evaluation and Policy Analysis, 24(2), 81-112. 
Diaconu, D. V., Radigan, J., Suskavcevic, M., \& Nichol, C. (2012). A multi-year study of the impact of the rice model teacher professional development on elementary science teachers. International Journal of Science Education, 34(6), 855-877.

Douglas, A. S. (2011). Learning on the job: A cultural historical activity theory approach to initial teacher education across four secondary school subject departments. Ethnography and Education, 6(2), 195-211. doi:10.1080/17457823.2011.587359

Duffy, G., \& Roebler, L. (1986). Constraints on teacher change. Journal of Teacher Education, 37(1), 55-58.

Engeström, Y. (1987). Learning by expanding: An activity-theoretical approach to developmental research. Helsinki: Orienta-Konsultit.

Engeström, Y. (1999). Activity theory and individual and social transformation. In Y. Engeström, R. Miettinen, \& R. Punamäki (Eds.), Perspectives on activity theory (pp.19-38). New York, NY: Cambridge University Press.

Engeström, Y. (2001). Expansive learning at work: Toward an activity theoretical reconceptualization. Journal of Education and Work, 14(1), 133-156. doi:10.1080/13639080123238

Eros, J. (2013). Second-stage music teachers' perceptions of their professional development. Journal of Music Teacher Education, 22(2), 20-33.

Eslami, R. Z. (2008). Teachers' sense of self-efficacy, English proficiency, and instructional strategies: A study of nonnative EFL teachers in Iran. TESL-EJ, 11(4).

Farrell, T. S. C. (2013). Reflecting on ESL teacher expertise: A case study. System, 41(4), 1070-1082.

Feiman-Nemser, S. (2003). What new teachers need to learn. Educational Leadership, 60, 25-29.

Fennema, E., Carpenter, T. P., Franke, M. L., Levi, L., Jacobs, V. R., \& Empson, S. B. (1996). A longitudinal study of learning to use children's thinking in mathematics instruction. Journal for Research in Mathematics Education, 27(4), 403-434.

Fessler, R., \& Christensen, J. C. (1992). The teacher career cycle: Understanding and guiding the professional development of teachers. Needham Heights, MA: Allyn \& Bacon.

Franke, M. L., Carpenter, T. P., Levi, L., \& Fennema, E. (2001). Capturing teachers' generative change: A follow-up study of professional development in mathematics. American Educational Research Journal, 38(3), 653-689. 
Freeman, D. (1992). Language teacher education, emerging discourse and change in classroom practice. In J. Flowerdew, M. Brock, \& S. Hsia (Eds.), Perspectives on second language teacher education (pp. 1-21). Hong Kong: Hong Kong City Polytechnic.

Freeman, D. (2001). Second language teacher education. In R. Carter \& D. Nunan (Eds.), The Cambridge guide to teaching English to speakers of other languages (pp. 72-79). Cambridge: Cambridge University Press.

Freeman, D. (2002). The hidden side of the work: Teacher knowledge and learning to teach. Language Teaching, 35, 1-13.

Fullan, M. (2007). The new meaning of education change. (3rd ed.). New York, NY:

Teachers College Press.

Furlong, J., \& Maynard, T. (1995). Mentoring student teachers. London: Routledge.

Ganser, T. (2000). An ambitious vision of professional development for teachers. NASSP Bulletin, 84(618), 6-12.

Garet, M. S., Porter, A., Desimone, L., Birman, B. F., \& Yoon, K. S. (2001). What makes professional development effective? Results from a national sample of teachers. American Educational Research Journal, 38(4), 915-945.

Gass, S. M., \& Mackey, A. (2006). Input, interaction and output: An overview. AILA Review, 19, 3-17.

Gatt, I. (2009). Changing perceptions, practice and pedagogy: Challenges for and ways into teacher change. Journal of Transformative Education, 7(2), 164-184.

Gess-Newsome, J. (2001). The professional development of science teachers for science education reform: A review of the research. In J. Rhoton \& P. Bowers (Eds.), Professional development planning and design (pp. 91-100). Arlington, VA: NSTA Press.

Glatthorn, A. A. (1984). Differentiated supervision. Alexandria, VA: Association for Supervision and Curriculum Development.

Glesne, C., \& Peshkin, A. (1992). Becoming qualitative researchers: An introduction. White Plains, N.Y: Longman.

Goldenberg, C., \& Gallimore, R. (1991). Local knowledge, research knowledge, and educational change: A case study of early Spanish reading improvement. Educational Researcher, 20(8), 2-14.

Goldschmidt, P., \& Phelps, G. (2007). Does teacher professional development affect content and pedagogical knowledge: How much and for how long? Economics of Education 
Review, 29(3), 432-439.

González, A., Montoya, C., \& Sierra, N. (2002). What do EFL teachers seek in professional development programs? Voices from teachers. IKALA, 7, 29-50.

Gosling, D. (2005). Peer observation of teaching: Implementing a peer observation of teaching scheme with five case studies (SEDA Paper 118). London: Staff and Educational Development Association.

Guskey, T. R. (2002). Professional development and teacher change. Teachers and Teaching, 8(3), 381-391. doi:10.1080/135406002100000512

Guskey, T. R. (2003). What makes professional development effective? The Phi Delta Kappan, 84(10), 748-750.

Gyeonggi-Do Education Information Archives. (2013). 자격증 과목별 퇴직 교원수

[Statistics for retired teachers by subject] Retrieved from http://www.goeia.go.kr/statistics/g04020201.asp\#url

Ha, M-A., \& Min, C-G. (2008). EFL 상황에서의 영어교사의 전문성 고찰 [The constituents of English teachers' professional competency in EFL context]. 영어교과교육, 7(2), 87-110.

Hall, G. E., \& Hord, S. M. (2001). Implementing change: Patterns, principles, and potholes. Needham Heights, MA: Allyn and Bacon.

Harry, B. (1996). These families, those families: The impact of research identity on the research act. Exceptional Children, 64, 292-300.

Hattie, J. (2003, October). Teachers make a difference: What is the research evidence? Paper presented to Australian Council for Educational Research Annual Conference, Melbourne.

Hawley, W.D., \& Valli, L. (1999). The essentials of effective professional development: A new consensus. In L. Darling-Hammond \& G. Sykes (Eds.), Teaching as the learning profession: Handbook of policy and practice. San Francisco: Jossey-Bass Publishers.

Hayes, D. (2009). Non-native English-speaking teachers, context and English language teaching. System, 37(1), 1-11. doi:10.1016/j.system.2008.06.001

Hendry, G. D., \& Oliver, G. R. (2012). Seeing is believing: The benefits of peer observation. Journal of University Teaching \& Learning Practice, 9(1). 
Hindin, A., Morocco, C. C., Mott, E. A., \& Aguilar, C. M. (2007). More than just a group: Teacher collaboration and learning in the workplace. Teachers and Teaching: Theory and Practice, 13(4), 349-376.

Hipp, K. K. \& Huffman, J. B. (Eds.). (2010). Demystifying professional learning communities: School leadership at its best. Lanham, MD: Rowman \& Littlefield Education.

Hitchcock, G., \& Hughes, D. (1995). Research and the teacher: A qualitative introduction to school-based research. London: Routledge.

Hiver, P. (2013). The interplay of possible language teacher selves in professional development choices. Language Teaching Research, 17(2), 210-227.

Hjelle, P. F. (2001). Reading between the lines: Teacher resistance to change (Doctoral dissertation). Retrieved from ProQuest Dissertations and Theses database. (UMI No. 3003638)

Hohn, M. D. (1998). Why is change so hard? Theories and thoughts about the organizational change process. Focus on Basics, 2, 1-8.

Hord, S. M. (2008). Evolution of the professional learning community. Journal of Staff Development, 29(3), 10-13.

Hord, S. M. (2009). Professional learning communities. Journal of Staff Development, 30(1), 40-43.

Hu, G. (2005). Contextual influences on instructional practices: A Chinese case for an ecological approach to ELT. TESOL Quarterly, 39(4), 635-660.

Huang, J. (2005). Teacher autonomy in language learning: A review of the research. Research Studies in Education, 3, 203-218.

Huberman, M. (2001). Networks that alter teaching: Conceptualizations, exchanges and experiments. In J. Soler, A. Craft, \& H. Burgess (Eds.), Teacher development: Exploring our own practice (pp. 141-159). London: Paul Chapman Publishing Ltd.

Huberman, M., \& Miles, M. (1984). Innovation up close. New York: Plenum.

Huling-Austin, L. (1992). Research on learning to teach. Journal of Teacher Education, 43(3), 173-180.

Hung, H-T., \& Yeh, H-C. (2013). Forming a change environment to encourage professional development through a teacher study group. Teaching and Teacher Education, 36, 153-165.

Igawa, K. (2008). Professional development needs of EFL teachers practicing in Japan and Korea. International Buddhist University Bulletin, 45, 431-455. 
Inbar-Lourie, O. (2001). Native and nonnative English teachers: Investigation of the construct and perceptions. (Unpublished doctoral dissertation). Tel Aviv University, Israel.

Ingvarson, L., Meiers, M., \& Beavis, A. (2005). Factors affecting the impact of professional development programs on teachers' knowledge, practice, student outcomes \& efficacy. Education Policy Analysis Archives, 13(10), 1-26.

Johnson, C. C. (2007). Effective science teaching, professional development and no child left behind: Barriers, dilemmas, and reality. Journal of Science Teacher Education, $18(2), 133-136$.

Johnson, C., Fargo, J., \& Kahle, J. B. (2010). The cumulative and residual impact of a systemic reform program on teacher change and student learning of science. School Science and Mathematics, 110(3), 144-159.

Karimi, M. N. (2011). The effects of professional development initiatives on EFL teachers' degree of self efficacy. Australian Journal of Teacher Education, 36(6). http://dx.doi.org/10.14221/ajte.2011v36n6.6

Katz, L. (1972). Developmental stages of preschool teachers. The Elementary School Journal, $73(1), 50-54$.

Kennedy, J. (1996). The role of teacher beliefs and attitudes in teacher behaviour. In G. T. Sachs, M. Brock, \& R. Lo (Eds.), Directions in second language teacher education (pp. 107-122). Hong Kong: City University of Hong Kong.

Killion, J., \& Harrison, C. (2006). Taking the lead: New roles for teachers and school-based coaches. Oxford, OH: National Staff Development Council.

$\mathrm{Kim}, \mathrm{J}-\mathrm{W}$. (2006). 최근 영어교육 분야의 연구방법, 연구성향 및 연구주제의 국제적 비교분석 [A comparative analysis of research studies in the TEFL journals: Focusing on research methodology, orientation, and topic]. 영어교육연구, 18(3), $141-154$.

Kim, K-S. (2005). Globalization, status political economy, and unsuccessful education reform in South Korea, 1993-2003. Education Policy Analysis Archives, 13(12), 126.

Kirkpatrick, T. A. (1984). The role of communicative language teaching in secondary schools: With special reference to teaching in Singapore. In B. K. Das (Ed.), Communicative language teaching (pp. 171-191). Singapore: Singapore University Press. 
Knight, J. (2009). What can we do about teacher resistance? The Phi Delta Kappan, 90(7), 508-513.

Krull, E., Oras, K., \& Sisask, S. (2007). Differences in teachers' comments on classroom events as indicators of their professional development. Teaching and Teacher Education, 23(7), 1038-1050.

Kubanyiova, M. (2006). Developing a motivational teaching practice in EFL teachers in Slovakia: Challenges of promoting teacher change in EFL contexts. TESL-EJ, 10(2), $1-17$.

Kumaravadivelu, B. (2006). Understanding language teaching: From method to post method. Mahwah, New Jersey: Lawrence Erlbaum Associates.

Kuutti, K. (1996). Activity theory as a potential framework for human-computer interaction research. In B. Nardi (Ed.), Context and consciousness: Activity theory and humancomputer interaction (pp. 17-44). Cambridge, Mass.: MIT Press.

Kwakman, K. (2003). Factors affecting teachers' participation in professional learning activities. Teaching and Teacher Education, 19(2), 149-170.

Lamie, J. (2004). Presenting a model of change. Language Teaching Research, 8(2), 115-142.

Laukkanen, R. (2008). Finnish strategy for high-level education for all. In N. C. Soguel \& P. Jaccard (Eds.), Governance and performance of education systems (pp. 305-324). Dordrecht, Netherlands: Springer.

Leadbetter, J. (2005). Activity theory as a conceptual framework and analytical tool within the practice of educational psychology. Educational and Child Psychology, 22(1), $18-28$.

Leander, K. M., \& Osborne, M. D. (2008). Complex positioning: Teachers as agents of curricular and pedagogical reform. Journal of Curriculum Studies, 40(1), 23-46.

Leithwood, K. A. (1992). The principal's role in teacher development. In M. Fullan \& A. Hargreaves (Eds.), Teacher development and educational change (pp. 86-103). Bristol, PA: Falmer Press.

Leont'ev, A. N. (1977). Activity and consciousness. Moscow: Progress Publishers.

Lerman, S., \& Zehetmeir, S. (2008). Face-to-face communities and networks of practicing mathematics teachers: Studies on their professional growth. In K. Krainer \& T. Wood (Eds.), Participants in Mathematics Teacher Education (pp. 133-153). Rotterdam, NL: Sense Publishers.

Leung, F. K. S. (2001). In search of an East Asian identity in mathematics education. Educational Studies in Mathematics. 47, 35-51. 
Li, D. (1998). “It's always more difficult than you plan and imagine": Teachers' perceived difficulties in introducing the communicative approach in South Korea. TESOL Quarterly, 32, 677-703.

Lim, J-H. (2013, November 14). 학교 성과급 위한 교사 직무연수 과열 양상 [An excessive tendency of teachers towards professional development courses for school performance payment]. News 1 Korea. Retrieved from http://cms.news1.kr/articles/1407265

Littlewood, W., \& Yu, B. (2011). First language and target language in the foreign language classroom. Language Teaching, 44(1), 64-77.

Llurda, E. (2004), Non-native-speaker teachers and English as an international language. International Journal of Applied Linguistics, 14, 314-323. doi: 10.1111/j.14734192.2004.00068.x

Long, M. H. (1996). The role of the linguistic environment in second language acquisition. In W. C. Ritchie \& T. K. Bhatia (Eds.), Handbook of research on language acquisition: Vol. 2. Second language acquisition (pp. 413-468). New York: Academic Press.

Lortie, D. C. (1975). Schoolteacher: A sociological study. Chicago: University of Chicago Press.

Luft, J. A. (2001). Changing inquiry practices and beliefs: The impact of an inquiry-based professional development programme on beginning and experienced secondary science teachers. International Journal of Science Education, 23(5), 517-34.

Lukacs, K. (2012). Exploring "the ripple in the pond" - A correlational study of the relationships between demographic variables and the teacher change agent scale. Current Issues in Education, 15(2).

MacKenzie, H., McShane, K., \& Wilcox, S. (2007). Challenging performative fabrication: Seeking authenticity in academic development practice. International Journal for Academic Development, 12(1), 45-54.

Manthei, J. (1992, April). The mentor teacher as leader: The motives, characteristics and needs of seventy-three experienced teachers who seek a new leadership role. Paper presented at the annual meeting of the American Educational Research Association, San Francisco.

Margolis, J. (2008). What will keep today's teachers teaching? Looking for a hook as a new career cycle emerges. Teachers College Record, 110(1), 160-194. 
Markus, H. R., \& Kitayama, S. (1991). Culture and the self: Implications for cognition, emotion, and motivation. Psychological Review, 98, 224-253.

Maughan, S., Teeman, D., \& Wilson, R. (2012). What leads to positive change in teaching practice (NFER Research Programme: Developing the Education Workforce). Slough: NFER.

McKay, S., \& Schaetzel, K. (2008). Facilitating adult learner interactions to build listening and speaking skills. Washington, DC: Center for Applied Linguistics.

Medgyes, P. (1983). The schizophrenic teachers. ELT Journal 37, 2-6.

Medgyes, P. (1994). The non-native teacher. London: Macmillan.

Meier, D. (1995). The power of their ideas. Boston: Beacon.

Menking, S. (2001). The communicative approach to teaching English in post-secondary institutions in Shimane, Japan. Retrieved from ERIC database. (ED461994).

Merilainen, M., \& Pietarinen, J. (2002, September). Primary teachers' professional development in the context of small rural schools. Paper presented at the European Conference on Educational Research, University of Lisbon.

Merkin, R. (2009). Cross-cultural communication patterns: Korean and American communication. Journal of Intercultural Communication, $20,5$.

Merriam, S. (1988). Case study research in education: A qualitative approach. London: Jossey-Bass.

Ministry of Education, Science, and Technology. (2005). 영어교육활성화 5 개년 종합대책 (2006-2010). [A five-year comprehensive countermeasure for English education revitalization (2006-2010).] Seoul: Author.

Ministry of Education, Science, and Technology. (2006). 2007 년도 교원연수 운영방향

[The directions of teacher training in 2007]. Seoul: Author.

Ministry of Education, Science, and Technology. (2008a). 교육공무원 성 과상여금

평가기준 설 명자료 [Criteria for performance payment system in the public sector in education]. Seoul: Author.

Ministry of Education, Science, and Technology. (2008b). 영어교사 심화연수 개선방안

[Improvement of intensive in-service English teacher training programme]. Seoul:

Author.

Ministry of Education, Science, and Technology. (2010). 교육만족도를 높이는 수업공개

활성화 매뉴얼 [A manual for open-class to increase satisfaction of education].

Seoul: Author. 
Ministry of Education, Science, and Technology. (2013). 2013년도 교원 연수 중점 추진 방향 [The directions of teacher training in 2013]. Seoul: Author.

Moeini, H. (2008). Identifying needs: A missing part in teacher training programs. Seminar.Net, 4(1), 1-12.

Morimoto, K. (1973). Notes on the context for learning. Harvard Educational Review, 10(4), 245-257.

Mundry, S. (2005). Changing perspectives in professional development. Science Educator, 14(1), 9-15.

Murdoch, G. (1994). Language development in teacher training curricula. ELT Journal, 48, 253-259.

Murphy, E., \& Rodriguez-Manzanares, M. A. (2008). Using activity theory and its principle of contradictions to guide research in educational technology. Australasian Journal of Educational Technology, 24(4), 442-457.

Nodeson, S., Beleya, P., Raman, G., \& Ramendran, C. (2012). Leadership role in handling employee's resistance: Implementation of innovation. Interdisciplinary Journal of Contemporary Research in Business, 4(1), 466-477.

Norton, B., \& K. Toohey (2001). Changing perspectives on good language learners. TESOL Quarterly, 35(2), 307-322.

Nunan, D. (1991). Language teaching methodology: A textbook for teachers. Cambridge: Cambridge University Press.

Organisation for Economic Co-operation and Development. (2005). Teachers matter: Attracting, developing and retaining effective teachers. Paris: OECD Publishing.

Owston, R. (2007). Contextual factors that sustain innovative pedagogical practice using technology: An international study. Journal of Educational Change, 8(1), 61-77.

Park, J-K. (2009). 'English fever' in South Korea: Its history and symptoms. English Today, 25(1), 50-57.

Patton, M. Q. (2002). Qualitative research and evaluation methods. Thousand Oaks, CA: Sage Publications.

Peery, A. B. (2004). Deep change: Professional development from the inside out. Lanham, MD: The Scarecrow Press, Inc.

Pennington, M. (1995). The teacher change cycle. TESOL Quarterly, 29(4). 
Peruski, L. (2003). Contradictions, disturbances, and transformations: An activity theoretical analysis of three faculty members' experience with designing and teaching online courses (Unpublished doctoral dissertation). Michigan State University.

Peshkin, A. (1988). In search of subjectivity - one's own. Educational Researcher, 17(17), 22.

Phillipson, R. (1992). Linguistic imperialism. Oxford: Oxford University Press.

Phothongsunan, S., \& Suwanarak, K. (2008). Native and non-native dichotomy: Distinctive stances of Thai teachers of English. ABAC Journal. 28(2). 10-30.

Porter, A. C., Garet, M. S., Desimone, L., \& Birman, B. F. (2003). Providing effective professional development: Lessons from the Eisenhower program. Science Educator, 12(1), 23-40.

Qualters, D. M. (2009). Creating a pathway for teacher change. Journal of Faculty Development, 23(1), 5-13.

Quick, H., Holtzman, D., \& Chaney, K. (2009). Professional development and instructional practice: Conceptions and evidence of effectiveness. Journal of Education for Students Placed at Risk (JESPAR), 14(1), 45-71.

Reigel, D. (2008). Positive feedback in pairwork and its association with ESL course level promotion. TESOL Quarterly, 42(1), 79-98.

Richards, J. C. (2008). Second language teacher education today. RELC Journal, 39(2), 158177.

Richards, J. C., \& Farrell, T. S. C. (2005). Professional development for language teachers. New York: Cambridge University Press.

Rogoff, B. (1990). Apprenticeship in thinking: Cognitive development in social context. New York: Oxford University Press.

Ross, J., \& Bruce, C. (2007). Professional development effects on teacher efficacy: Results of randomized field trial. The Journal of Educational Research, 101(1), 50-60. doi:10.3200/JOER.101.1.50-60

Roth, W-M., \& Lee, Y. J. (2007). "Vygotsky’s neglected legacy”: Cultural-historical activity theory. Review of Educational Research, 77, 186-232.

Rubdy, R. (2008). Diffusion of innovation: A plea for indigenous models. TESL-EJ, 12(3).

Rust, V. D., \& Dalin, P. (1990). Teachers and teaching in the developing world. London: Garland.

Sannino, A., Daniels, H., \& Gutiérrez, K.D. (2009). Learning and expanding with activity theory. Cambridge, UK: Cambridge University Press. 
Saraniero, P., \& Goldberg M. R. (2011). The impact of professional development interventions on teacher learning in arts integration. Presented at the 2011 conference of the American Educational Research Associates (AERA), New Orleans, LA. Retrieved from http://dream.sdcoe.net/resources/DREAM_AERA.pdf

Sarason, S. B. (1996). Revisiting the culture of the school and the problem of change. New York: Teachers College Press.

Saraswathi, V. (1991). Coping with teacher resistance: Insights from INSET programmes. In E. Sadtono (Ed.), Language teacher education in a fast changing world (Anthology Series 29, pp. 75-87). Singapore: Regional Language Centre.

Seoul Metropolitan Government. (2013, April). 서울 교육 주요 변화 분석. [Analysis of major changes in education in Seoul]. Statistics of Seoul, 68: Author. Retrieved from http://stat.seoul.go.kr/jsp2/WWS8/webjin_view.jsp?wj_id=68

Seoul Metropolitan Office of Education. (2009). 영어공교육강화 추진계획. [SMILE (School-Managed Innovation of Learning English) Project]. Seoul: Author.

Serdiukov, P., \& Tarnopolsky, O. (1999). EFL teachers' professional development: A concept, a model, and tools. Retrieved from ERIC database. (ED 439604).

Shields, P. M., Marsh, J.A., \& Adelman, N. E. (1998). Evaluation of NSF's statewide systemic initiatives Program: The SSIs impact on classroom practice. Menlo Park, CA: SRI.

Shulman, L. S., \& Carey, N. B. (1984). Psychology and the limitations of individual rationality: Implications for the study of reasoning and civility. Review of Educational Research, 54(4), 501-524.

Sikes, P. J. (1992). Imposed change and the experienced teacher. In M. Fullan \& A. Hargreaves (Eds.), Teacher development and educational change (pp. 36-55). London: Falmer Press.

Silver, R. E., \& Steele, R. S. (2005). Priorities in English language education policy and classroom implementation. Language Policy, 4(1), 107-128.

Singh, G., \& Richards, J. C. (2006). Teaching and learning in the language teacher education course room: a critical sociocultural perspective. RELC, 37(2), 149-175.

Smit, B. (2003). The emotional state of teachers during educational policy change. Paper presented at the European Conference on Educational Research, University of Hamburg, Germany. 
Smith, C., \& Gillespie, M. (2007). Research on professional development and teacher change: Implications for adult basic education. In J. Comings, B. Garner, \& C. Smith (Eds.), Review of adult learning and literacy: Connecting research, policy, and practice (pp. 205-244). Mahwah, NJ: Lawrence Erlbaum Associates.

Stake, R. E. (1988). Case study methods in educational research: Seeking sweet water. In R. M. Jaeger (Ed.), Complementary methods for research in education (pp. 253-278). Washington, DC: American Education Research Association.

Steffy, B. E., Wolfe, M. P., Pasch, S. H., \& Enz, B. J. (Eds.). (2000). Life cycle of the career teacher. Thousand Oaks, CA: Corwin Press.

Steffy, B., \& Wolfe, M. (2001). A life-cycle model for career teachers. Kappa Delta Pi Record. 38(1), 16-20.

Stein, M. K., \& Wang, M. C. (1998). Teacher development and school improvement: The process of teacher change. Teaching and Teacher Education, 4(2), 171-187.

Stein, M. K., Smith, M. S., \& Silver, E. A. (1999). The development of professional developers: Learning to assist teachers in new settings in new ways. Harvard Educational Review, 69(3), 237-269.

Stiles, K., Loucks-Horsley, S., \& Hewson, P. (1996). Principles of professional development for mathematics and science education: A synthesis of standards (NISE Brief, Vol 1). Madison, WI: National Institutes for Science Education.

Stivers, J., \& Cramer, S. F. (Eds.). (2009). A teacher's guide to change: Understanding, navigating, and leading the process. California: Corwin.

Stoll, L. (2011). Leading professional learning communities. In J. Robertson \& H. Timperley (Eds.), Leadership and Learning (pp. 103-117). London: Sage.

Swafford, J. O., Jones, G. A., \& Thornton, C. A. (1999). The impact on instructional practice of a teacher change model. Journal of Research and Development in Education, $32(2), 69-82$.

Tang, C. (1997). The identity of the nonnative ESL teacher. TESOL Quarterly, 31, 577-580.

Tarone, E. (2005). Schools of fish: English for access to international academic and professional communities. The Journal of Asia TEFL, 2(1), 1-20.

Timperley, H., Wilson, A., Barrar, H., \& Fung, I. (2007). Teacher professional learning and development: Best evidence synthesis iteration (BES). Wellington, New Zealand: Ministry of Education. 
Tschannen-Moran, M., \& Hoy, A. W. (2007). The differential antecedents of self-efficacy beliefs of novice and experienced teachers. Teaching and Teacher Education, 23(6), 944-956.

Tsui, A. B. M. (2003). Understanding expertise in teaching: Case studies of EFL teachers. Cambridge: Cambridge University Press.

Ur, P. (1990). In language teaching, which is more important: language or teaching? The Teacher Trainer, 4(3). Retrieved from http://www.tttjournal.co.uk/index.php?page=back_articles

Vygotsky, L. S. (1978). Mind in society. Cambridge, MA: Harvard University Press.

Waldron, N. L., \& McLeskey, J. (2010). Establishing a collaborative school culture through comprehensive school reform. Journal of Educational and Psychological Consultation, 20(1), 58-74. doi:10.1080/10474410903535364

Wallace, M. (1995). Training foreign language teachers: A reflective approach. Cambridge: Cambridge University Press.

Wells, C., \& Feun, L. (2007). Implementation of learning community principles: A study of six high schools, NASSP Bulletin, 91(2), 141-160.

Wenger, E. (1998). Communities of practice: Learning, meaning, and identity. Cambridge, UK: Cambridge University Press.

Williamson, R., \& Blackburn, B. R. (2010). Dealing with resistance to change. Principal Leadership. 10(7), 73-75.

Wong, R. (2013). The sustainability of change in teacher beliefs and practices as a result of an overseas professional development course. Journal of Education for Teaching, $39(2), 152-168$.

Worthen, H. (2008). Using activity theory to understand how people learn to negotiate the conditions of work. Mind, Culture and Activity, 15, 322-338.

Yamagata-Lynch, L. C. (2010). Activity systems analysis methods: Understanding complex learning environments. New York: Springer.

Yamaguchi, C. (2002). Towards international English in EFL classrooms in Japan. The Internet TESL Journal, 8(1).

Yan, C., \& He, C. (2012). Bridging the implementation gap: An ethnographic study of English teachers' implementation of the curriculum reform in China. Ethnography and Education, 7(1), 1-19.

Yin, R. K. (2009). Case study research: Design and methods (4th ed.). Los Angeles: Sage Publications. 
Zehetmeier, S. (2010). Sustainability of professional development. Proceedings of CERME 6, 1951-1960. 


\section{Appendix A: Semi-structured interview questions}

1. How has your teaching practice changed over your career? Can you give me an example?

2. Can you describe any changes made within yourself?

3. Can you describe any changes made within the classroom?

4. Can you describe any changes made outside of the classroom?

5 . Tell me why you maintain your current teaching practices.

6. What does PD mean to you?

7. What changes do you attribute to PD? Tell me about these.

8. If nothing from PD has affected your teaching practice, what has affected your current teaching practice?

9. Which aspect(s) of PD make(s) you think that the particular PD led to those changes?

10. If the changes have persisted over time, what has sustained the changes?

11. If not, what has made it difficult for you to sustain changes in your practice?

\section{Examples for prompts}

2. For example, can you think of your changes in subject matter knowledge or pedagogical content knowledge? How about your attitudes or beliefs related to any part of your teaching practice?

3. For example, can you think of any changes in your instructional skills, relationship with students or understanding of students?

Can you show me lesson plans you have designed or notes about students or their learning that you have taken, which can illustrate your changes?

4. For example, can you think of any changes related to your relationship with other colleagues or leadership?

Can you show me staff meeting minutes or teaching materials that you designed with collaboration with other colleagues, which can illustrate your changes?)

9. Can you show me documents which illustrate the contents of the PD programme or reports you had made of that PD programme? 


\section{Appendix B: Information sheet for teachers}

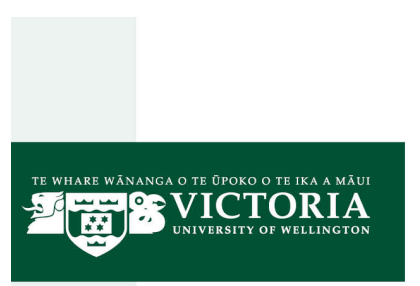

SCHOOL OF EDUCATIONAL PSYCHOLOGY AND PEDAGOGY

TE KURA MĀTAI HINENGARO TIKANGA MĀTAURANGA

FACULTY OF EDUCATION, PO Box 17-310, Donald St, Karori, Wellington 6147, New Zealand

Phone + 64-4-4639502 Fax +64-4-4639521 Email sepp@vuw.ac.nz Web www.victoria.ac.nz/education

\section{Project: Teachers' Perceptions of Changes to Teaching Practice and the Influence of Professional Development: Experienced EFL Teachers in South Korea}

Dear teacher,

My name is Jeonghyun Cho. I have been worked as an EFL teacher at public middle schools in South Korea and I currently enrolled in a Master of Education at Victoria University of Wellington in New Zealand. I would like to invite you to participate in my Master's research project and I believe that your cooperation will be valuable for my research. The aim of the project is to investigate how experienced EFL teachers perceive teaching practice has changed over time as a result of professional development (PD). I have contacted you because you are an experienced teacher and I hope you will share your experiences of PD with me. I hope that the information gathered from my project will inform the development of PD that will meet the needs of experienced teachers like you.

\section{Interview}

Before the interview, I would like to invite you to have a brief meeting with me. This will enable us to get to know each other and to discuss any questions you might have. The interview will take approximately one hour after school hours. You will be asked to nominate a date and time that would suit you and a location that is mutually agreed upon. The interview will be conducted in Korean. I would like your permission to audiotape this interview. It will be transcribed and translated into English. Korean transcripts and English translation of the transcripts will be returned to you for clarification and further comment. Your feedback is highly valued.

\section{Documents}

I would also like to ask you to share documents relating to either your practice or PD experiences such as lesson plans, contents of PD programmes in which you participated, and reports which you made of the PD programmes. If you are willing to share these documents, you could either give them to me at the time of the interview, or email them to me later. Any information which may lead to identification of people or organisations in the documents will be removed.

\section{Confidentiality}

I would like to assure you that all information gathered for this project will remain confidential to myself, my two supervisors, and a colleague who will be asked to check some of the data as a reliability measure. If this is the case, the colleague will be asked to 
sign a confidentiality agreement not to disclose any part of your data or to make copies of them. No names or identifying information about individuals, schools, and organisations will be given at any point.

\section{Ethics}

I would like to inform you that Victoria University of Wellington requires ethical approval to be obtained for research. This research has been assessed and approved by the Faculty of Education Human Ethics Sub-committee under delegated authority from the Victoria University Human Ethics Committee (Reference number: RM 19869). If you have any ethical concern about this project, you should contact Allison Kirkman, Chair of the Victoria University of Wellington Human Ethics Committee by emailing allison.kirkman@vuw.ac.nz.

Please note that there is no obligation for you to give consent to participate in this project. If you choose to give consent you have the right to change your mind and withdraw up until data analysis commences. There will be no penalty for not taking part in this project.

\section{Data storage and deletion}

The data will be securely stored in password-protected files and in a locked cabinet. The data may be required in the process of Master's thesis examination and as such will be kept for two years after publication. After this time it will be destroyed through being shredded in the case of transcripts, or wiped in the case of audio-recorded data.

\section{Reporting/ Dissemination}

The findings of this project will be submitted to the Victoria University of Wellington Faculty of Education for Master's thesis examination and deposited in the University Library. Findings may also be presented at a conference or in academic journal articles. A summary of the findings will be sent to you upon your request.

If you have questions or concerns about this project at any time and would like to receive further information about the project, please feel free to contact me using the information below. You can also contact my supervisors, Sue Cherrington

(Sue.Cherrington@vuw.ac.nz) and Margaret Gleeson (Margaret.Gleeson@vuw.ac.nz).

Thank you for considering this invitation.

Sincerely,

Jeonghyun Cho

010-8715-0224 (South Korea)

(+64) 22-070-0224 (New Zealand)

chojeon@myvuw.ac.nz

jeonghyun.jh@gmail.com 


\title{
Appendix C: Consent form for teachers
} \\ SCHOOL OF EDUCATIONAL PSYCHOLOGY AND PEDAGOGY \\ TE KURA MĀTAI HINENGARO TIKANGA MĀTAURANGA \\ FACULTY OF EDUCATION, PO Box 17-310, Donald St, Karori, Wellington 6147, New Zealand \\ Phone +64-4-4639502 Fax +64-4-4639521 Email sepp@vuw.ac.nz Web www.victoria.ac.nz/education

\section{Project title: Teachers' Perceptions of Changes to Teaching Practice and the Influence of Professional Development: Experienced EFL Teachers in South Korea} \\ This research has been assessed and approved by the Faculty of Education Human \\ Ethics Sub-committee under delegated authority from the Victoria University Human \\ Ethics Committee (Reference number: RM 19869). \\ Please tick following boxes to indicate that you agree with the statements and to provide \\ informed consent for your participation in this project. \\ - I have had an opportunity to ask questions about this project and have had them \\ answered to my satisfaction. \\ - I understand that participation in this project is voluntary and I may withdraw \\ permission for my data to be included in this project at any time prior to \\ commencement of data analysis without having to give any reasons. \\ - I understand that the data collected about me will be kept confidential to the \\ researcher and her research supervisors. A colleague who will check the data as a \\ reliability measure will be required to sign a confidentiality agreement. \\ - I understand that a copy of the interview transcription and a copy of the English \\ translation will be given to me for clarification and further comment. \\ - I understand that the findings published from this project will not include any \\ information that could lead to the identification of myself and my school. \\ - I understand that all data will be kept secure and destroyed two years after publication. \\ - I understand that the data I provide will be used only by the researcher for this thesis \\ examination, a conference, and academic journal articles.
}


$\mathbf{Y} \quad$ I would like to receive a summary of the results of this research when it is completed.

$\mathbf{Y} \quad \mathbf{N} \quad$ I agree to share documents such as teaching and PD materials with the researcher.

$\mathbf{Y} \quad \mathbf{N} \quad$ I agree to participate in this research. This will involve being interviewed and having that interview audio recorded.

Name

Signature

Date

Email address

Please return this consent form to the researcher in the envelope provided.

Thank you. 
Appendix D: Research schedule

\begin{tabular}{|c|c|}
\hline Task to be undertaken & Completion date \\
\hline Interview Han & 1 July 2013 \\
\hline Interview Choi & 2 July 2013 \\
\hline Interview Shin & 3 July 2013 \\
\hline Interview Kang & 10 July 2013 \\
\hline Interview Seo & 12 July 2013 \\
\hline
\end{tabular}

